\title{
INTEGRATED FIELD TESTING OF FUEL CELLS AND MICRO-TURBINES
}

\author{
PHASE I REPORT \\ Concept Development and Evaluation of the Prospects for \\ the Deployment of DG on Long Beach Island
}

\author{
Topical Report - Budget Period 1 \\ Grant Agreement DEFC2600NT41012 \\ with the
}

New Jersey Board of Public Utilities

Division of Energy

Prepared by:

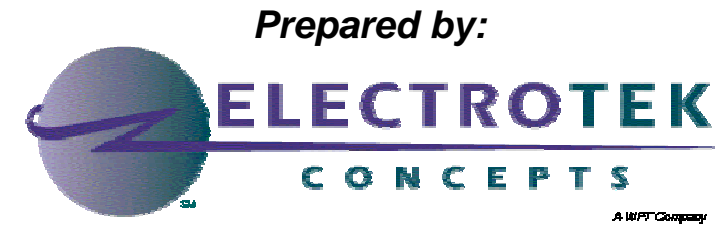

Electrotek Concepts, Inc.

2111 Wilson Boulevard, Suite 323

Arlington, VA 22201

Phone (703) 351-4492

Fax (703) 351-4495

February 2002 
$\sim$ Table of Contents

Executive Summary _._-_-_-_-_

Introduction

Base Case A nalysis

Alternative Plans

Economic Evaluation _-_-_-_ 23

DG SITING ANALYSIS

Appendix A: Circuit M odel Details_-_-_ 38

Appendix B. DG Siting A nalysis D etails 


\section{Executive Summary}

This report is based on work performed under a grant issued by The New Jersey Board of Public Utilities (NJBPU) Division of Energy to Conectiv Power Delivery and Electrotek Concepts to investigate the technical and economic challenges of implementing advanced distributed generation (DG) technologies on Long Beach Island, New Jersey. This report is on the analysis performed for Phase I of the project titled "Integrated Field Testing of Fuel Cells and Microturbines," which was proposed in response to Solicitation No. DE-PS36-00GO10499, Initiative on Cooperative Programs with States for RD\&D, from the US DOE Office of Energy Efficiency \& Renewable Energy.

In Phase I, we have conducted a technical and economic evaluation of the prospects for the deployment of DG on Long Beach Island (LBI). This work has been performed with the combined efforts of Conectiv and Electrotek engineers.

LBI is a summer resort area six miles off the $\mathrm{NJ}$ coast with a permanent population of 15,000 in the winter rising to well over 100,000 residents in the summer. The peak summer load exceeds $70 \mathrm{MW}$ for only a few days, while the normal daily peak demand is between $30-40 \%$ of the annual peak. Thus, the load factor is quite poor from the perspective of utility revenue. This creates a somewhat unusual planning problem as the area load grows to exceed the maximum capacity of the power supply that makes the application of DG a viable alternative to the normal "wires" solution.

The area is fed by an aging $23 \mathrm{kV}$ sub-transmission system, which is, in turn, supplied by a 69 $\mathrm{kV}$ transmission system. There are three distribution substations on the island supplying a $12.47 \mathrm{kV}$ distribution system. The $23 \mathrm{kV}$ system is near maximum capacity when the summer peak occurs. There are five $23 \mathrm{kV}$ submarine cables feeding the island from the mainland. For at least two possible contingencies in these cables, the peak load out of the Beach Haven substation cannot be served. For the summer of 2001, Conectiv covered these contingencies with $5 \mathrm{MW}$ of diesel engine gensets installed in the Beach Haven substation.

There is between 5 and 7 years of capacity remaining in the normal configuration of the $23 \mathrm{kV}$ system. The $69 \mathrm{kV}$ system will be reinforced by 2004 with an extension of a $230 \mathrm{kV}$ line from Sands Point. However, in the meantime, an outage on the $69 \mathrm{kV}$ line to Sands Point can make it difficult to serve the northern part of the island. Transmission system studies suggested a need for $5 \mathrm{MW}$ to help cover this contingency. Studies were performed for placing this generation on the island to help reinforce the distribution system. The optimal location was found to be a few miles north of the Ship Bottom substation. This would cover the contingency and would free up capacity on the Barnegat and Island feeders to aid in serving those areas during the contingency.

An additional $2 \mathrm{MW}$ of DG would be needed by about 2003 in the southern part of the island to continue to cover the $23 \mathrm{kV}$ contingencies until the normal capacity of the system is exceeded.

The additional capacity is needed only in the summer months due to the seasonal nature of the load. Therefore, leasing mobile gensets on trailers is a very cost-effective option for covering the contingencies.

The chief competing alternative to using DG to maintain the power delivery reliability on LBI is a "wires" solution. The $69 \mathrm{kV}$ system would be extended to the Ship Bottom substation on the island and the $23 \mathrm{kV}$ system retired. $12.47 \mathrm{kV}$ express feeders would be run from Ship Bottom 
to the southern part of the island to pick up the distribution load now served from the Bay Ave and Beach Haven substations.

There are a number of factors that will likely lead to the eventual adoption of the wires plan. The $23 \mathrm{kV}$ system is aging and, at some point, the cost of maintaining the system will make it uneconomic to continue operating it. The capacity of the system in the normal configuration (no contingencies) will not be sufficient to serve the peak load. While utility engineers are willing to use DG to cover contingencies, they are very reluctant to rely on DG for base capacity. The main question in this regard is how long to defer the construction using DG.

The focus of this project is ultimately to be dispersed, small DG technologies such as fuel cells and microturbines. It is not practical to consider these to defer the construction of the wires solution described above. This would require more than $7 \mathrm{MW}$ of capacity installed in the appropriate locations within 3-4 years. Since there is a limited application of these technologies, it does not appear feasible to institute a program that could get that much capacity on line in sufficient time. Besides, the $23 \mathrm{kV}$ system could fail, which would require that the $69 \mathrm{kV}$ plan be implemented anyway. This would eliminate any value the DG might have for deferral.

The value of the smaller DG technologies with respect to the LBI power delivery system is to extend the life of the $12.47 \mathrm{kV}$ distribution system well out into the future. A number of the feeders are currently heavily loaded and, if nothing is done, will require upgrading within the next decade. Also, serving the entire island at $12.47 \mathrm{kV}$ will require longer express feeders, yielding relatively high losses at peak load. If the load continues to grow, substantial investment will have to be made to reconductor existing lines and add new lines. If the implementation of DG can nearly keep pace with the load growth, it is conceivable that the upgrades can be deferred to where there is substantial benefit.

The deferral of future distribution system investment would be dependent on achieving not only a certain capacity of DG, but having it installed in the proper location. Generally, the loads more distant from the substation should be targeted. Our analysis shows that the greatest benefit would be achieved if the small DG were installed in the Northern halves of the Island and Barnegat feeders and the Southern part of the Holgate feeder. There is also a good benefit to feeder capacity for DG installed to the South of the present Bay Ave. substation. These should be the areas targeted first by a demand-side DG program.

The rate of DG deployment would not have to keep pace exactly with load growth to have substantial benefit. Due to losses, it is not uncommon for DG installed and operating at beneficial locations on the distribution feeder to increase the capacity of the feeder by $20 \%$ $40 \%$ more than the capacity of the DG. Therefore, if optimally located, the DG need only be implemented at a pace of $70 \%-80 \%$ of the growth for indefinite deferral of new major feeder construction. Indefinite deferral may be an unrealistic goal. However, if the pace of demandside DG implementation can be a substantial percentage of the total need, several year's deferral can be achieved, which would have significant value. It should be pointed out that if the DG is located too close to the substation, or in other areas where there are operating difficulties, there will be very little benefit to the supply side.

The economics of customer-sited DG are enhanced by 1) the ability to sell excess power to the grid, 2) co-generating to utilize waste heat, and 3) participation in PJM Active Load Management (ALM) program and Load Response Program (LRP). 
Power is purchased either through net metering ${ }^{1}$ or small power purchase (up to $1 \mathrm{MW}$ ) tariffs. In either case, the inability to offset the entire utility power rate makes it difficult to generate electricity on-site economically for most of the year ${ }^{2}$. This means that some of the most attractive sites would be those customers with an additional high value in thermal load. A few prospective sites have been identified and evaluated. Several ownership and tie-in arrangements have been analyzed which indicates the economic viability of customer-sited generation. Phase 2 (implementation) and Phase 3 (deployment) will afford the opportunity to demonstrate the efficacy of customer-sited DG. If sufficient DG could be deployed, including the approximately $1.5 \mathrm{MW}$ of existing backup generation on LBI, sufficient DG capacity would be available to future capital spending by the utility. The economics of customer-sited DG can be further enhanced by capacity payments received through the ALM program and energy payments received through the LRP.Photovoltaic (PV) solar systems on residential rooftops offer an interesting possibility. Many of the loads in the areas where the best feeder benefits are likely to occur are residences (northern and southern extremities of the island). The peak output of PV systems is also likely to be coincident with the peak load. Many newer homes are what would be termed "upscale," suggesting owners with significant personal wealth. There are some hopes that the present high demand for PV in California will eventually result in lower prices due to increase manufacturing capacities. However, even with current subsidies, costs are currently high and it would require owners with substantial resources to afford PV systems. These would be installed behind the meter and would be subject to net metering rules.

There are still many details to work out to achieve an effective, efficient, and economical application of DG on LBI that has benefits to all parties involved. To this end, it is recommended that work proceed to Budget Period 2 to demonstrate the benefits to both the utility and selected customers based on the deployment of advanced DG technologies.

${ }_{1}^{1}$ In New Jersey, net metering laws apply to renewable technologies ad fuel cells under $100 \mathrm{~kW}$.

${ }^{2}$ The utility does not purchase power at the retail rate allowing for a fair recovery of its power delivery costs. 


\section{Introduction}

This is a report of the Phase I effort for this project, which is to conduct a technical and economic evaluation of the prospects for the deployment of DG on Long Beach Island.

The work in this phase consists of five tasks:

1. Circuit data compilation and model development,

2. Development of the base case,

3. Development of the alternative cases,

4. Technical evaluations through a comprehensive power flow analysis, and

5. Economic analysis of the various cases over a 10-year planning horizon.

Each of these tasks has been completed and the results are presented in this report along with pertinent details of some of the key analysis.

\section{PLANNING AREA}

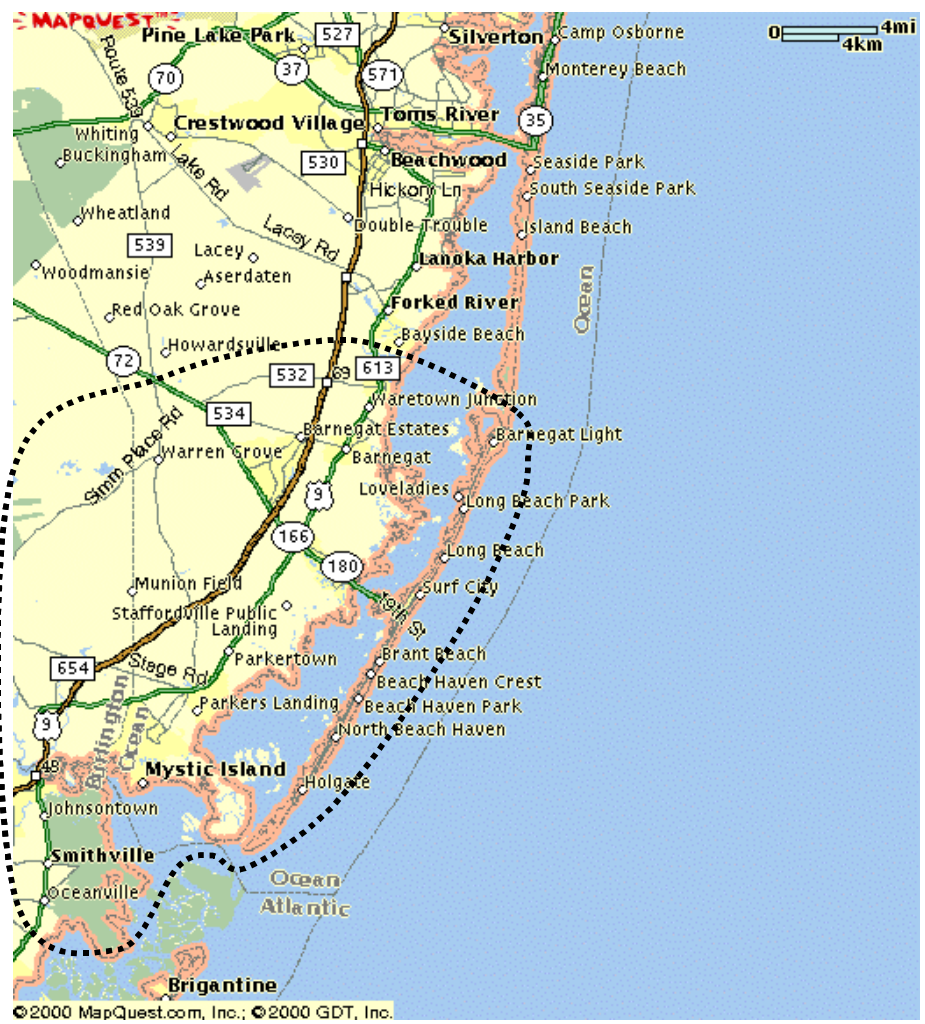

Figure 1. Long Beach Island Planning Area

Figure 1 shows a map of the Long Beach Island (LBI) Planning Area that was investigated in this project. The transmission system as well as some of the distribution system within the area indicated by the dotted line was modeled. Thus, impacts of proposed solutions to the capacity constraints of the system supplying LBI could be observed and quantified. 
LBI is a summer resort area six miles off the $\mathrm{NJ}$ coast with a permanent population of 15,000 in the winter rising to well over 100,000 residents in the summer. The peak summer load exceeds $70 \mathrm{MW}$ for only a few days, while the normal daily peak demand is between $30-40 \%$ of the annual peak. Thus, the load factor is quite poor from the utility revenue perspective. This creates a somewhat unusual planning problem as the area load grows to exceed the maximum capacity of the power supply that makes the application of DG a viable alternative to the normal "wires" solution.

\section{CAPACITY EVALUATION}

The system supplying power to LBI can have loading constraints at time of peak load. Prior to the summer of 2001, a failure of a key component during peak load would result in over $4 \mathrm{MW}$ of load becoming unserved.

The island is served from two substations on the mainland by five $23 \mathrm{kV}$ submarine cables and one $12.47 \mathrm{kV}$ feeder. Contingencies of most concern to the utility engineers involve failures of the underwater portion of the $23 \mathrm{kV}$ cables supplying power to the Southern end of the island. In particular, if the southernmost cable is lost, the maximum power that be served out of the Beach Haven substation is approximately $12 \mathrm{MW}$. The load at that substation is projected to have the potential to exceed $16 \mathrm{MW}$. Thus, over $4 \mathrm{MW}$ of load is at risk of being curtailed should the failure coincide with peak load.

When a submarine cable fails, the repairs can take 2-3 weeks. In contrast, a failure on an overhead line might take only 2-3 hours to repair. Although the load peaks on LBI are short and largely confined to weekends and holidays, a submarine cable failure represents significant exposure for the inability to serve load. This risk has been present for several years. The cable is now older, with more splices, increasing the chances of an inopportune failure. Also, the populace was sensitized to power outages during the summer of 1999. A combination of these two concerns led Conectiv to choose to cover this contingency during the summer of 2001 by placing $5 \mathrm{MW}$ of diesel gensets on trailers at the Beach Haven substation.

The load is projected to grow at 1.2 - 1.5 MVA per year. With the present peak load at nearly 73 MVA, this is approximately a $2 \%$ growth rate. At this rate, our simulations indicate that the present power delivery system in its normal configuration will reach its limit for supplying the island load by no later than 2007 . This could occur as early as 2005 if there is a particularly hot summer. The plot in Figure 2 illustrates this, which is the result of a simulation to estimate the amount of load exceeding the maximum capacity of the lines delivering power to LBI. This is the energy for each peak day that occurs each year. A small amount of overload begins in the $5^{\text {th }}$ year, which corresponds to 2005 . By 2007, this characteristic begins to turn up sharply, which is a frequent indicator that it is time to correct the situation. This loading corresponding to the assumed growth for the years 2005 to 2007 is $81 \mathrm{MW}$ and $84 \mathrm{MW}$, respectively. It should be pointed out that most utility planners would choose to invest in new capacity long before the normal capacity is exceeded. In an area with a better load factor (ratio of average load to peak load) it generally would be economical to add new delivery capacity shortly after the time when the peak load can no longer be served during the most critical single line outage contingency. In this case, the relatively infrequent occurrence of peak load makes it potentially attractive to solve the capacity shortfall with distributed generation rather than wires. 


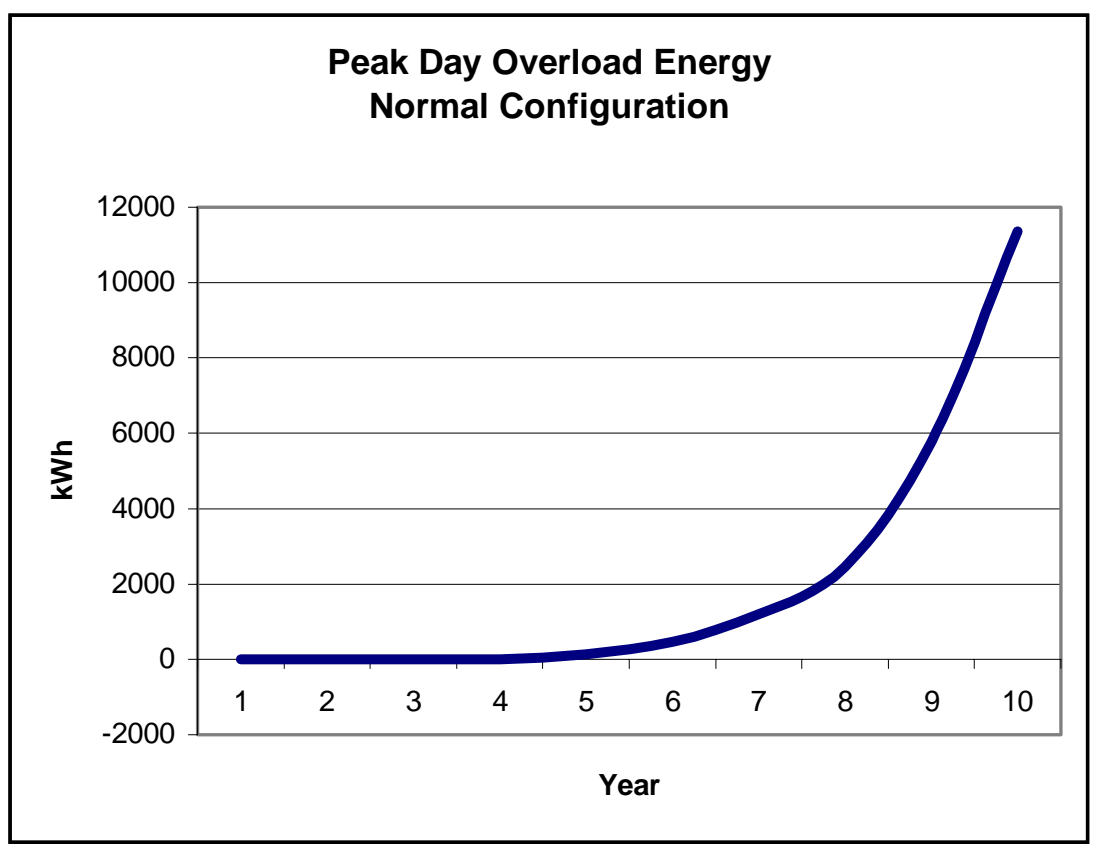

Figure 2. Estimate of Amount of Overload in the Power Supply System to LBI for Each Peak Load Day for the Normal System Configuration (No Contingencies)

The LBI capacity situation can be summarized as follows:

- It is presently not possible to cover all line out contingencies without the aid of approximately $5 \mathrm{MW}$ of generation at Beach Haven substation. The generation need only operate in case of emergency and could employ generation technologies with limited allowable operating times.

- The base capability of the system to deliver power to the island without contingencies will be exceed by approximately the year 2006. To continue operating with the present system beyond that date will require either an expanded load curtailment program or additional support from generation during normal operating conditions. This will eventually require DG technologies with lower emissions to operate the requisite number of hours. 


\section{Base Case Analysis}

Refer to Appendix A for circuit model details. The circuit model of the LBI Planning Area was implemented in Electrotek's Distco Suite ${ }^{\mathrm{TM}}$ software. This software platform can represent both the transmission system and distribution simultaneously and simplifies the task of performing annual simulations necessary for evaluating planning options. An equivalent was made of the transmission system behind the $69 \mathrm{kV}$ buses at the Lewis and Sands Point substations. The $12.47 \mathrm{kV}$ distribution systems on $\mathrm{LBI}$ as well as a few feeders on the mainland were modeled in detail. The loading simulations were performed using the monthly load shapes shown in Appendix A.

\section{ANNUAL LOAD SHAPE}

A basic understanding of the capacity issues on LBI can be observed in Figure3. This plot shows the peak load of each day relative to the yearly peak. For over 8 months of the year, the peak daily load ranges from 20 to $40 \%$ of the annual peak. Then the load spikes up sharply just before Memorial Day and continues at the higher value through Labor Day weekend. The peak of each week occurs on the weekend.

Note that the data for June was created from average weekly data for the summer because actual metered data was missing for this period.

The annual peak occurs when high temperatures coincide with a weekend or holiday when many people are on the island.

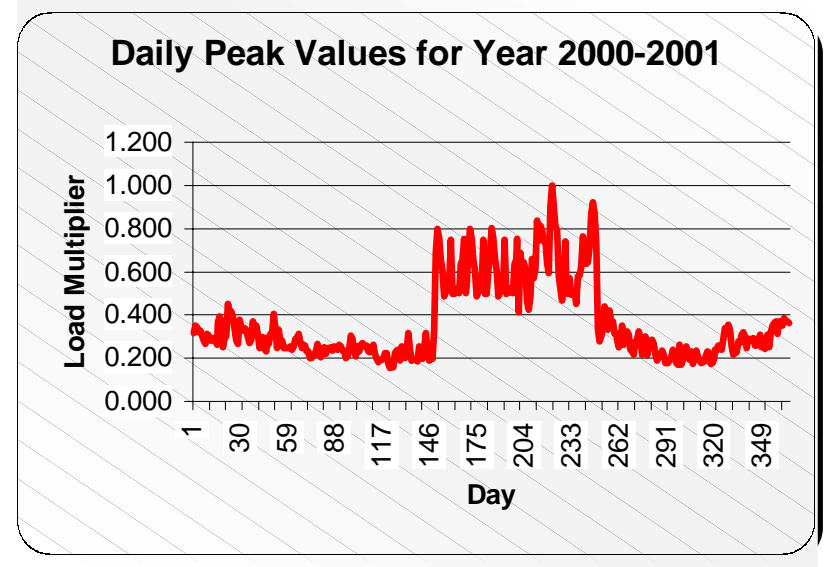

Figure 3. Annual Load Shape Assumed For Studies

\section{CONSTRAINTS IN THE 23 KV SUB-TRANSMISSION SYSTEM}

While there are also problems in the $69 \mathrm{kV}$ system, much of the power delivery constraint on this system are due to limitations in the $23 \mathrm{kV}$ sub-transmission system that supplies most of the load on the island. Therefore, it is informative to analyze some of the characteristics of this system. Figure 4 shows an estimate of the annual loss profile. This chart shows the energy (kWh) losses that occur at each hour of the day, month by month. This chart, and others like it, shows results from nearly 1500 power flow solutions. The loss chart is interesting because the losses are proportional to the square of the current, which gives a picture that accentuates the differences in the power flow behavior of the system throughout the year. 
This chart shows clearly the dilemma faced by utility planners in this case. For most of the year, the system has more than adequate capacity and is severely stressed for only a very brief period. The peak generally occurs only once each year in one of the summer months.

Another informative picture is a chart (Figure 5) that shows when the system is overloaded over this same period of time. The values plotted here are computed during the same annual simulation that produced the loss chart. However, in this case, an accounting is kept of the energy flowing through lines that is above the capacity limit of the lines. This is proportional to the amount of energy in load that would have to be curtailed if the loading were to be kept below capacity limits. This particular chart shows the results for one of the energy meters in the circuit model and represents approximately $1 / 3$ of the total energy above the $23 \mathrm{kV}$ system capacity for the first year of the simulation. This is a relatively small amount of energy - only a few thousand kWh - but grows considerably in subsequent years. The important thing to note from this chart is the shape and timing of the constraint. The load shape is taken from Summer 2000 data and the main peak occurred in August, with a smaller peak early in September. The large peak is very brief. Thus, whatever solution is found to solve the problem must be available at this time.

This shape of loading is a common characteristic of applications that can be addressed by peaking generation installed locally. Not only is the load capacity met, but for the period of need, there is also a possible additional bonus benefit of considerable loss reduction in the power delivery system.

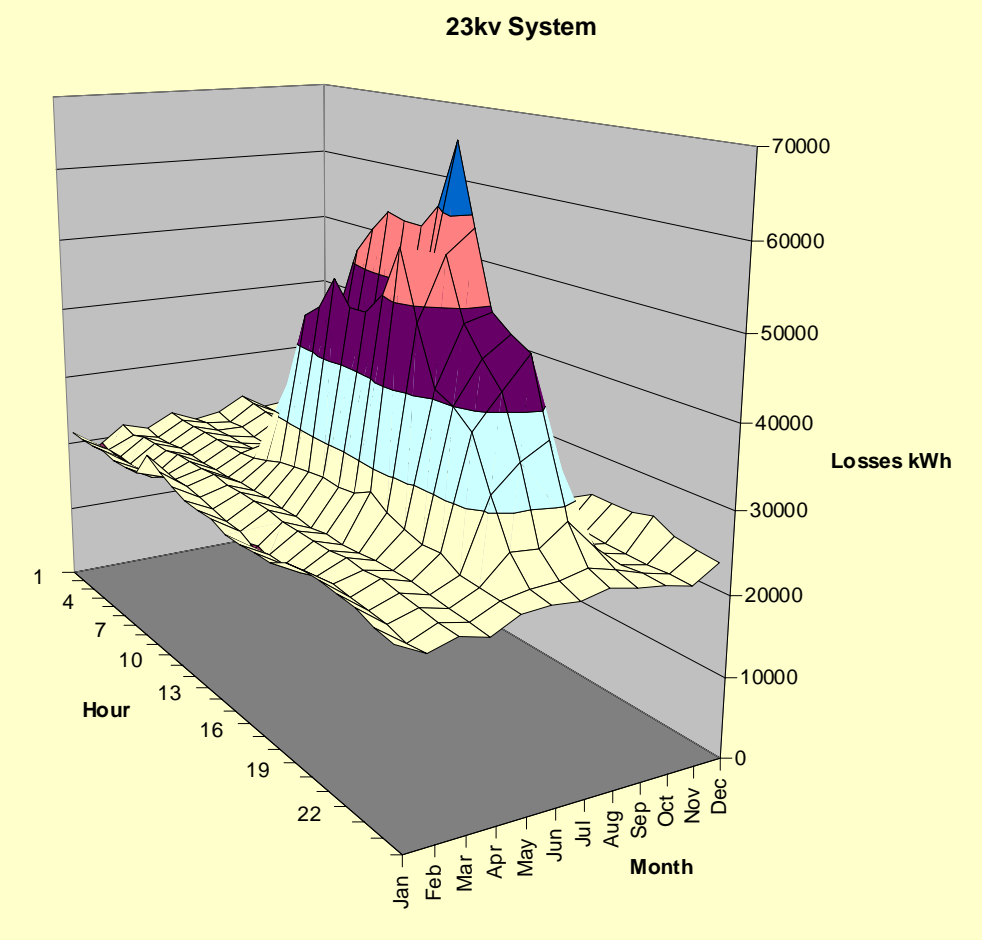

Figure 4. Annual Loss Profile for 23 kV Sub-transmission System 


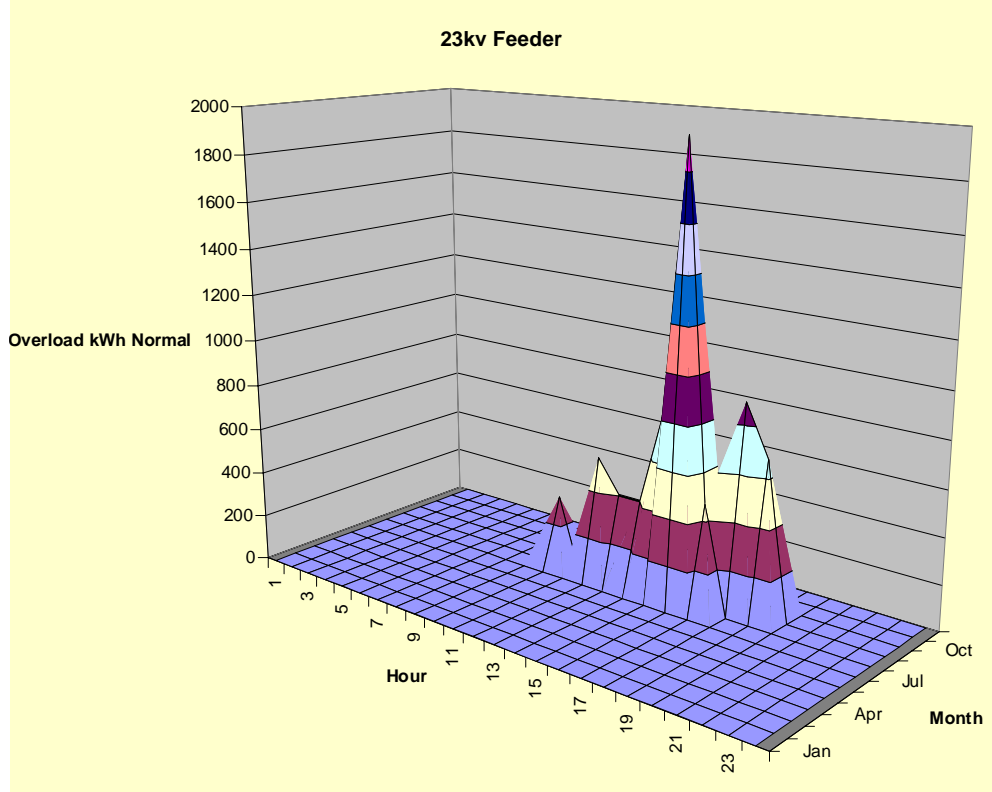

Figure 5. Profile of Overloads On 23 KV System in Year 1 


\section{Alternative Plans}

The two basic types of plans we wish to compare in this report are:

1. A conventional utility system upgrade. We will refer to this as the "wires" solution because it basically involves investing in lines, cables, and transformer that conduct electricity from a remote source of generation to the load by wire.

2. Distributed resource solutions. These would be generation facilities installed locally on LBI to meet load demand either continuously or only during times of peak demand.

Two types of distributed resource solutions have been considered: diesel or gas engine gensets for peaking generation and distributed small generation in a high-efficiency combined heat and power application such as microturbines and fuel cells.

\section{THE "WIRES" SOLUTION}

This is the more traditional utility supply-side delivery solution. Conectiv has evaluated a number of plans and has settled on a preferred plan of action that involves the following steps relevant to the local power delivery system to LBI:

- Retire the $23 \mathrm{kV}$ system

- Extend the $69 \mathrm{kV}$ from Cedar to Ship Bottom Substation

- Replace the existing 23/12.47 kV transformers in Ship Bottom substation with two 69/12.47 kV, 70 MVA transformer

- Run $12.47 \mathrm{kV}$ express feeders from Ship Bottom to Bay Ave and Beach Haven substations, which will likely be converted to regulator stations

- Continuing upgrades of the $12.47 \mathrm{kV}$ feeders as the load on the island grows over the years.

There is an additional step in the wires solution that is not directly related to the local supply, but certainly has an impact. By 2004, a $230 \mathrm{kV}$ transmission line is to be in place that will basically parallel the existing $69 \mathrm{kV}$ system. The construction of this line is dictated by the needs of the transmission system and will provide another high capacity link from the Sands Point area to the Atlantic City area. The $230 \mathrm{kV}$ line will be tied into the $69 \mathrm{kV}$ system at the Cedar and Motts Farm substations. This will greatly strengthen the transmission system. Until this is installed, there is a potential capacity shortfall when the $69 \mathrm{kV}$ line from Sands Point to Cedar is out. Approximately $80 \%$ of the power into the LBI planning area at peak load is delivered via this line. If it were out of service at peak load, the $69 \mathrm{kV}$ system would fall short of being able to serve the entire load by between 5 and $10 \mathrm{MW}$. Therefore, in addition to the 23 $\mathrm{kV}$ capacity constraints, DG will be evaluated as one means to cover this $69 \mathrm{kV}$ line contingency.

Figure 6 depicts the proposed upgrade to the LBI power supply system as described above. 


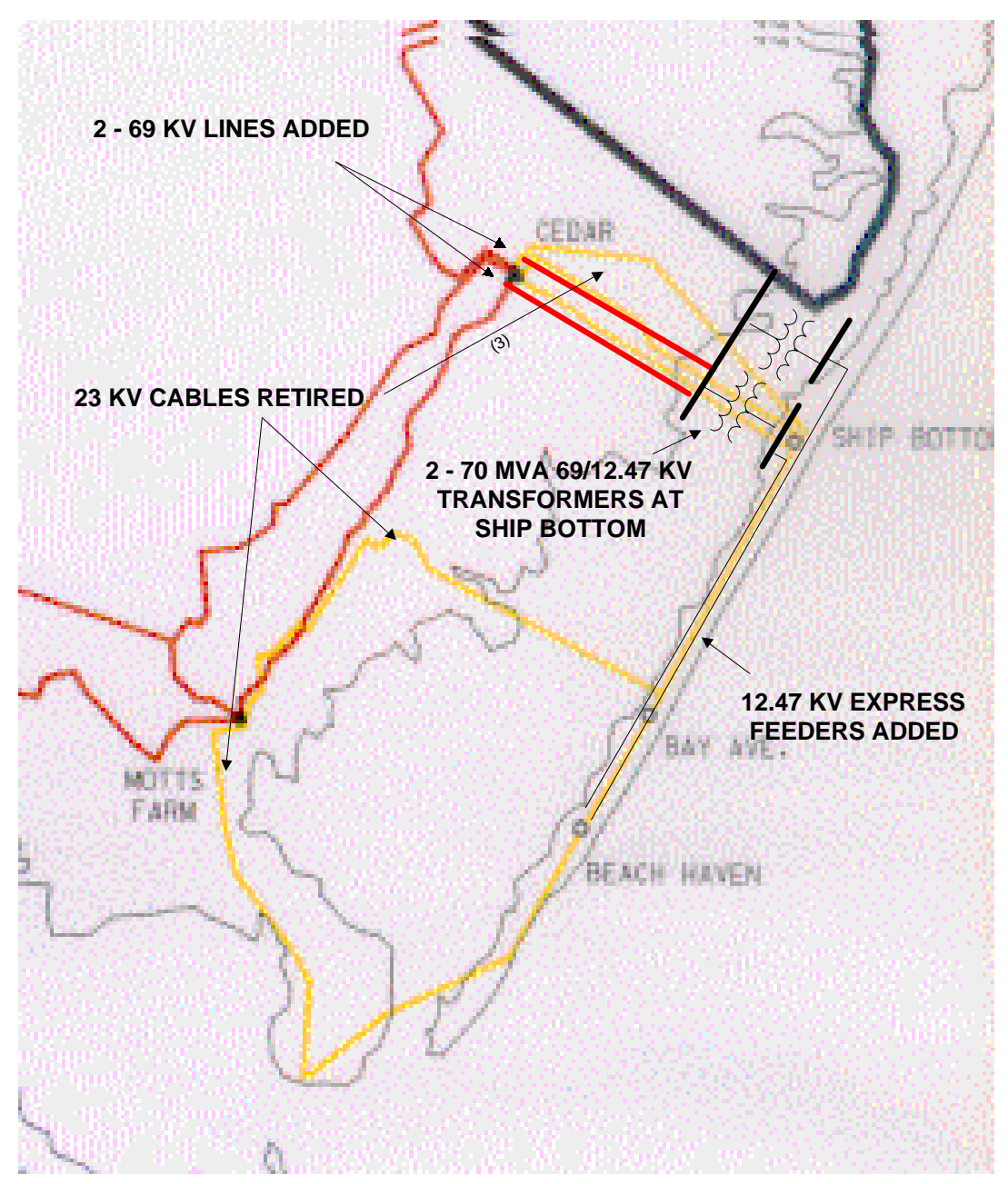

Figure 6. Key Elements of Proposed Wires Solution

Note the redundancy designed into this solution. There is at least two of each major component, allowing the possibility of continuing to serve the load with the remaining component while the failed one is being replaced. This is a typical " $\mathrm{N}-1$ " contingency planning practice that many utilities employ. The two $69 \mathrm{kV}$ lines will likely not occupy exactly the same right-of-way to reduce the probability that a single event will take out both lines.

The capacity provided by the proposed wires solution is rated at 110 MVA. This rating is determined by assuming a failure of one of the key components in the $69 \mathrm{kV}$ supply. The most limiting is the failure of one of the new substation transformers at Ship Bottom. Should this happen, a 40 MVA mobile spare transformer would be brought in. Thus, the capacity is the sum of the ratings of the two transformers under this contingency: $70+40=110$ MVA.

The peak load is current hovering around $70 \mathrm{MW}$ is growing at a rate averaging about $1.5 \mathrm{MW}$ per year. Thus, this upgrade will provide adequate transmission and substation capacity for the island for nominally 20 more years, assuming constant load growth.

To accomplish this increase in capacity, Conectiv estimates that the total incremental cost specific to this project is approximately $\$ 10 \mathrm{M}$. This does not count some upgrade work already scheduled for the Ship Bottom substation. This results in an average first cost of the project of: 


\section{$\$ 10 M / 110$ MVA $\approx \$ 90 / k V A$}

This places this project within the normal range of utility wires-based capacity investments of $\$ 20-\$ 100 / \mathrm{kVA}$. While the proposed project is on the high side of the normal range, its cost is typical of similar investments throughout the utility industry.

If we levelize this cost over a nominal life of 20 years at a weighted annual cost of capital of $6 \%$, the annual cost is $\$ 871,800$, which results in a value of approximately $\$ 8 / k V A-y r$. Similarly, if the life is only 10 years, this number increases to $\$ 12 / \mathrm{kVA}$-yr. This gives a range of values with which to make comparison with DG solutions. On this basis, these values will appear much smaller than the cost of DG solutions, but this is not the only way to look at these costs.

If we were to base the incremental cost on the incremental capacity provided, the numbers will be higher. Using logic similar to above, Conectiv rates the present power delivery system at 65 MVA. Thus, the incremental capacity gained by the $\$ 10 \mathrm{M}$ investment is $45 \mathrm{MVA}$. Using this as the base, the cost of the incremental capacity is approximately $\$ 220 / \mathrm{kVA}$, or in the range of $\$ 20-\$ 30 / k V A-y r$. This places the cost closer to values with which some types of DG can be competitive. This suggests it might be economic to consider DG options as an alternative to this upgrade - at least, for a certain number of years.

\section{ENGINE GENSET SOLUTIONS}

The engine genset solution consists of purchasing or leasing mobile diesel (or natural gas) gensets on trailers for peaking applications on the island.

After simulating, numerous situations, the following plan was developed.

- $5 \mathrm{MW}$ of diesel gensets initially at Beach Haven substation to cover contingency of loss of the $23 \mathrm{kV}$ submarine cable.

- $5 \mathrm{MW}$ of diesel or gas engine gensets installed north of Ship Bottom Substation - 2.5 MW each on Island and Barnegat feeders - to help support the area for the contingency resulting from the loss of key $69 \mathrm{kV}$ lines. This would be used from the $2^{\text {nd }}$ year onward until the new $230 \mathrm{kV}$ transmission system required by PJM is completed (scheduled for 2004).

- $2 \mathrm{MW}$ additional (total of $7 \mathrm{MW}$ ) from 2003 onward at Beach Haven to continue to cover the $23 \mathrm{kV}$ cable contingency until approximately the $6^{\text {th }}$ year $(2006)$.

This plan covers all likely single line outage contingencies until the system capacity to serve the load is exceeded in the normal configuration without contingency. It is possible to extend the life of this plan if the gensets can be operated for peaking capacity without a line out contingency. This could require the use of gas engines instead of diesels to meet emissions limitations. This plan allows the utility planner to defer major wires investment for a few years. One of the advantages of this is that one can wait to see if the projected load growth actually develops. If it does not, the investment can be further deferred, assuming there are not other mitigating circumstances. 


\section{Impact of 5 MW DG at Beach Haven on Losses and System Capacity}

One interesting analysis that was performed on the genset plan was to determine the impact of the $5 \mathrm{MW}$ diesel peaking units at Beach Haven on the power delivery system. This was done not only to confirm that the units could support the load during the contingency but also to evaluate the impact while in the normal configuration to identify other possible benefits. The impact on losses leads to some interesting observations.

When the $5 \mathrm{MW}$ generator was operating at the assumed peak system load, the total demand into the LBI planning area dropped by $6.5 \mathrm{MW}$. This suggests that at this load level, reducing the load in this location reduces delivery losses by $30 \%$ of the size of the load reduction. This indicates that the system delivering power to Beach Haven can be severely constrained at times. This estimate is higher than one typically finds, but, perhaps, not unreasonable. In other cases, the reduction in more typically no more than $10-15 \%$ for the first increment of DG added to the system.

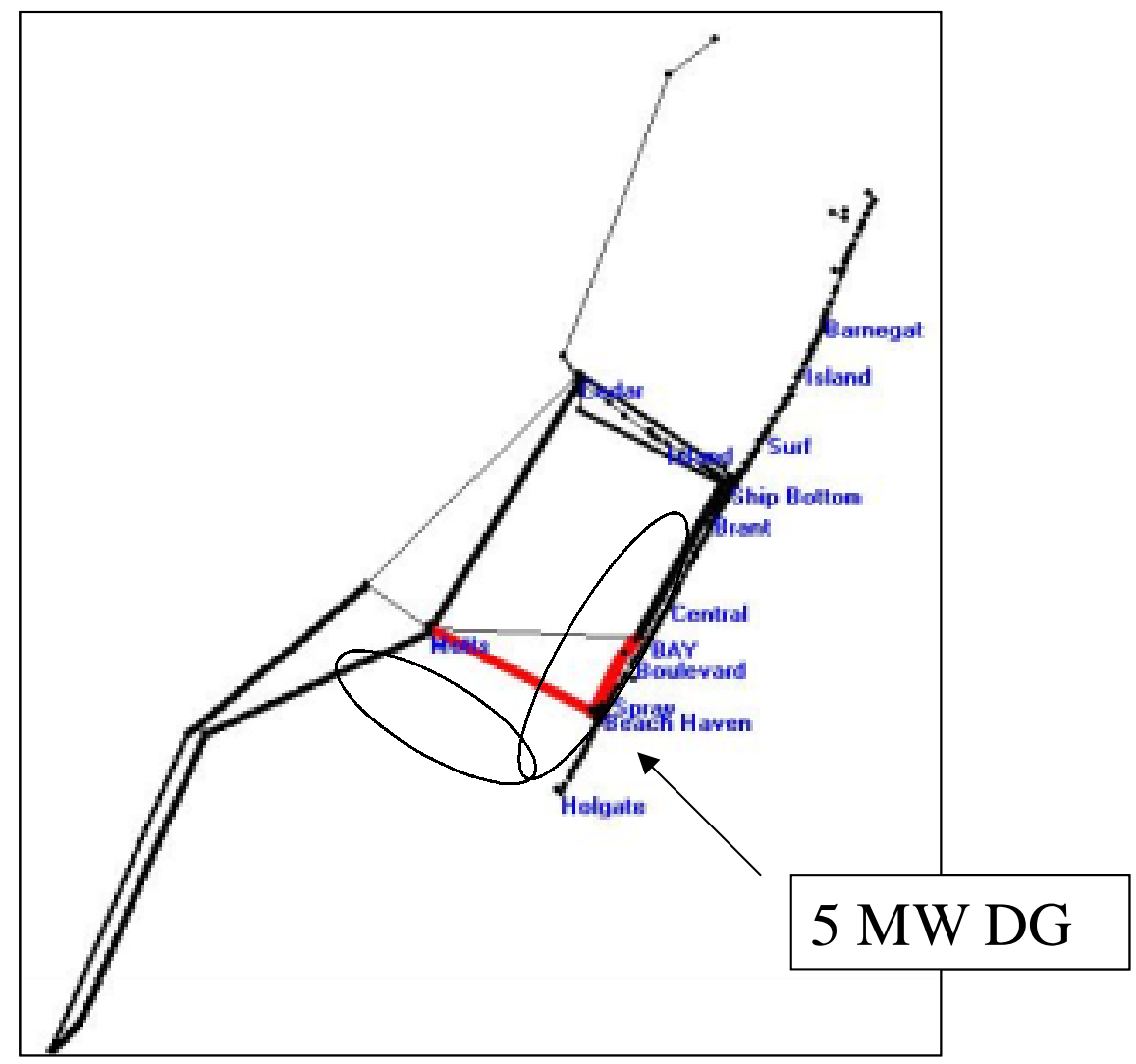

Figure 7. Power Flow Showing Lines Achieving Greatest Percent Improvement in Losses Due to the Addition of 5 MW of DG at Beach Haven

It must be emphasized that the amount of loss reduction achievable is very much time- and location-dependent. It is also sensitive to the load models assumed by the analyst. One should not assume that DG placed at other locations on the island would achieve the same effect. This great of an improvement is also not achievable except at very high load levels. Regardless, this high amount of loss reduction confirms a highly stressed delivery system, which was well known at the outset of this project. 
The total power delivery losses for the planning area are estimated to range from $8-9 \%$ at peak load, depending on how the loading is modeled. This includes the distribution feeders on the island, but not all on the mainland. This is not an unusual value for heavily loaded systems on which planning studies for upgrades are being performed. In fact, an old engineering ruleof-thumb learned by one of the investigators in the 1970's states that one of the criteria for deciding when a distribution system should be upgraded is when the losses at peak load reach $8 \%$. In this case, many of the losses come from the $23 \mathrm{kV}$ sub-transmission system.

An attempt was made to further characterize the losses in the system. Figures 7 and 8 illustrate where the DG has the greatest impact on the losses it two different ways.

In Figure 7, the thickness of the line segments is proportional to the percent reduction in losses in each segment. The lines most significantly impacted are the $23 \mathrm{kV}$ lines serving the Beach Haven substation (circled). The loop from Cedar Substation, down the island, and back to Motts Farm sees the greatest percentage change. This would seem to confirm the prior analysis indicating the $23 \mathrm{kV}$ system feeding the southern part of the island has the greatest constraints. Some of the $69 \mathrm{kV}$ lines also see a significant percentage change in losses, although not to the degree of the $23 \mathrm{kV}$ lines. There is no significant change in the distribution feeder losses because of the location of the generators. They are interconnected to the utility system at the $12.47 \mathrm{kV}$ buses in the substation ahead of the feeders. Thus, there is no reduction of current on the feeders.

The percentage change is not the complete story. Figure 8 shows the absolute value of the loss reduction in each line segment. The line segments with more than $50 \mathrm{~kW}$ are pointed out (and shown in red, if viewing this diagram in color). Again, segments in the $23 \mathrm{kV}$ loop are highlighted. In addition, two $69 \mathrm{kV}$ lines have more than $50 \mathrm{~kW}$ loss reduction. In particular, this analysis emphasizes the importance of the $69 \mathrm{kV}$ line from Cedar northward to Sands Point. This is a relatively long line bringing more than half of the power into the planning area. While the percentage change in this line is small, the line contributes significantly to increased losses in the area when there is an increase in load. (A $230 \mathrm{kV}$ line is scheduled to parallel the $69 \mathrm{kV}$ system by 2004, which will reduce the sensitivity of losses to changes in load on the island.) 


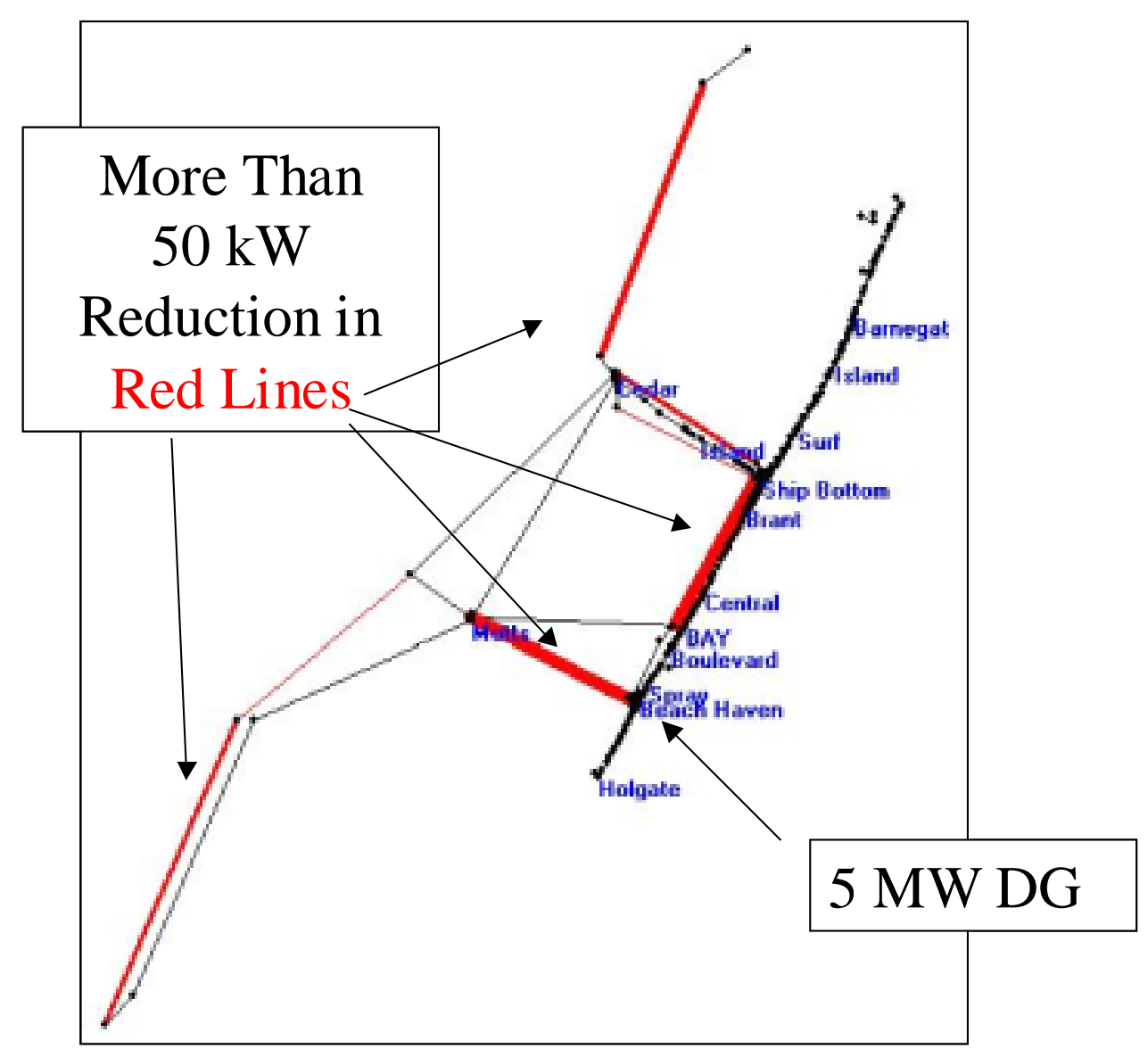

Figure 8. Power Flow Showing Line Segments Achieving Greatest Absolute Improvement in Losses Due to the Addition of 5 MW of DG at Beach Haven

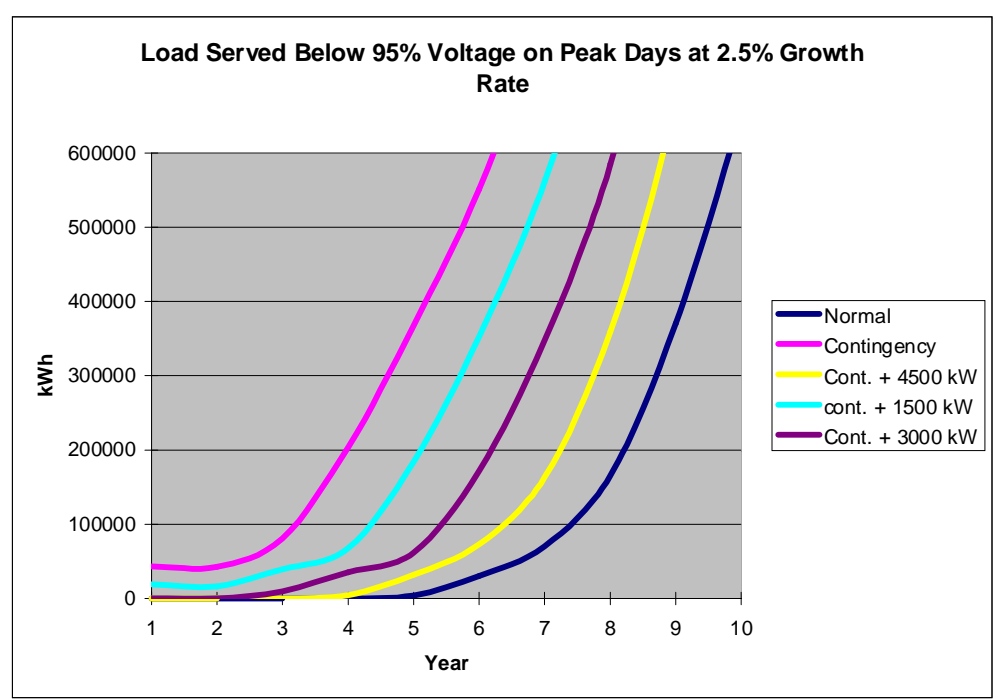

Figure 9. Relative Impact of Various Amounts of DG at Beach Haven on System Capacity

Figure 9 is one of a number of similar charts that can show the relative benefit of DG at the Beach Haven substation on the capacity of the system. In this case, the capacity is measured 
with respect to the ability of the system to delivery power to all points on the island with a satisfactory voltage (at least $95 \%$ of rated). The chart shows that the normal system configuration (rightmost curve) can continue to serve the load without significant undervoltages until about the $6^{\text {th }}$ year. This agrees with the similar chart based on overload in the $23 \mathrm{kV}$ system (Figure 2).

The diesel gensets at Beach Haven are used to cover contingencies on the transmission and sub-transmission system. The left most curve shows the unserved energy characteristic for the worst-case contingency that was identified - with the southernmost $23 \mathrm{kV}$ cable out. There are significant problems even for Year 1 and become much worse by the $3^{\text {rd }}$ year. The next 3 curves to the right of this curve illustrate the relative impact of adding $1500 \mathrm{~kW}$ of generation. The curves indicate that each $1500 \mathrm{~kW}$ of DG can cover the contingency for approximately one additional year. On this basis, it will take $6000-7000 \mathrm{~kW}$ of DG peaking capacity to continue to cover the contingency until we reach the limit of the system to continue supplying the load while in the normal configuration.

This analysis does not consider using the DG to continue to supply load past the time when the system reaches its capacity in the normal configuration.

\section{MW of Gensets To Support 69 kV Contingencies}

Until 2004, when the $230 \mathrm{kV}$ upgrade is anticipated, approximately 5 more MW of generation is required to cover some critical failures on the $69 \mathrm{kV}$ system. By placing the generation on the distribution system instead of in the substations, some additional capacity relief is achieved by relieving losses and reactive power requirement.

Studies were performed to find to optimal locations for these generators. It was assumed the 5 MW in Beach Haven substation were already in place and locations for sought for additional 2.5 MW gensets to meet the peak load in 2003 with the $69 \mathrm{kV}$ line from Sands Point to Cedar out of service. Several variations on the optimization criteria were attempted. All the results were similar, with a typical solution shown in Figure 10. This result was obtained by optimizing on capacity relief measured by energy exceeding normal ratings based on line overloads and voltage profile with a small adder for losses. Losses were weighted 1/10 of the other criteria (see Appendix A for explanation for this approach). There was one unit each on the Island and Barnegat feeders in the North part of the island and one unit on the Holgate feeder in the South. The unit on the Holgate feeder was determined to be required based on the assumed rating of 12 MVA for the Beach Haven substation. However, this rating comes from a contingency of the $23 \mathrm{kV}$ system and may not apply to this contingency.

The two locations in the North take into consideration the additional support needs during the contingency. Most of the benefits of distributed deployment are achieved as long as the gensets are sited at least 3 miles North of the Ship Bottom substation.

To evaluate the impact of the two $2500 \mathrm{~kW}$ gensets on the operation of the Barnegat and Island feeders, a simulation was carried out with the gensets sited in the vicinity of Harvey Cedars. Of particular interest are the voltage regulation upon interconnection and disconnection of the gensets and the in feed into faults affecting coordination of line reclosers and fused laterals. These two operating issues are usually the first to cause problems when there is too much DG capacity on a radial distribution feeder. 
A typical one-line schematic of the circuit configuration for each of these gensets is shown in Figure 11. The gensets would nominally be placed on the sections of feeder past the line recloser and regulator, although one may actually end up on the source side of the regulator. However, this figure serves to illustrate the issues.

At peak load, the voltage change is computed to be approximately $4 \%$ when the generation is connected or disconnected. Diesel and gas engine gensets can come up to full power in a matter of seconds - much faster than utility voltage regulation equipment will normally respond. Thus, the connection and disconnect change would be evaluated the same in this case. For smaller, more widely distributed generation that comes on at random times, the sudden disconnection is normally the condition of interest. (This will happen during utility fault clearing.) After switching, the utility voltage regulators and capacitors will adjust to the new loading conditions after a minute or so.

Our recommendation for the maximum allowable change is generally around $5 \%$ unless there are fast acting voltage-regulating devices on the feeder. Standard utility voltage regulators would typically not time out and change tap for 30 seconds or more. Special options can be available on some models to begin tap changing more quickly. If that feature is being used, utilities might allow up to a $10 \%$ change. The $4 \%$ change is within our recommendation in either case and the voltage change when the generation is connected and disconnected should be tolerable in this feeder location.

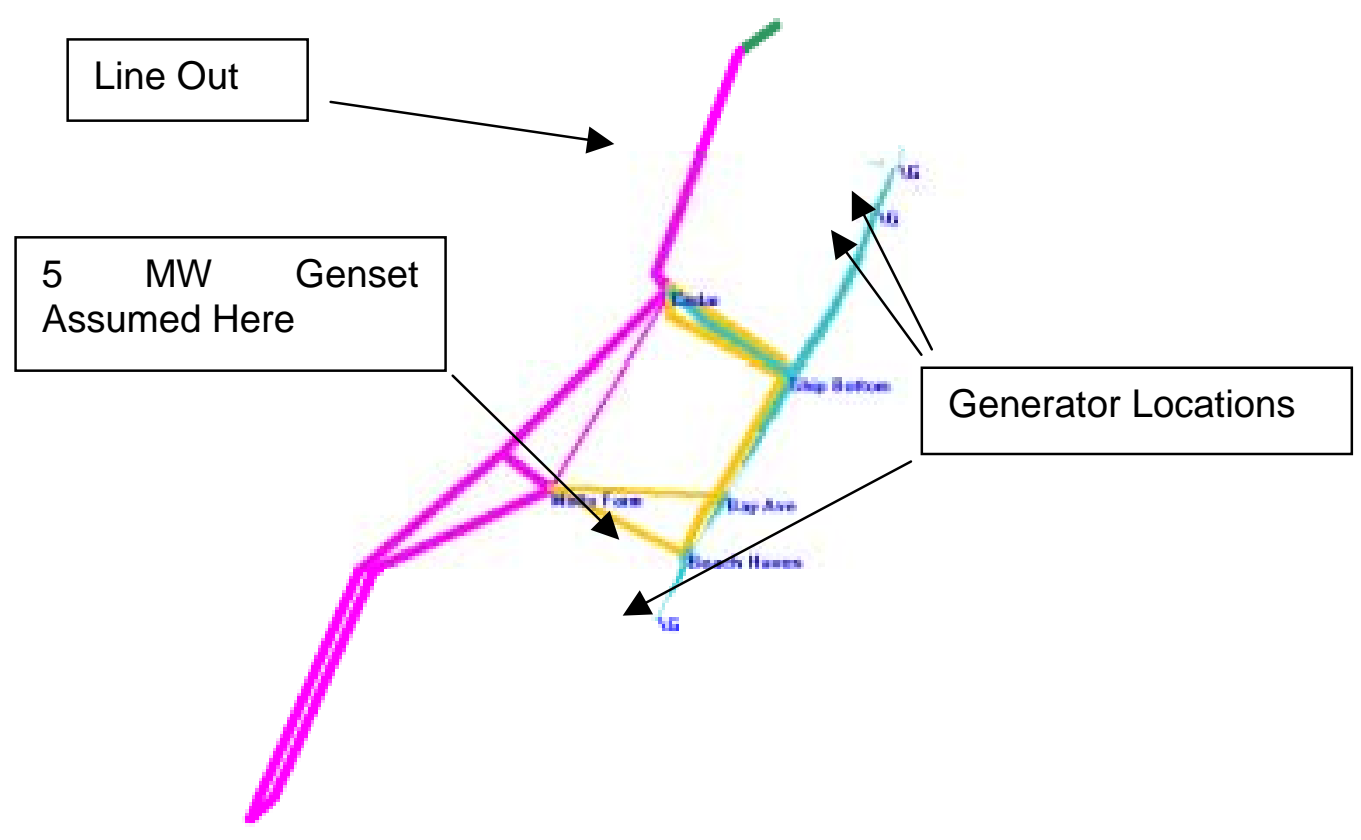

Figure 10. Optimal Locations for 2.5 MW Gensets, Year 3. Optimized for Voltage and Overload Capacity Relief.

The line reclosers are set to try to save the fuses for faults on fused laterals. They generally have one fast operation on an "A" curve. The laterals are fused with a 65T link in this area. Figure 12 shows the coordination chart for this condition. The fuse chosen for analysis was located where the nominal available fault current is $1200 \mathrm{~A}$. For the fault simulated the current 
in the fuse was approximately $1000 \mathrm{~A}$ without any generation present. At this value, the recloser operates in $0.06-0.08 \mathrm{~s}$ and the fuse requires approximately $0.2 \mathrm{sec}$ to operate. This leaves substantial protection margin and the fuse saving operation can be expected to succeed in the vast majority of cases.

Assuming the generators are rated at $3000 \mathrm{kVA}$ and have a $27 \%$ transient reactance (Xd') the total current in the fuse could be as much as $1400 \mathrm{~A}$ when the generators are operating at peak load. This corresponds to a melting time of $0.1 \mathrm{~s}$ ( 6 cycles). The recloser operates in 0.05 $0.06 \mathrm{~s}$. Again, there would appear to be coordination and there should be much of the time. However, asking mechanical breakers to trip and clear consistently in less than 6 cycles is expecting quite a lot. Any time the fuse melting time drops to $0.1 \mathrm{~s}$, or less, there is a race between the upline mechanical device and the fuse, which will not always be won by the recloser. This will be particularly true if the fuse has been weakened by previous fault clearing events. Therefore, it is our assessment that the presence of this much generation will likely lead to an increased number of inadvertent fuses blowings.

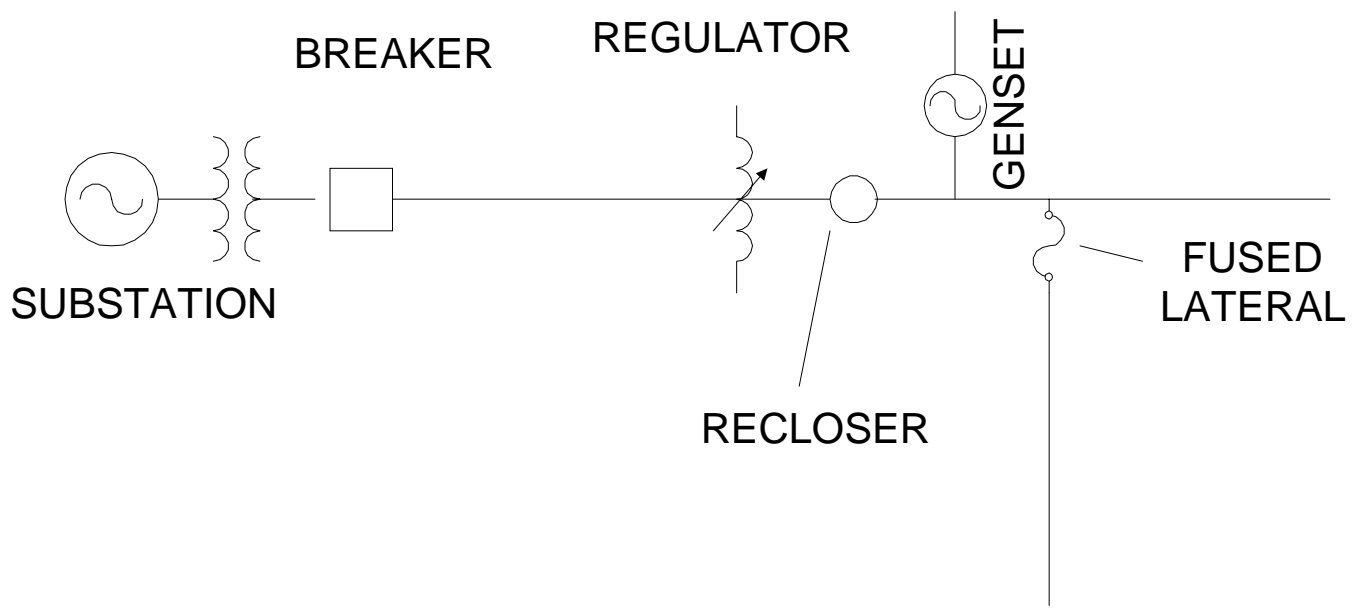

Figure 11. Schematic of the System for the 2.5 MW Gensets in the North Part of the Island.

However, this is not a deal killer in this case. Fuse saving has always been a sensitive power quality issue between customers and the utility. Like many other utilities serving more urbane residential customers, Conectiv reports that there has been some consideration of abandoning fuse saving in this area due to customer complaints. Saving the fuse for a lateral serving only a few customers requires briefly interrupting the power for all customers beyond the recloser. While this is a cost saving to the utility, many customers view it as poor power quality. Customers are sometimes more likely to be understanding if they are without power for 30 minutes, or so, while the fuse is being changed.

The other consideration in this analysis is that the generation must be running when a fault occurs. Since the generation is designed to be peaking generation that runs only a few hours each year, there is a low probability that it will be running when there is a fault. Therefore, the utility in this case should be able to accommodate the generation without significant changes to its overcurrent protection practices. The generation is near the limit with respect to voltage 
regulation and we would not expect that much more generation could be added on the feeders without making some significant changes to operating practices.

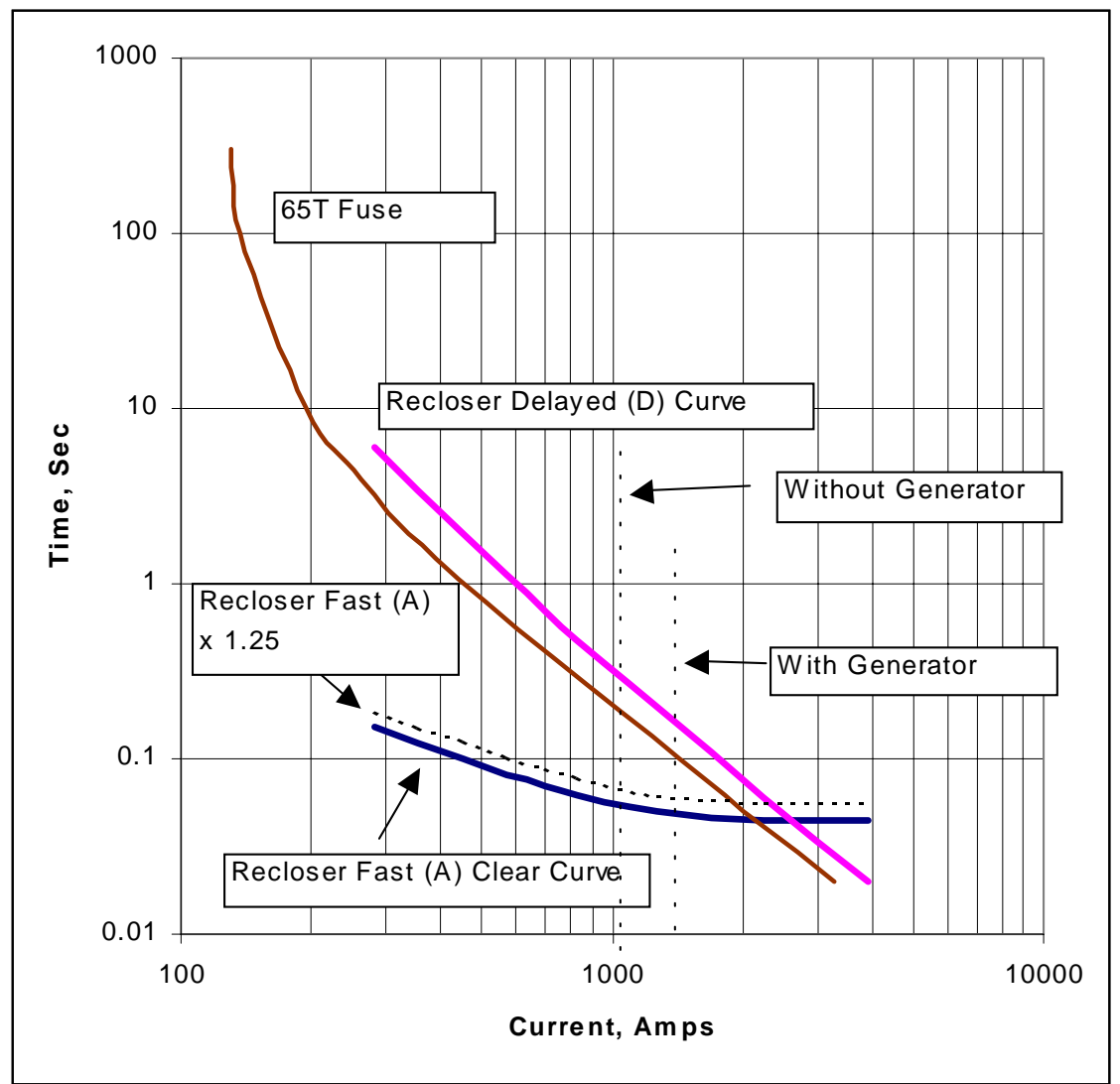

Figure 12. Coordination of Line Recloser and Lateral Fuse on Barnegat Feeder With Respect to Presence of a $2500 \mathrm{~kW}$ Genset. 


\section{DISTRIBUTED SMALL GENERATION SOLUTION}

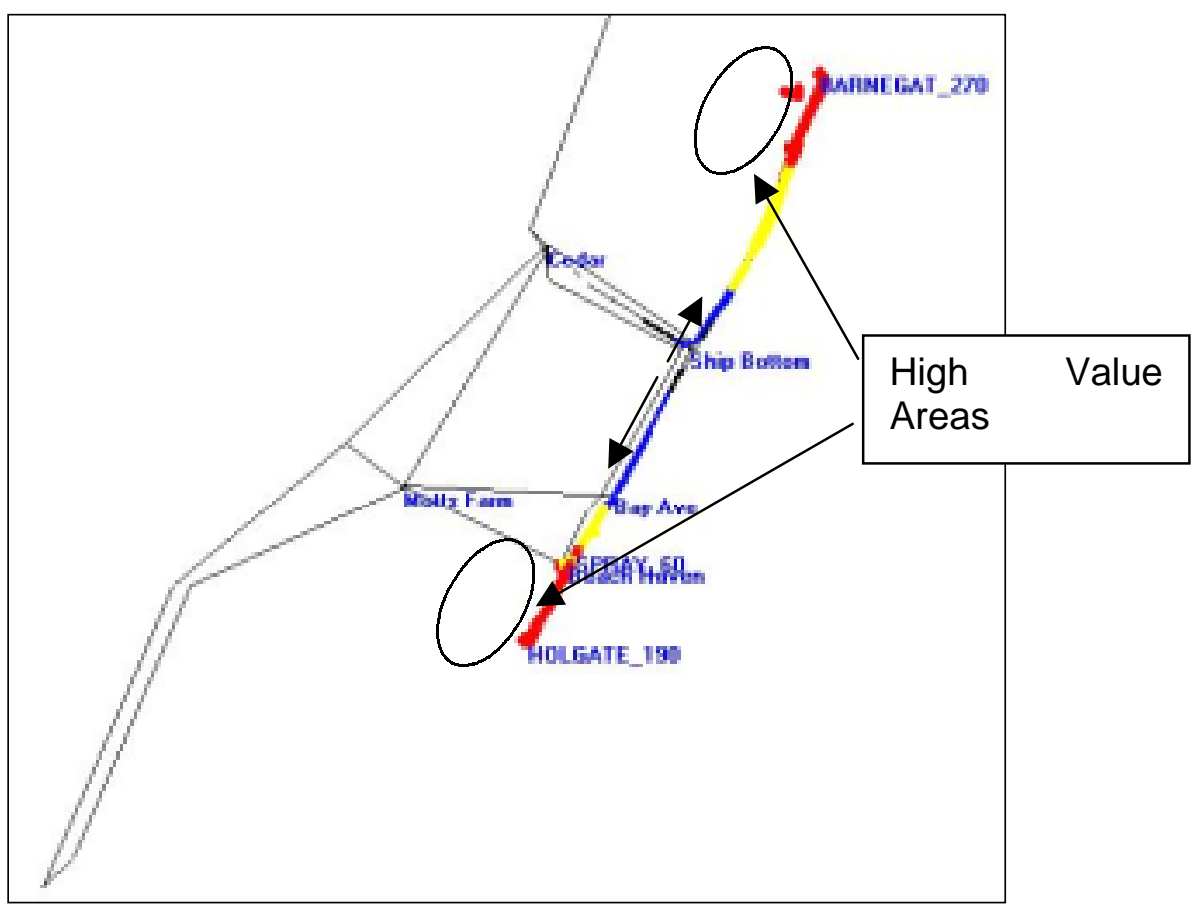

Figure 13. The Relative Value of Distributed DG on LBI to the Power Delivery System Increases with Distance from the Ship Bottom Substation.

Figure 13 shows the results for one measure of the relative value of widely distributed DG to the power delivery system.

We have assumed in this evaluation that the main wires upgrade to the transmission system and the Ship Bottom substation will have been accomplished. Then we will be looking at smaller distributed resources to defer the need for future upgrades to the $12.47 \mathrm{kV}$ system.

This chart shows the areas of the $12.47 \mathrm{kV}$ feeders on Long Beach Island that would likely result in the most capacity relief from load reduction. These would be the areas to target for distributed small generation technologies. This particular chart was developed based simply on peak load loss reduction. Other measures of capacity relief give similar results that differ only by degree. The topology of the circuit dictates where the maximum benefit will occur. The greatest benefit occurs for areas now served by the Holgate, Barnegat, and Island feeders.

The conclusion one may draw from this is that the best chance for smaller distributed generation sources to have any impact on the costs of operating the distribution system is to put a program in place that will encourage the installation of such systems at the island extremities. DG installed in the areas nearer Ship Bottom substation is not likely to have enough benefit to the distribution system to defer future upgrades over the next 20 years or so. The constraints that force upgrades will be in the lines and cables that move the power to the ends of the island out of the Ship Bottom substation. 


\section{Applicable Distributed Technologies}

What kind of distributed technologies might be able to meet this need? This project is nominally to assess the application of fuel cells and microturbine-based generation. Both of these technologies would convert natural gas, already supplied to the island, into electrical and thermal energy.

To have any real benefit to the power delivery system, this generation must be available when needed. The only times that the delivery is stressed is at peak load. At other times, which are the bulk of the year, the system does not need the generation support.

Both fuel cell and microturbine technologies are most economic and efficient when matched with thermal loads that coincide with the electrical demand. Microturbines are commonly available in 30-60 kW increments. They may be applied in standby and peaking applications, although they are more effective if there is also a thermal load that allows operation for much longer duty cycles. Good candidates for microturbine applications are light industrial facilities and commercial establishments with more than $30 \mathrm{~kW}$ load. These facilities should ideally have a thermal load that can be satisfied by the microturbine or a high-value load with a need for emergency backup power. This is where the basic economic justification for the technology must exist.

Fuel cells are more of a base-load technology that should be operated most of the time. They can be applied in sizes up to a few hundred $\mathrm{kW}$. Their quiet operation with very low emissions makes fuel cells potentially attractive options for commercial and institutional facilities with substantial heating and cooling load.

To get any capacity credit with respect to the power delivery system, the generation will not only have to be located in the proper place, but should be operating at peak load. The peak is largely an air conditioning peak that occurs on hot summer weekends. This places some special requirements on distributed resources on $\mathrm{LBI}$ that are different from many mainland loads with weekday peaks:

1. The facility must be open and operating during the weekend. While certain loads would be eliminated with this consideration, others catering to tourism such as restaurants, hotels, and amusement parks should be good candidates

2. For CHP applications, the thermal load must likely include chillers as well as hot water and other heat loads.

Without these two characteristics, it would not appear possible to offer capacity credits for relief of delivery capacity. Any capacity credits would have to come through the regional power market via an aggregator of DG.

The added value for the DG must come from the need for thermal load and the need for backup power.

One technology that meets the criteria is solar photovoltaic (PV) generation. While this technology is not the intended focus of this investigation, it is obvious that high ambient temperatures due largely to insolation cause the load peak on the island. Therefore, the peak output from roof top PV will likely coincide with the peak load. PV is also eligible for net metering in New Jersey. Another aspect that relates to this case is that much of the load 
growth on LBI is reported to be due to building new, larger residences. By targeting the builders and owners, it is possible that a substantial portion of the growth in peak load can be offset with PV installed on the roofs of new houses.

\section{Amount of Generation Required}

Assuming that the load continues to grow by 1.2 - $1.5 \mathrm{MW}$ per year, the amount of DG that would have to be installed to maintain the margins on the distribution system will have to be of a similar value. However, the location of the generation will be as important as the amount.

The main distribution system constraint will be on the feeders supplying power to either end of the island. The Barnegat feeder is supplying about $11 \mathrm{MW}$ on peak, including losses. The Beach Haven substation peak is projected at $16.5 \mathrm{MW}$. The total Island load is currently approximately 72 MVA. If the growth is distributed uniformly over the island, the amount of generation required to counter the growth in the extremities is:

\section{Barnegat: $11 / 72 \times 1700=260 \mathrm{~kW}$}

\section{Beach Haven: $16.5 / 72 \times 1700=390$ kW}

If the generation is located well out on the feeder, a little less generation will be required because of loss reduction. Therefore, we can estimate that it will require somewhere between 600 and $700 \mathrm{~kW}$ of DG each year to counter the load growth in the critical areas. This generation would have to be located in the proper location to achieve capacity relief on the distribution system.

Of course, if the growth is not uniform, then it may take more or less than these estimates to avoid having to upgrade the feeders or add new feeders in the area serving the extremities of the island.

\section{Amount of Generation that can be Accommodated}

There would have to be a certain amount of generation added to counter the load growth and maintain margins in the supply system. However, there is an upper limit to how much generation can be tolerated before there have to be significant changes in the power supply system.

The $12.47 \mathrm{kV}$ distribution system is operated in a radial configuration. All the voltage regulation and short circuit protection devices on the system assume power flow from only one direction. While a certain capacity of other sources can be accommodated, there is a limit.

Fuel cells, microturbines, and PV systems all interface to the utility system through electronic power converters. Most devices limit the fault current infeed to approximately 2 per unit of rated current. Thus, the impact on the coordination of overcurrent protective devices due to fault current infeed is likely minimal. The most limiting issue is likely to be voltage regulation, with some aspects also related to utility fault clearing practices.

The proposed IEEE interconnection standard requires distributed generation to disconnect from the electric power system (EPS) when the power is interrupted and remain disconnected until power has been restored for five minutes. Voltage regulation during this interval can be a problem, particularly if the EPS has become reliant on DG to maintain service to the load. 


\section{Economic Evaluation}

In this section we will discuss the economics of deferring the $23 \mathrm{kV}$ replacement (the "wires plan") by DG and, also, the long-term prospects for small distribution generation based on energy efficient technologies such as fuel cells and microturbines in CHP applications.

\section{DEFERRING THE WIRES PLAN BY DG}

As stated previously, the cost to replace the $23 \mathrm{kV}$ system is estimated, in round numbers, at $\$ 10 \mathrm{M}$. As with many similar utility construction projects, we will assume that the investment will not be made all at once, but will be spread equally over two years. It is also estimated that to continue to operate the $23 \mathrm{kV}$ system will result in an average of $\$ 200 \mathrm{~K}$ to be spent each year to perform maintenance. Repair of submarine cable can be very expensive. This may actually escalate due to increasing failures with age, but we will assume that it remains constant.

If look at a 10-year period, the cash flows will appear as in Table 1. This table also shows the amount of genset capacity that will have to be leased each year to accomplish the deferral by covering the contingencies. Only the amount of generation required to support the $23 \mathrm{kV}$ system contingencies is considered in this evaluation. It is assume that the $5 \mathrm{MW}$ for covering the $69 \mathrm{kV}$ contingencies is justified by other means. Initially, $5000 \mathrm{~kW}$ is required, increasing to 7000 by 2003 . This is basically to cover the Beach Haven constraint and can be accomplished by installing slightly larger gensets in the same location as was used in 2001. Depending on growth assumptions, and the risks the utility wishes to take, this will suffice until either 2005 or 2006. We will assume 2006. After that, we assumed the next logical unit size would lead to a total of $10000 \mathrm{~kW}$. Of course, in actual practice, these sizes would be re-evaluated annually.

Table I

Assumed Cash Streams (Millions of \$) for Deferring Wires Solution the Indicated Number of Years

\begin{tabular}{|l|l|l|l|l|l|l|l|l|l|l|l|}
\hline & $\mathbf{0}$ & $\mathbf{1}$ & $\mathbf{2}$ & $\mathbf{3}$ & $\mathbf{4}$ & $\mathbf{5}$ & $\mathbf{6}$ & $\mathbf{7}$ & $\mathbf{8}$ & $\mathbf{9}$ & $\begin{array}{l}\text { KW } \\
\text { req'd }\end{array}$ \\
\hline 2001 & $\$ 5$ & $\$ 0.2$ & $\$ 0.2$ & $\$ 0.2$ & $\$ 0.2$ & $\$ 0.2$ & $\$ 0.2$ & $\$ 0.2$ & $\$ 0.2$ & $\$ 0.2$ & 5000 \\
\hline 2002 & $\$ 5$ & $\$ 5$ & $\$ 0.2$ & $\$ 0.2$ & $\$ 0.2$ & $\$ 0.2$ & $\$ 0.2$ & $\$ 0.2$ & $\$ 0.2$ & $\$ 0.2$ & 5000 \\
\hline 2003 & & $\$ 5$ & $\$ 5$ & $\$ 0.2$ & $\$ 0.2$ & $\$ 0.2$ & $\$ 0.2$ & $\$ 0.2$ & $\$ 0.2$ & $\$ 0.2$ & 7000 \\
\hline 2004 & & & $\$ 5$ & $\$ 5$ & $\$ 0.2$ & $\$ 0.2$ & $\$ 0.2$ & $\$ 0.2$ & $\$ 0.2$ & $\$ 0.2$ & 7000 \\
\hline 2005 & & & & $\$ 5$ & $\$ 5$ & $\$ 0.2$ & $\$ 0.2$ & $\$ 0.2$ & $\$ 0.2$ & $\$ 0.2$ & 7000 \\
\hline 2006 & & & & & $\$ 5$ & $\$ 5$ & $\$ 0.2$ & $\$ 0.2$ & $\$ 0.2$ & $\$ 0.2$ & 7000 \\
\hline 2007 & & & & & & $\$ 5$ & $\$ 5$ & $\$ 0.2$ & $\$ 0.2$ & $\$ 0.2$ & 10000 \\
\hline 2008 & & & & & & & $\$ 5$ & $\$ 5$ & $\$ 0.2$ & $\$ 0.2$ & 10000 \\
\hline 2009 & & & & & & & & $\$ 5$ & $\$ 5$ & $\$ 0.2$ & 10000 \\
\hline 2010 & & & & & & & & & $\$ 5$ & $\$ 5$ & 10000 \\
\hline 2011 & & & & & & & & & & $\$ 5$ & \\
\hline
\end{tabular}

Simply put, we assume that there will be $\$ 200 \mathrm{~K}$ maintenance expenses until the two-year construction begins. Deferring the major investment has a value that will depend on the weighted average cost of capital (WACC). The net present value (NPV) of each cost stream in Table 1 was computed. Figure 14 shows the difference between adjacent streams, or the NPV of the savings by deferral in each year for three different WACC values. 


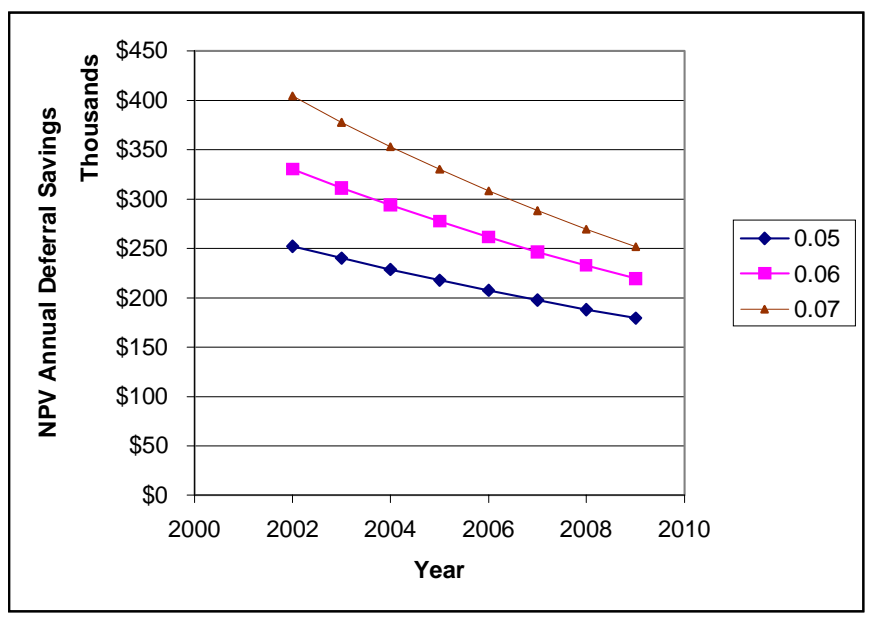

Figure 14. Net Present Value of Annual Savings of Deferring Wires Plan Year-by-Year for Three Values of WACC: $5 \%, 6 \%$, and $7 \%$

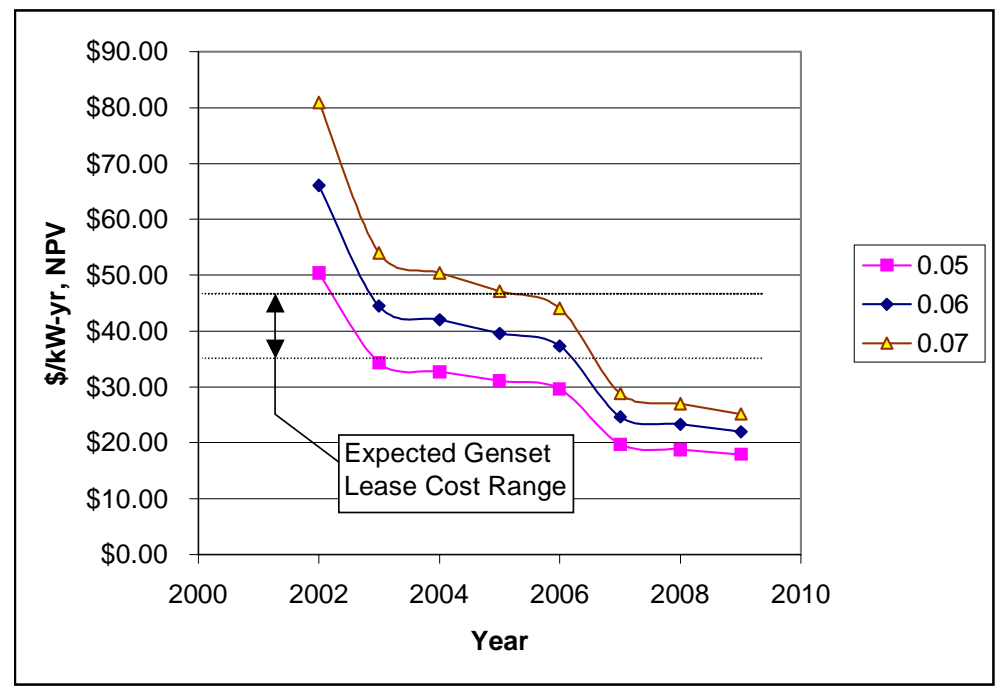

Figure 15. Marginal Costs with Respect to Generator Capacity of Deferring Wires Plan with Gensets.

While the savings are substantial - $\$ 300$ - $\$ 400 \mathrm{~K}$ per year, initially - the cost to achieve deferral are also significant. A certain amount of generation is required as indicated in the table. Figure 15 shows the marginal costs of the savings relative to the amount of generation required for each year for the same three WACC values.

Superimposed on the chart is the typical expected range of costs for leasing trailered diesel or natural gas engine gensets. This value is somewhat location-dependent and size-dependents, but is not expected to be lower than the bottom end of the range. It should be noted that this is currently the least expensive generation option available today directly from the manufacturers. Neglecting the possible acquisition of used equipment salvaged from some other operations, it is expected that all other technologies will plot much higher on this chart.

Therefore, the gensets are practically the only economic DG technology for providing enough capacity to defer the wires plan. This analysis assumes that there will be no loss of reliability 
because there will always be enough generation present to cover contingencies at least as well as the present $23 \mathrm{kV}$ system. Therefore, there is no unserved energy penalty applied and it would appear from Figure 15 that it very well could be economic to defer the wires plan with the gensets at least for a few years.

The greater the cost of capital coupled with lower cost of generation, the greater the economic value of deferral. There would appear to be little question that $5000 \mathrm{~kW}$ could be economic. When it is necessary to increase the amount of DG to $7000 \mathrm{~kW}$, the economics are a bit more tenuous, if we are simply using the gensets to cover contingencies and not produce any revenue. Finally, it would appear that it would not be economical to go to the third step of $10,000 \mathrm{~kW}$ unless there was some other cash flow generated. Interestingly, the time to increase past $7000 \mathrm{~kW}$ coincides with the $23 \mathrm{kV}$ delivery system reaching its limits in the Normal configuration.

There are two other observations that are often made regarding utilities in this situation:

1. Running the gensets as a hedge against high power prices introduces benefits that allow the genset-based solution to be economic for a longer period.

2. If the utility did not have to make the full investment in the DG, the deferral would look economic for more years. This assumes that customers have some incentive (capacity credit, need for backup, etc.) that would entice them to make the investment and use it for the benefit of the power delivery system.

Figure 16 shows the price-duration curve for local marginal power prices in the Cedar substation area for the last full year for which prices were available when this analysis was done, 1999. The expected range of operating costs for the gensets is between $\$ 60$ and $\$ 90$ per $\mathrm{mWH}$, depending on price of fuel. If it is assumed that the gensets can be operated to take full advantage of the prices and will be operated whenever the price is favorable, this would result in a net revenue of $\$ 58$ and $\$ 54 / \mathrm{kW}$-yr, respectively, based on the number of hours and average prices shown. This would offset most, if not all, of the costs of leasing the gensets.

It should be pointed out that when the price peak coincides with a loading peak like that simulated in the planning studies, which is not necessarily the case, there is a significant additional bonus to operating the gensets of perhaps $20-30 \%$ by the incremental reduction in delivery losses. Also, it may not be possible due to emissions constraints to operate the gensets for the full number of hours. Local regulation limit diesel gensets to about 150 hours. However, gas engines may be operated as much as $1000 \mathrm{hr}$, which should be sufficient for covering the peak price periods. 


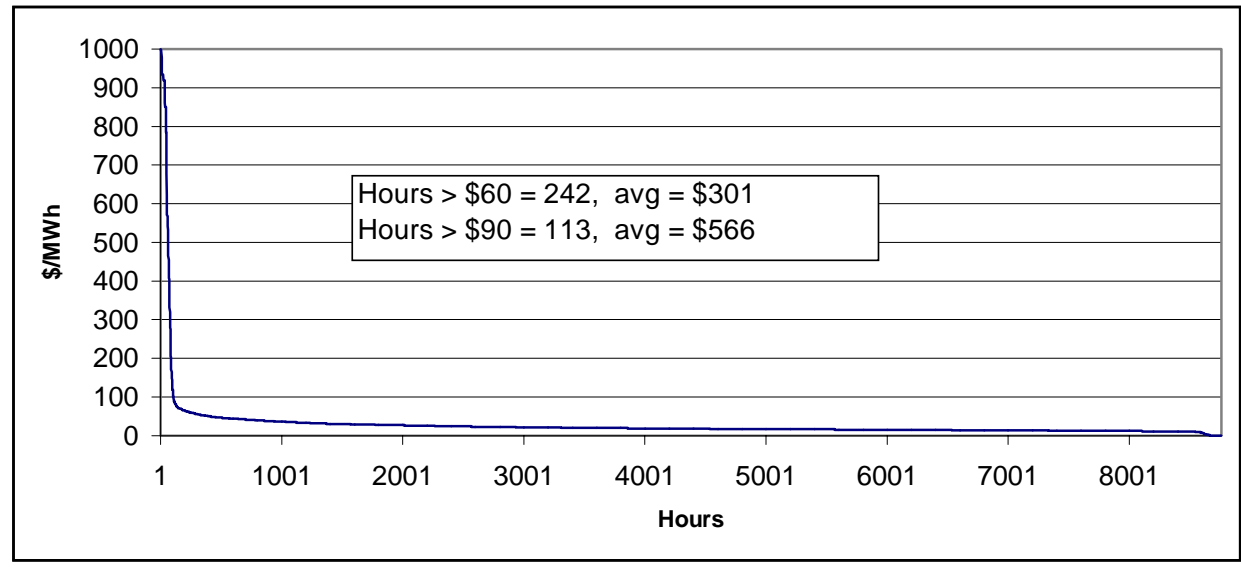

Figure 16 Local marginal price-duration curve for 1999.

A demand-side DG solution to defer the replacement of the $23 \mathrm{kV}$ system may not me practicable due to the following issues:

1. Getting enough capacity. There is a present need for $5 \mathrm{MW}$ escalating to $7 \mathrm{MW}$ within 2 - 3 years. It would be very difficult to get the logistics for a customer-based program in place in time to provide the necessary capacity.

2. Getting the capacity in the right location. The generation would have to be in the Southern half of the island. Ideally, one would hope to find in this area a few large customers in need of backup generation. Since the island is largely residential and light commercial, this appears unlikely.

Thus, the only DG option that would appear to compete with the proposed wires solution is the utility-leased gensets option. This would appear to offer both a technical and economic alternative until at least 2005 or 2006. After that, the economics would depend greatly on the local marginal power prices and the ability to participate sufficiently in that market.

\section{SMALL, CUSTOMER-OWNED DISTRIBUTED GENERATION}

As we have seen in the preceding, any capacity credit given to small, widely distributed DG is not likely to be significant for relieving constraints on the power delivery system. Therefore, the economics of these systems must stand on their own on a site-by-site basis, less credits offered by governmental agencies to promote societal benefits due to environmental and energy efficiency considerations.

In this section, we evaluate the expected economics for typical installation of fuel cells and microturbine applications in the LBI environment. Examples are given of specific sites proposed for follow-on work in this project.

Capacity Credits from the Utility: While replacing the $23 \mathrm{kV}$ system will provide sufficient supply capacity for the island for perhaps 20 years, or more, there will be a continuing need to upgrade the $12.47 \mathrm{kV}$ feeder system. The feeders distributing power to the Northern and Southern extremities are currently near their load-carrying limit at the peak island load. If the utility were to offer any capacity credits to customers to install generation, the most likely areas would be those served by the Holgate feeder and the Northern half of the Barnegat feeder. 
Other areas would have less benefit because there will be more options for transferring load to prevent overloading. When overload occurs in the two extremities, new distribution feeder facilities must be built at a cost of, typically, \$20/kVA to $\$ 100 / k V A$.

If the assumed growth of 1.7 MVA per year is uniformly distributed over the feeders on the Island, it would require approximately 600 - $700 \mathrm{~kW}$ of distributed generation each year to counter the load growth on these two feeders. Ideally, nearly $400 \mathrm{~kW}$ of that would be located on the Southern part of the island and the remainder in the North. Of course, the actual distribution will be different if the growth is not uniform, but this gives an idea of what size of program is needed.

The success of demand side DG will depend on the commercialization of new technologies for residential applications. There are many companies beta testing small fuel cells for home use that provide electric service along with much of the heating demand of a single residence. If the cost of these units becomes economically competitive with other sources of power, DG can make significant inroads in supply-constrained areas such as LBI. 


\section{DG SITING ANALYSIS}

The goal of this study is to evaluate the feasibility of installation of customer-sited fuel cells and microturbines at three Long Beach Island facilities Fuel cells and microturbine are good candidates for use on a dense area like Long Beach Island due to their low emissions and quiet operation. These facilities were chosen based on being open the year around and having a significant thermal load, which allows use of cogeneration for greater efficiency. The three facilities for which case studies are presented below are the St. Francis Community Center, The Harvey Cedars Bible Conference and the Long Beach Island Grade School.

\section{APPROACH}

Generation technologies evaluated for these facilities are the UTC PC 25 fuel cell and the Capstone $30 \mathrm{~kW}$ and $60 \mathrm{~kW}$ microturbines with the ability to co-generate thermal energy, usable for heating and domestic hot water systems. To select and size generators for each of these facilities, the following analysis conditions were assumed:

- Generators are interconnected and synchronized and operate in parallel with the grid. The grid supplies electric load not supplied by the generators.

- Generators are embedded in the existing heating and hot water system;

- Available thermal energy is first used for domestic hot water; remaining thermal energy available is used for supplemental input to the heating system during the heating season.

- During the non-heating season, thermal energy in excess of what is used for domestic hot water is dissipated into the atmosphere through water or air-cooling devices.

Based on these conditions, various options are evaluated comprising:

- Several options with different number of generators and different modes of operation evaluated for each facility in comparison with the base case

- An option with load curtailment during the three summer months evaluated for each of the St. Francis Community Center and the Harvey cedars Bible Conference.

For details on the methodology for evaluating the customer-sited DG, see Appendix B.

The following cases present a description of the three facilities evaluated. For a detailed description of each facility, see Appendix B.

\section{ST FRANCIS COMMUNITY CENTER}

\section{Existing Facility Description}

St Francis Community Center includes the building of the Center itself and the church. Building space heating is provided by two sources. About $90 \%$ of the building space is heated by the central heating system. Three roof-mounted units heat $10 \%$ of the space. Central heating 
system is equipped with the natural gas (NG)-fired Weil McLain boiler with a burner manufactured by "Power Flame Burner" company.

\section{Proposed Design Modification}

Two options were proposed for modification of the existing electric and thermal energy supply system. One option includes installation of a $200 \mathrm{~kW}$ fuel cell to co-generate electric and thermal energy for covering the existing electricity demand and part of the thermal energy demand. Another option proposes to cover the existing facility electric demand by one or two 60 kW microturbine generators with co-generation of thermal energy used for hot water and heating systems.

\section{OPTION 1}

The PC25 fuel cell has two separate thermal energy outputs - low temperature heater with about $140{ }^{0} \mathrm{~F}$ hot water output, and high temperature heater with about 200 to $240{ }^{\circ} \mathrm{F}$ hot water output. It was assumed that fuel cell power plant is incorporated into both existing systems central water heating system and domestic hot water system. A flowchart of the proposed system modification is presented in Fig 17.

Return heating water enters the low heat energy (LHE) heater (1) of the fuel cell (2) and comes out heated to $140{ }^{\circ} \mathrm{F}$, it is further directed to the water/water heater (3) for domestic hot water, and flows to the high heat energy (HHE) heater (4) of the fuel cell. After the HHE heater, heating water is returned to the existing accumulating tank (5). If the water temperature is sufficiently high for the heating system supply, it is pumped to the central heating system. If additional heating of the supply water is required, the existing boiler (6) starts to increase the supply water temperature to the required level, using the existing control system set points

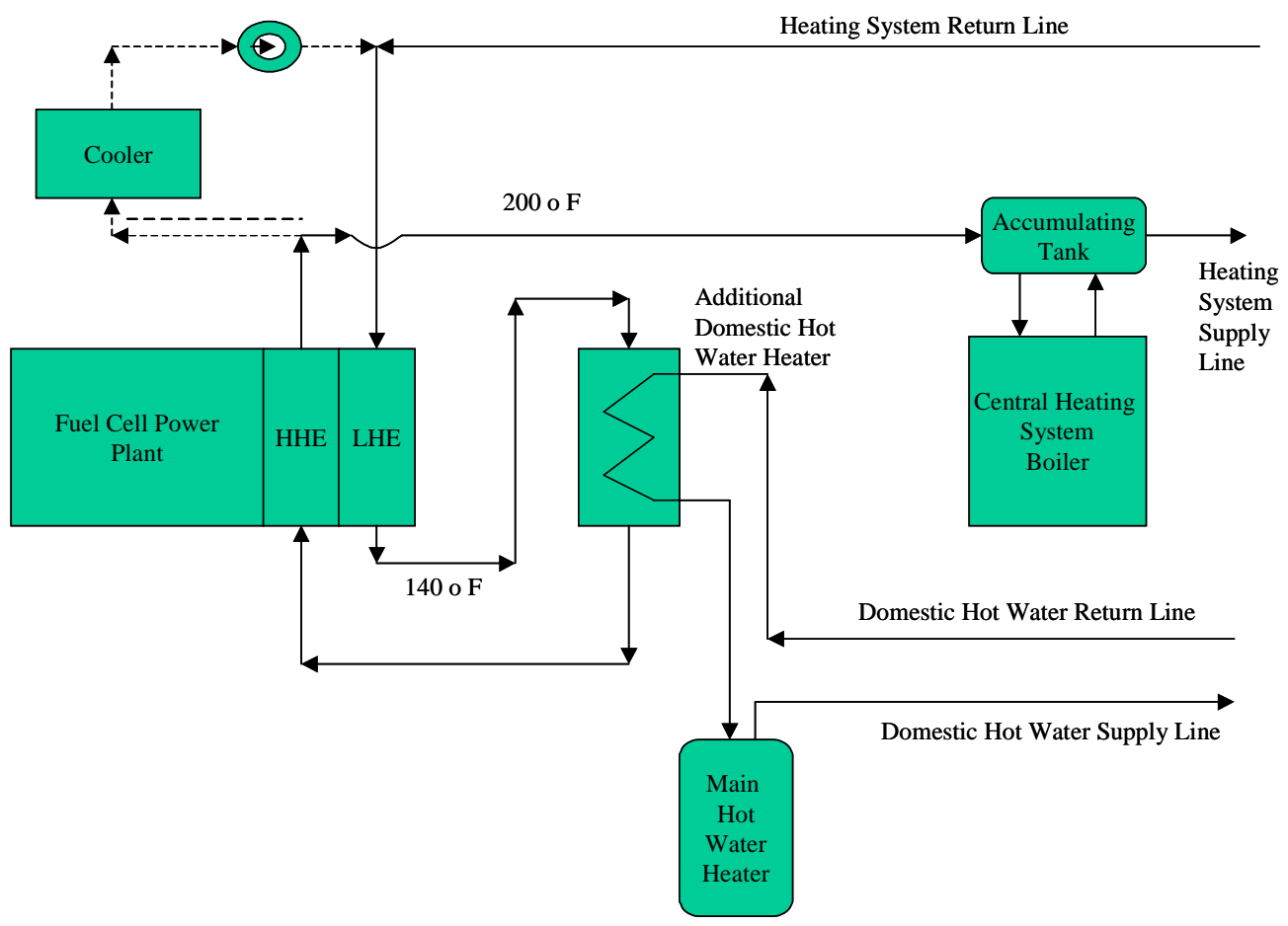

Figure 17. Option 1: Proposed Heating System Modification with Fuel Cell 
The water/water heater for domestic hot water (3) is included in the existing domestic hot water system before the existing hot water heater (7). Water returned from the domestic hot water loop goes first through the new water/water heater and further follows to an existing hot water heater. Existing hot water control system will start the main water heater if the temperature of the hot water after the fuel cell is lower than the set point and reheat it. If fuel cell plant provides enough heat for the domestic hot water, existing water heater will stay idle.

During the summer, when heating is not required, the water heating loop of the fuel cell plant is disconnected from the main central heating system, and is ran by the additional pump (8) first through the LHE heater (1) to water/water heater (3), and HHE heater (4). Then hot water is directed to a cooler (9), which dissipates the rest of the thermal energy to the atmosphere.

This design allows utilization of the existing thermal energy generation equipment and associated control systems, as well as existing pumps and piping.

Operation of the fuel cell has the following disadvantages, associated with operation in a loadfollow mode.

Reduction of the electrical load is accompanied by reduction of thermal energy output, with zero thermal output below $100 \mathrm{~kW}$.

Fuel cell startup from cold condition to full load requires about three hours. It also cannot quickly respond to sharp changes of the facility electric load (startup of large chillers, etc)

Therefore, another option with installation of microturbine-generators was also evaluated.

\section{OPTION 2}

Gas-fired microturbines can work in the load follow mode with the heat output proportional to the electric load according to the graph in Figure 18.

It is assumed that microturbines are installed using the same design approach as the fuel cell generator. Based on the forecast facility electric demand, one of the scenarios with microturbines assumes installation of one $60 \mathrm{~kW}$ turbine, and two other scenarios propose installation of two $60 \mathrm{~kW}$ turbines, where one turbine is working all year long with the second turbine starting when the facility load is higher than $60 \mathrm{~kW}$.

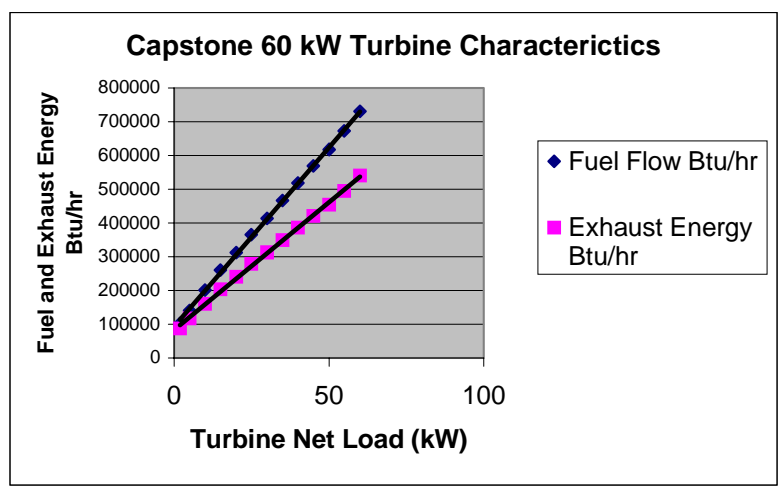

Figure 18. Microturbine Characteristics 


\section{Evaluated Scenarios}

For all scenarios, the fuel cell or microturbine is operating in an electric load-follow mode. When demand exceeds generating capacity, the grid supplies residual demand. If facility demand is less than maximum fuel cell capacity, electricity generation is reduced with a commensurate reduction of thermal energy output. In the non-heating season unconsumed thermal energy is dissipated to the atmosphere. If the amount of thermal energy produced is insufficient to satisfy thermal energy demand, additional thermal energy is supplied by the existing boiler (for the central heating system) and by the existing domestic hot water heater. A total of five scenarios were developed for evaluation of the St. Francis Community Center.

\section{BASE CASE SCENARIO}

Annual energy expenses for the base case is calculated consisting of the following components:

- Annual cost of electricity - facility electric energy demand profile and current contract price of electricity;

- Annual cost of natural gas - sum of three components

1. Annual NG consumption for domestic hot water

2. Annual NG consumption for the central heating system - based on20 years average heating degree days (HDD) data

3. Annual NG consumption for roof-mounted heaters $-10 \%$ of $N G$ consumption is for the central heating system.

Annual O\&M (except of fuel and electricity) for operation of existing electrical, heating, and domestic hot water equipment was not calculated, because it will be approximately the same for all three scenarios. Annual O\&M expenses associated with operation of fuel cell/micro turbine generators are included in other scenarios.

\section{SCENARIO 1}

The fuel cell is operated year around. Thermal energy developed by the fuel cell plant is used for domestic hot water preparation and space heating. If thermal energy produced by fuel cell is insufficient to serve facility's thermal energy demand, additional thermal energy is supplied by the existing boiler (for the central heating system) and by the existing domestic hot water heater.

\section{SCENARIO 2}

The fuel cell operates during the heating season. In the non-heating season the fuel cell plant is not operated and electricity is purchased from the grid and the existing hot water heater is used for domestic hot water. 


\section{SCENARIO 3}

One $60 \mathrm{~kW}$ microturbine generator is installed and operates year around in conditions similar to in Scenario 1.

\section{SCENARIO 4}

Two $60 \mathrm{~kW}$ turbines are installed with one turbine operating year around and the second turbine operating when the facility demand exceeds $60 \mathrm{~kW}$.

\section{SCENARIO 5}

Two $60 \mathrm{~kW}$ turbines operating are installed and operated in a mode similar to Scenario 4 . It is assumed that the facility is participating in the PJM Alternative Load Management (ALM) and the Load Response Program (LRP) during three summer months, and receives capacity and energy payments according to the PJM clearing price for the Atlantic Electric zone.

\section{RESULTS}

Number of years for payback and internal rate of return shown on Table 1 are based on full cost of capital and installation net of subsidies ${ }^{3}$

Table 1. Financial Analysis Results for St. Francis Community Center

\begin{tabular}{|c|c|c|c|c|c|c|}
\hline & \multirow{2}{*}{$\begin{array}{l}\text { Base } \\
\text { case }\end{array}$} & \multicolumn{2}{|c|}{ Fuel Cell } & \multicolumn{3}{|c|}{ Microturbine(s) } \\
\hline & & $\begin{array}{c}\text { Scenario } \\
1\end{array}$ & $\begin{array}{c}\text { Scenario } \\
2\end{array}$ & $\begin{array}{c}\text { Scenario } \\
3\end{array}$ & $\begin{array}{c}\text { Scenario } \\
4\end{array}$ & $\begin{array}{c}\text { Scenario } \\
5\end{array}$ \\
\hline Natural gas & $\$ 13,256$ & $\$ 19,708$ & $\$ 15,261$ & $\$ 32,848$ & $\$ 34,142$ & $\$ 25,353$ \\
\hline Electricity & $\$ 73,389$ & 0.00 & $\$ 47,343$ & $\$ 26,923$ & $\$ 8,386$ & $\$ 42,465$ \\
\hline Total Expenses & $\$ 86,645$ & $\$ 19,708$ & $\$ 62,605$ & $\$ 59,772$ & $\$ 42,529$ & $\$ 67,818$ \\
\hline Electricity Payments & & & & & & $\$ 9,811$ \\
\hline ICAP payment & & & & & & $\$ 7,200$ \\
\hline Annual Profit & & $\$ 66,937$ & $\$ 24,039$ & $\$ 26,873$ & $\$ 44,116$ & $\$ 35,838$ \\
\hline Capital Expenses & & $\$ 300,000$ & $\$ 300,000$ & $\$ 106,080$ & $\$ 177,500$ & $\$ 177,500$ \\
\hline O\&M Expenses & & $\$ 35,000$ & $\$ 35,000$ & $\$ 2,500$ & $\$ 2,500$ & $\$ 2,500$ \\
\hline $\begin{array}{ll}\begin{array}{l}\text { Payback } \\
\text { (years) }\end{array} & \text { Period } \\
\end{array}$ & & $\bar{N} / \mathrm{A}$ & $\bar{N} / \mathrm{A}$ & 4.35 & 4.27 & 5.32 \\
\hline $\begin{array}{l}\text { Internal Rate of } \\
\text { Return } \\
\text { For } 10 \text { years (\%) }\end{array}$ & & 1.2 & $\mathrm{~N} / \mathrm{A}$ & 18.9 & 19.5 & 13.5 \\
\hline
\end{tabular}

\footnotetext{
${ }^{3}$ Rebates for Fuel Cell cost are available from the DOD/DOE rebate program of $\$ 1000 / \mathrm{kw}$ and the New Jersey Clean Energy Program of $60 \%$ of cost and installation net of other subsidy programs. Net revenue does not include cost sharing associated with Budget Period 2.
} 


\section{HARVEY CEDARS BIBLE CONFERENCE}

\section{Description of Existing Facility}

Harvey Cedars Bible Conference is a complex of several buildings including a Conference center building, a building with a dining hall, a gym and a Bay View lodge, a chapel, a motel, an indoor pool and a maintenance building (Figure 19). Each building is equipped with a separate central heating system and a domestic hot water system. The thermal energy generating equipment for both systems is in boiler rooms in each building.

The annual electric load profile for the entire complex suggests that one $60 \mathrm{~kW}$ turbine can cover the entire electrical load for the entire year except July and August and daily peak periods in June and September. Two $60 \mathrm{~kW}$ turbine generators can cover the electric load for the entire year except peak demand during some summer days.

Analysis of the facility thermal load show that one turbine can cover thermal input for the domestic hot water for the cluster of five buildings - conference center, dining hall, Bay View lodge, gym, and maintenance building (total annual average NG input of 207,572 Btu/hr) and a part of the thermal input of the Conference Center' central heating system.

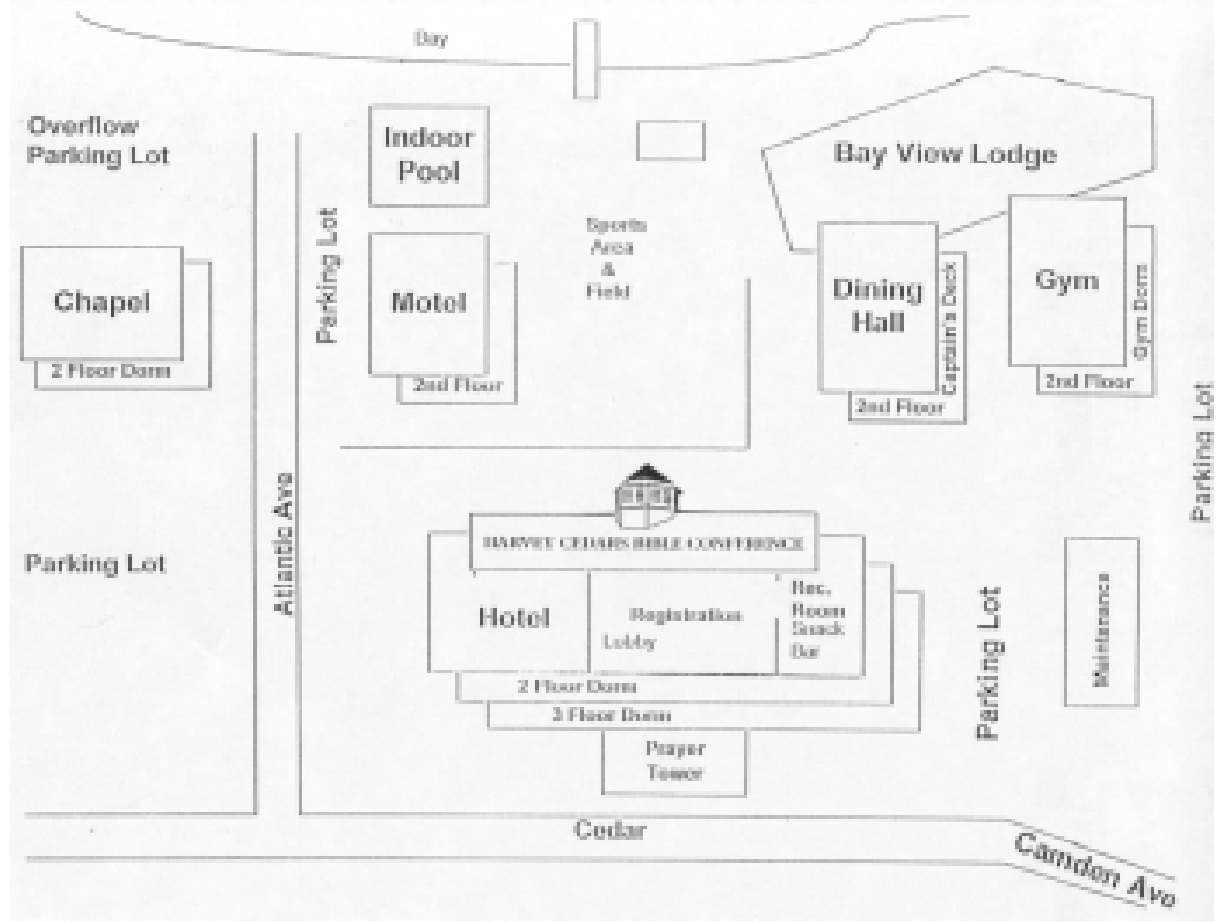

Figure 19. Harvey Bible Conference Layout 
These buildings are closely located, and installation of the turbines in the outside enclosure near the Conference Center will avoid extended underground or aboveground pipelines construction thereby reducing installation costs for the piping system.

\section{Proposed Design Modification}

Two options are proposed for modification of the existing electric and thermal energy supply system. One option includes installation of one $60 \mathrm{~kW}$ microturbine generator to co-generate electric and thermal energy for covering up to $60 \mathrm{~kW}$ of the facility electricity demand and part of the thermal energy demand. Additional electricity demand is purchased from the grid. A second option proposes to cover the existing facility electric demand by two $60 \mathrm{~kW}$ microturbine generators with co-generation of thermal energy used for hot water and heating systems. In both cases turbine(s) are installed near the Conference Center and first supply thermal energy for domestic hot water in five buildings with the rest of thermal output to serve as a supplemental input to the Conference Center central heating system. In the non-heating season, unused thermal energy is dissipated to the atmosphere.

Gas-fired microturbines can work in the load follow mode with the heat output proportional to the electric load according to the graph in Figure 18.

\section{Evaluated Scenarios}

Five scenarios were developed for evaluation of the Harvey Cedars Bible Conference.

\section{BASE CASE SCENARIO}

Same as for St Francis Community Center.

\section{SCENARIO 1}

One $60 \mathrm{~kW}$ microturbine generator is installed and operated in the electric demand follow mode year around.

\section{SCENARIO 2}

Two $60 \mathrm{~kW}$ turbines are installed with one turbine is operating year around and the second turbine operating when facility demand exceeds $60 \mathrm{~kW}$.

\section{SCENARIO 3}

Two $60 \mathrm{~kW}$ turbines are installed and operated in a mode similar to Scenario 2. It is assumed that the facility is participating in the PJM Alternative Load Management (ALM) and the Load Response Program (LRP) during three summer months, and receives capacity and energy payments according to the PJM clearing price for the Atlantic Electric zone.

\section{SCENARIO 4}

This scenario is similar the scenario 2, except the fact that the turbine assigned for the peak load covering has a capacity of $30 \mathrm{~kW}$ instead of $60 \mathrm{~kW}$. 


\section{SCENARIO 5}

This scenario is similar to the scenario 3 with combination of one $60 \mathrm{~kW}$ turbine and one $30 \mathrm{~kW}$ turbine.

\section{Results}

Number of years for payback and internal rate of return shown on Table 2 are based on full cost of capital and installation net of subsidies ${ }^{4}$

Table 2. Financial Analysis Results - Harvey Cedars Bible Conference

\begin{tabular}{|c|c|c|c|c|c|c|}
\hline \multirow[t]{2}{*}{$\begin{array}{l}\text { Annual Expenses } \\
\text { and Profits }\end{array}$} & \multirow{2}{*}{$\begin{array}{l}\text { Base- } \\
\text { case } \\
\text { Scenario }\end{array}$} & $1 \times 60 \mathrm{~kW}$ & $2 \times 60 \mathrm{~kW}$ & $2 \times 60 \mathrm{~kW}$ & $\begin{array}{l}60 \mathrm{~kW}+ \\
30 \mathrm{~kW}\end{array}$ & $\begin{array}{l}60 \mathrm{~kW}+ \\
30 \mathrm{~kW}\end{array}$ \\
\hline & & $\begin{array}{l}\text { Scenario } \\
1\end{array}$ & $\begin{array}{l}\text { Scenario } \\
2\end{array}$ & $\begin{array}{l}\text { Scenario } \\
3\end{array}$ & Scenario 4 & Scenario 5 \\
\hline Natural gas & $\$ 20,027$ & $\$ 30,796$ & $\$ 34,670$ & $\$ 22,991$ & $\$ 35,978$ & $\$ 23,039$ \\
\hline Electricity & $\$ 42,435$ & $\$ 6,380$ & $\$ 725$ & $\$ 24,628$ & $\$ 3,447$ & $\$ 31,765$ \\
\hline Total Expenses & $\$ 62,463$ & $\$ 37,177$ & $\$ 35,396$ & $\$ 47,619$ & $\$ 39,426$ & $\$ 54,605$ \\
\hline $\begin{array}{l}\text { Electricity } \\
\text { Payments }\end{array}$ & & & & $\$ 16,394$ & & $\$ 12,529$ \\
\hline Annual Profit & & $\$ 25,286$ & $\$ 27,067$ & $\$ 31,238$ & $\$ 23,037$ & $\$ 20,188$ \\
\hline Capital Expenses & & $\$ 106,080$ & $\$ 177,500$ & $\$ 177,500$ & $\$ 144,304$ & $\$ 144,304$ \\
\hline O\&M Expenses & & $\$ 2,500$ & $\$ 2,500$ & $\$ 2,500$ & $\$ 2,500$ & $\$ 2,500$ \\
\hline $\begin{array}{l}\begin{array}{l}\text { Payback period } \\
\text { (years) }\end{array} \\
\end{array}$ & & 4.66 & 8.23 & 7.18 & 8.03 & 9.16 \\
\hline $\begin{array}{l}\text { Internal Rate of } \\
\text { Return for } 10 \text { years } \\
\text { (\%) }\end{array}$ & & 17.0 & 6.4 & 9.9 & 7.0 & 3.9 \\
\hline
\end{tabular}

\section{LONG BEACH ISLAND GRADE SCHOOL}

\section{Existing Facility Description.}

Long Beach Island Grade School (LBI GS) consists of one building. This building is equipped with a central heating system and domestic hot water system. Thermal energy generating equipment for both systems is suited in the boiler room.

Annual electric load profile of the school (see Fig 14) shows that one $60 \mathrm{~kW}$ turbine can cover the school electrical load along the entire year except for the daily peak periods in December, January and February.

Analysis of the facility thermal load shows that the turbine can supply thermal input for the domestic hot water and part of the thermal input for the central heating water supply. Installation of the turbine outside of the building near the boiler room will permit to avoid extended underground or aboveground pipelines construction and reduce installation costs for piping system.

\footnotetext{
${ }^{4}$ Net revenue does not include cost sharing associated with Budget Period 2.
} 
To develop a NG consumption profile, assumptions similar to the St, Francis Center and the Harvey Cedars Bible Conference were used, i.e. NG consumption necessary for preparation of domestic hot water was determined during off heating season, and assumed to be constant for the entire year. NG consumption for the central heating system in LBI GS was determined as a difference between the total NG consumption and thermal input to the domestic hot water system..

\section{Proposed Design Modification}

Three scenarios for modification of the existing electric and thermal energy supply system are evaluated. All scenarios include installation of one $60 \mathrm{~kW}$ micro turbine generator to cogenerate electric and thermal energy. Thermal energy demand for domestic hot water is satisfied first with the remaining thermal output to be used to supplement the central heating system demand, if necessary modifications are made to the existing steam-based system.

\section{Evaluated Scenarios}

Three scenarios were developed for evaluation of the LBI Grade School.

\section{BASE CASE SCENARIO}

Same as above

\section{SCENARIO 1}

One $60 \mathrm{~kW}$ micro turbine generator is installed and operated in an electric demand follow mode year around. Thermal energy developed by the turbine is only used for domestic hot water. Thermal energy for the existing space heating system continues to be provided by the existing steam boilers.

\section{SCENARIO 2}

One $60 \mathrm{~kW}$ turbine is installed and modification of one or two existing steam boilers to operate as heat recovery generators. Thermal energy developed by the turbine is used for domestic hot water preparation and for the central heating system during the heating season.

\section{SCENARIO 3}

One $60 \mathrm{~kW}$ turbine is installed operating in the load-follow mode similar to Scenarios 1 and 2 . It is assumed that the entire amount of the thermal energy is available for use during the heating season.

\section{Results}

Number of years for payback and internal rate of return shown on Table 2 are based on full cost of capital and installation net of subsidies ${ }^{5}$

Table 3. Energy, Capital and O\&M Expenses for Long Beach Island Grade School

\footnotetext{
${ }^{5}$ Net revenue does not include cost sharing associated with Budget Period 2.
} 


\begin{tabular}{|c|c|c|c|c|}
\hline \multirow{2}{*}{$\begin{array}{l}\text { Annual Expenses } \\
\text { and Profits }\end{array}$} & \multirow{2}{*}{$\begin{array}{c}\text { Base- } \\
\text { case } \\
\text { Scenario }\end{array}$} & \multicolumn{3}{|c|}{ Micro Turbine Generator } \\
\hline & & $\begin{array}{c}\text { Scenario } \\
1\end{array}$ & $\begin{array}{c}\text { Scenario } \\
2\end{array}$ & $\begin{array}{c}\text { Scenario } \\
3\end{array}$ \\
\hline Natural gas & $\$ 48,837$ & $\$ 63,553$ & $\$ 44,202$ & $\$ 63,553$ \\
\hline Electricity & $\$ 37,350$ & $\$ 306$ & $\$ 306$ & $\$ 306$ \\
\hline Total Expenses & $\$ 86,187$ & $\$ 63,860$ & $\$ 44,509$ & $\$ 63,860$ \\
\hline Annual Profit & & $\$ 22,327$ & $\$ 41,678$ & $\$ 22,327$ \\
\hline Capital Expenses & & $\$ 106,080$ & $\$ 106,080$ & $\$ 200,000$ \\
\hline O\&M Expenses & & $\$ 2,500$ & $\$ 2,500$ & $\$ 2,500$ \\
\hline Payback period (Years) & & 5.35 & 2.71 & 5.10 \\
\hline $\begin{array}{l}\text { Internal Rate of Return } \\
\text { for } 10 \text { years }(\%)\end{array}$ & & 13.4 & 35.1 & 14.6 \\
\hline
\end{tabular}

\section{CONCLUSION}

The above analysis indicates that the microturbine when used for cogeneration has the potential to be a cost-effective generator for customer-sited generation on Long Beach Island. For all scenarios where the microturbine is used for both the St. Francis Community Center and the Long Beach Island Grade School, a double-digit internal rate of return may be realized. In the case of the Harvey Cedars Bible Conference, one $60 \mathrm{~kW}$ microturbine operated year around is the only scenario evaluated which produces a similar rate of return.

In contrast, the PC25 fuel cell did not show a comparable level of IRR for this application. The savings realized cannot overcome the relatively high cost of the $200 \mathrm{~kW}$ PC25 fuel cell (net of subsidies). Two factors contributed to this result: 1) electric demand (about $60 \mathrm{~kW}$ ) of the St. Francis Center during the heating season is insufficient to justify the capital cost of a $200 \mathrm{~kW}$ unit, and 2) the fuel cell does not produce any external heat below $100 \mathrm{~kW}$ due to the heat demand of the internal reformer thus negating the benefits of a CHP application. At this time, there is no known year around facility on Long Beach Island whose load is high enough to justify a PC25, the only fuel cell commercially available. As smaller fuel cell units become commercially available, the use of these very low polluting, quiet generators will be much more economically attractive.

\section{Recommendation:}

The results of this analysis clearly indicate the efficacy of deploying advanced distributed generation on Long Beach Island. Use of distributed generation will improve system reliability and reduce system cost in an environmentally acceptable manner. Based on these findings, it is strongly recommended that the project proceed to Budget Period 2 for installation and testing. 


\section{Appendix A: Circuit Model Details}

This appendix gives a summary of the modeling and analysis details for the evaluation of the power system supplying Long Beach Island, NJ. It is not practical to print all the data detail here. Rather, we describe the methods used to develop the models and evaluate the system.

The circuit model data came from the utility, Conectiv Power Delivery. The assessment model is designed to represent the entire distribution planning area, which includes the subtransmission and transmission system interconnecting the various substations. Conectiv generally performs its planning studies on the transmission system separately from the distribution system. Therefore, the base data for the circuit came from two data sets:

1. The transmission system data came from a model developed for the PSS/ETM computer program from Power Technologies (PTI).

2. A Conectiv computer program named TFEED that models the individual $12.47 \mathrm{kV}$ distribution feeders.

The transmission data models a great deal of the Eastern part of the U.S. power grid. Since we were interested only in a few buses surrounding the LBI area, the first task was to extract the circuit model for the buses of interest and make an equivalent to represent the system behind those buses.

The transmission model stops at the distribution substation buses in our area of interest. The TFEED data picks up from the substation and models the distribution feeders is detail, with approximately 10 - 30 node points represented on each feeder.

The circuit data were converted into a format compatible with Electrotek's Distco Suite ${ }^{\mathrm{TM}}$ software. This software is capable of simulating various engineering impacts of DG on a given power system as well as performing economic evaluations. One feature of the software is to create visual images of the circuit to help identify loading constraints. Neither the PSS/E data nor the TFEED data contained geographical coordinate data. The graphical data was obtained by scanning in circuit maps provided by the utility.

\section{ELECTRIC POWER SYSTEM SUPPLY TO LBI}

Figure A-1 shows a portion of a Conectiv transmission system map with the area of interest outlined. The area modeled begins with the $230 \mathrm{kV}$ bus at Sands Point and include the $69 \mathrm{kV}$ and $23 \mathrm{kV}$ systems down to the $69 \mathrm{kV}$ bus at Lewis. 


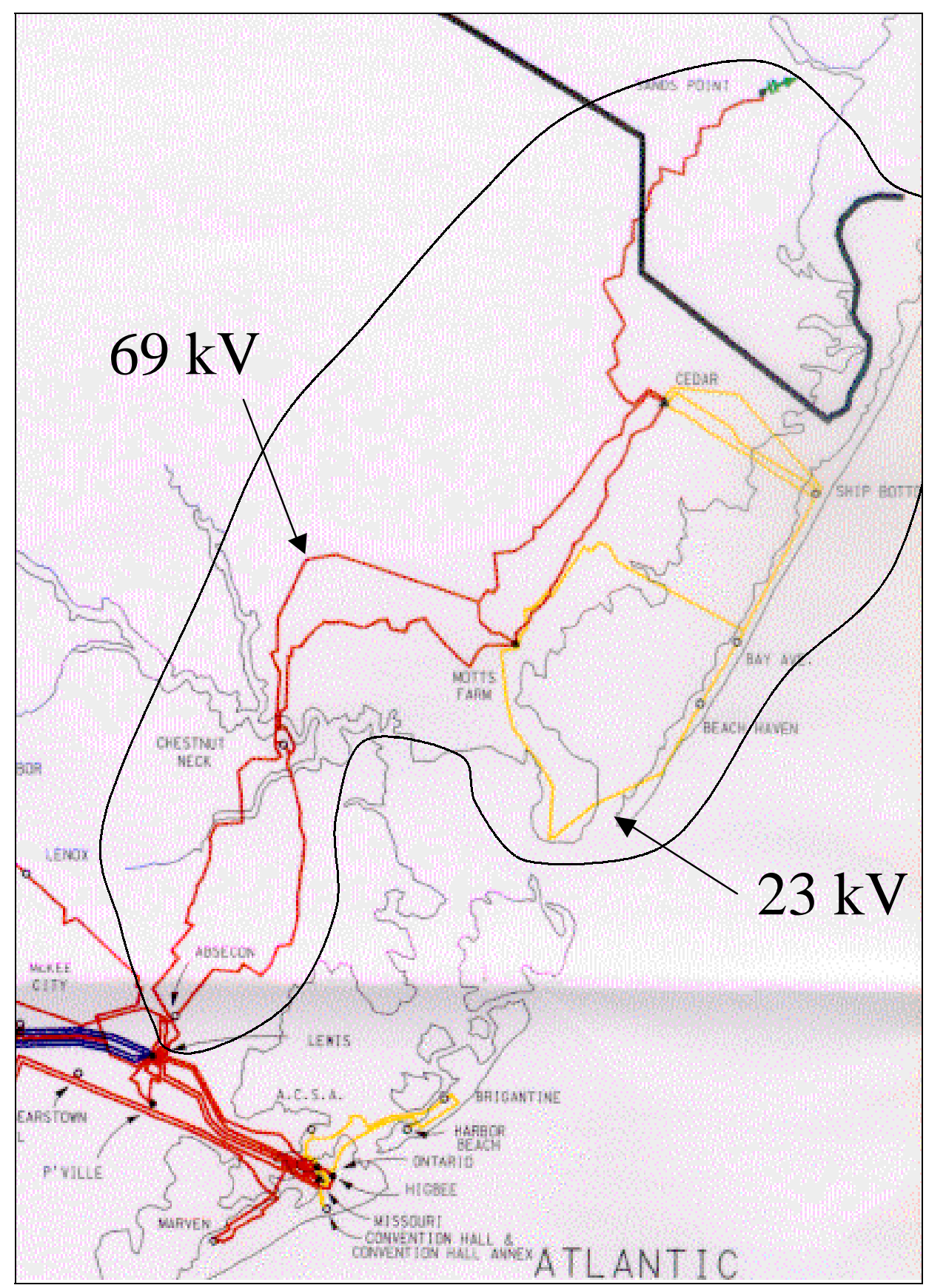

Figure A-1. Map of planning area showing transmission facilities modeled in the simulations.

\section{SYSTEM MAPS}

Figure A-2 through A-4 show the one-line schematics of the planning area as drawn by the Distco Suite software. Each map highlights a different portion of the system as indicated in the figure captions. 


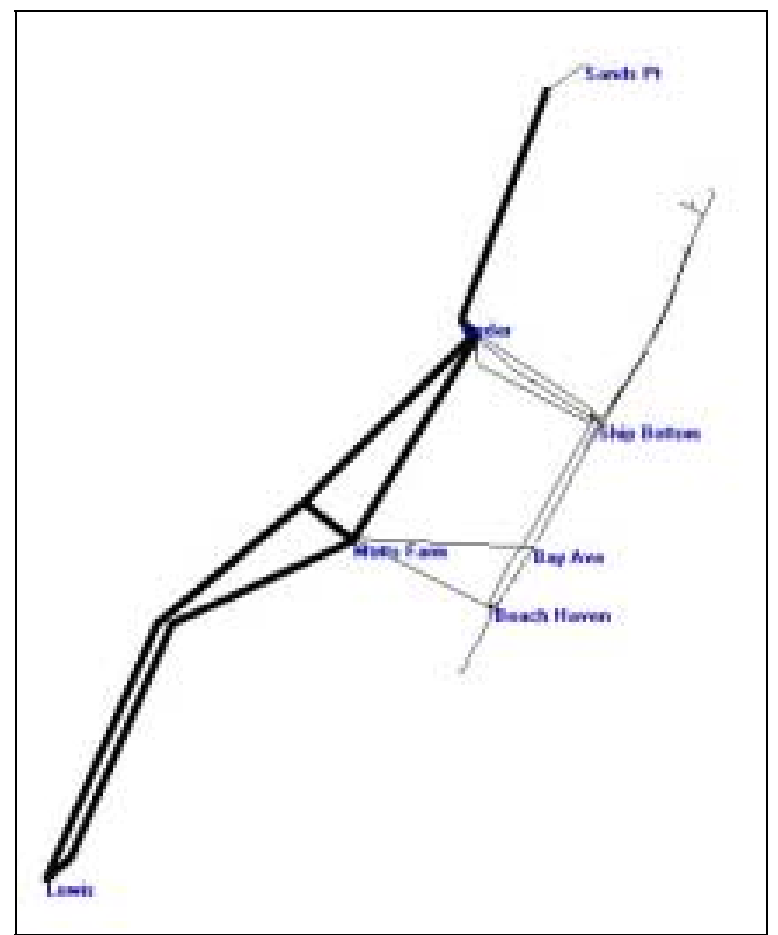

Figure A-2. LBI Planning Area With 69 kV Transmission System Highlighted.

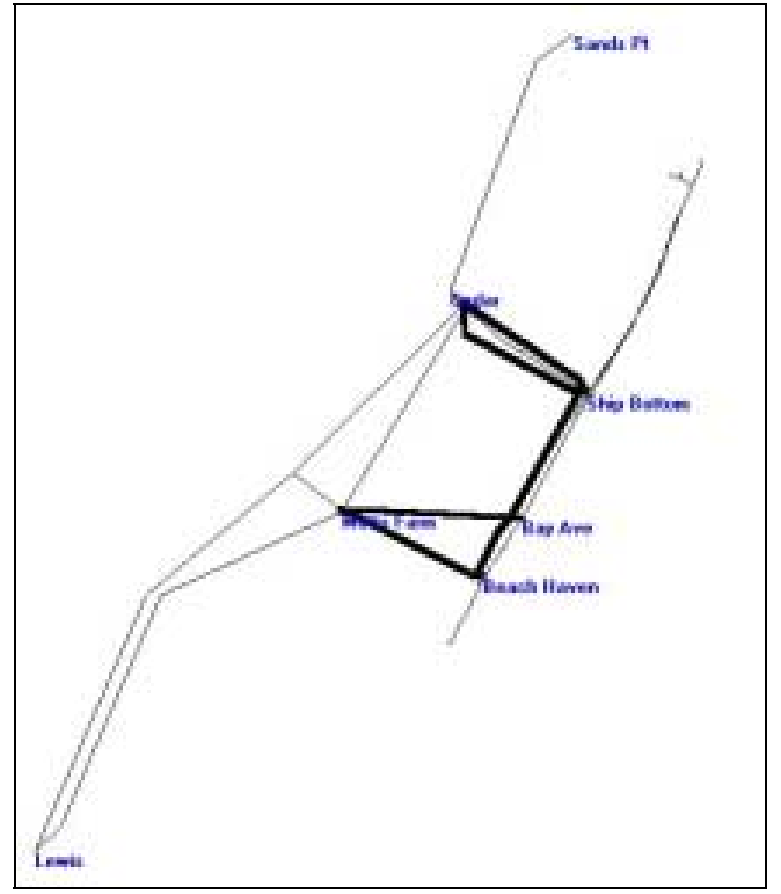

Figure A-3. LBI Planning Area With 23 kV Sub-transmission System Highlighted. 


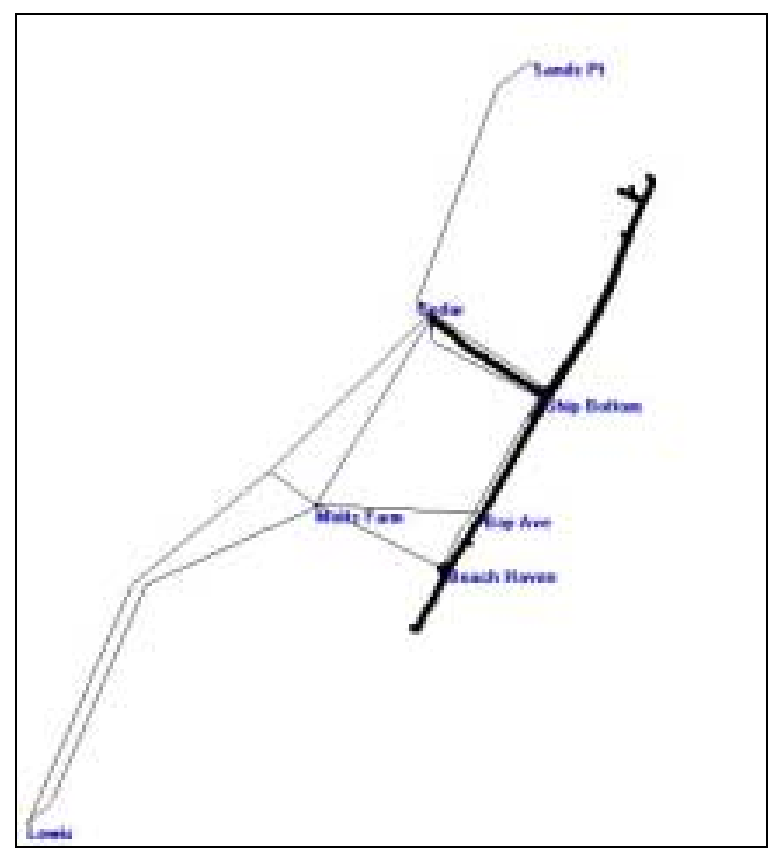

Figure A-4. LBI Planning Area With 12.47 Distribution System Highlighted.

\section{DISTRIBUTION FEEDERS}

Figures A-5 (a) - (d) show the locations and routs of the various $12.47 \mathrm{kV}$ feeders relative to the rest of the planning area. 


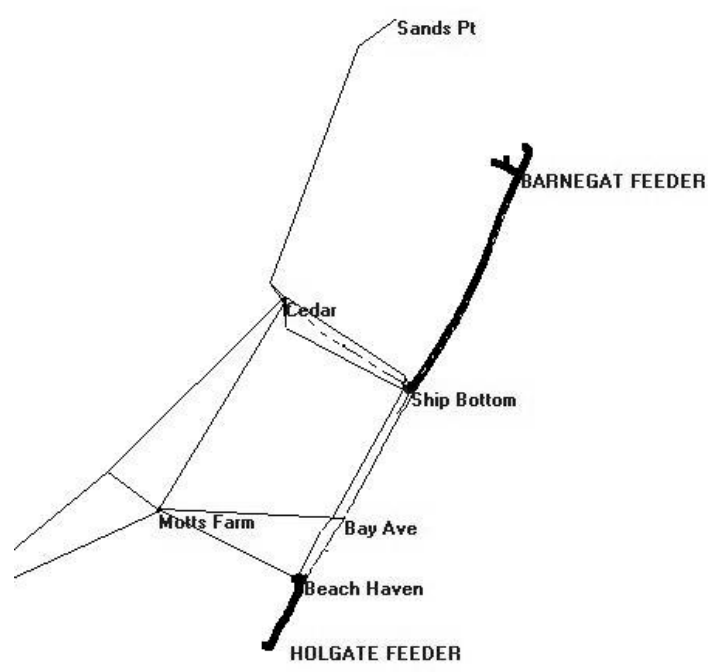

a) Barnegat and Holgate Feeders

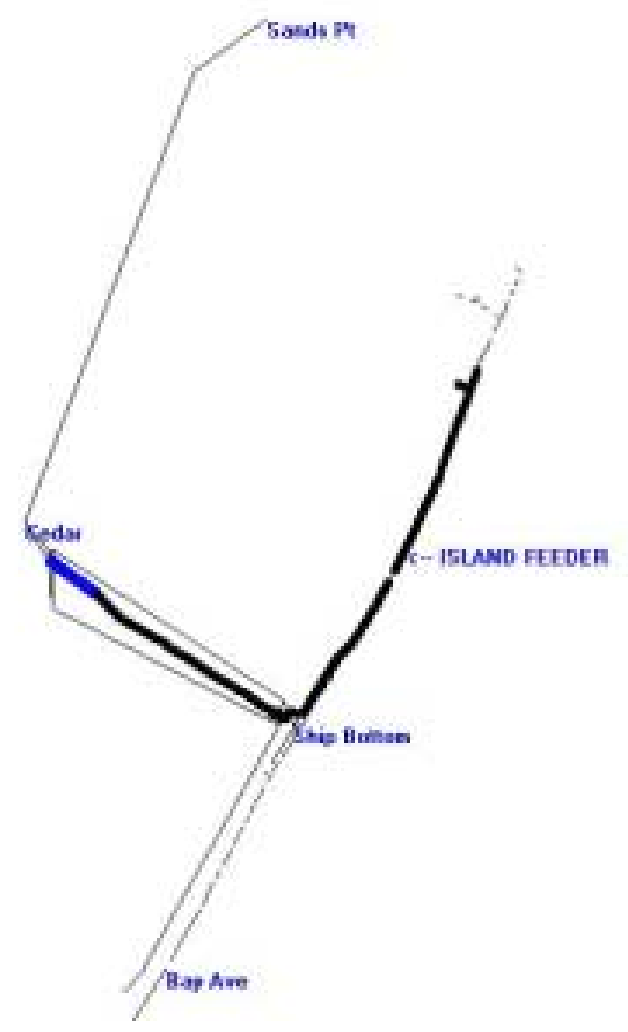

c) Island Feeder
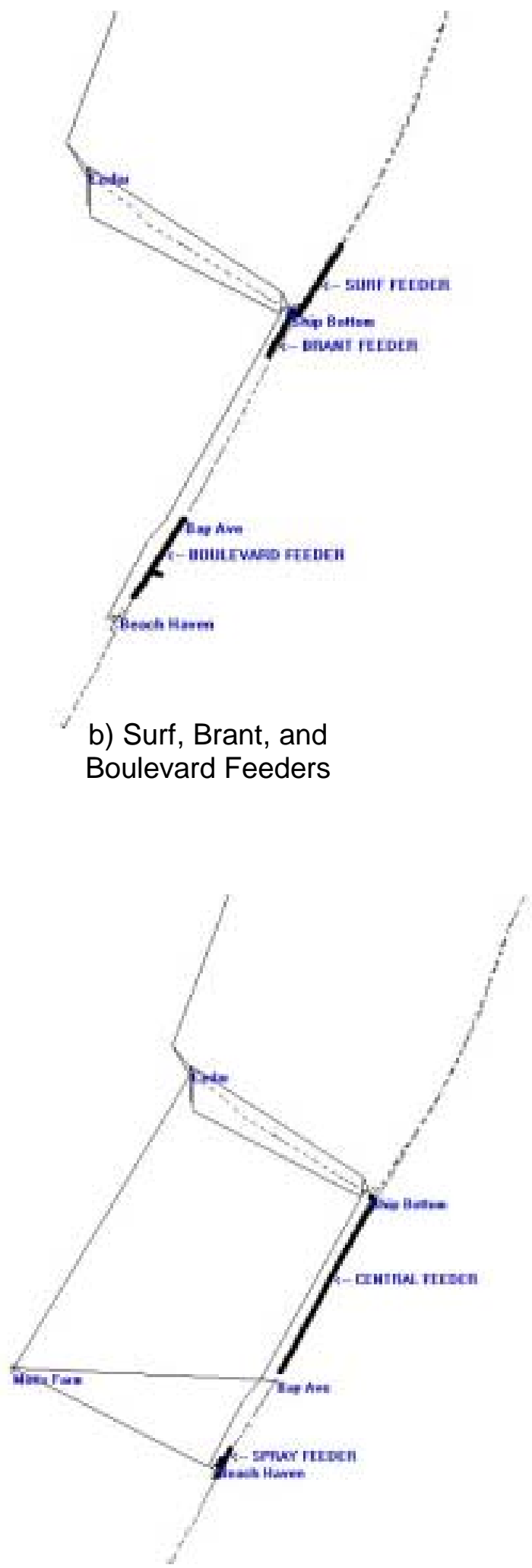

d) Central and Spray

Feeders

Figure A-5. Maps showing the Routes of the $12.47 \mathrm{kV}$ feeders. 


\section{ENGINEERING ANALYSIS PROCEDURES}

This is a description of the steps and procedures involved in the engineering analysis. Specifically we will address:

- Building the circuit model

- Modeling challenges that were encountered

- Determining the capacity of the system

- How to define ratings for use in determining the capacity

- Ratings used for LBI case

- Modeling load growth characteristics

- DG siting analysis

\section{Circuit Model}

The circuit model includes detailed models all the distribution feeders supplying the island as well as two distribution feeders on the mainland from the same Cedar substation bus supplying the Island feeder. Of course, the $23 \mathrm{kV}$ system and the portion of the $69 \mathrm{kV}$ system previously indicated are modeled. The model consists of 725 lines, transformers, capacitors, loads, and generators connected to 315 buses.

The PSS/E data included only the positive-sequence impedance data while zero-sequence data were also available from the TFEED model. The main issue is the capacity of the system and we were not particularly concerned with unbalanced load issues for this analysis. Therefore, the positive-sequence equivalent model suffices. The Distco Suite model is nominally a full three-phase model, but can accept a positive-sequence model. This cuts the number of nodes by a factor of 3 and, all things being equal would generally be expected speed the solution. This is important for performing annual simulations in a reasonable amount of time. However, since the solution method makes use of sparsity, the gain is not as much as one might expect. The LBI planning area at peak load is very stressed, which makes convergence difficult, particularly when attempting to model growing load. This tends to lengthen solution times and nullifies some of the time advantages of using positive-sequence equivalents.

\section{Modeling Challenges}

There were a number of difficulties encountered in building the circuit model and establishing to base case so that we could readily see the impact of DG on the system:

1. The transmission and distribution system data were for different computer programs, as is typical. Therefore, translation and merging of data was necessary. One issue was that the load models did not agree precisely. Slightly different planning criteria are used for distribution and transmission studies. The distribution model was assumed to take precedence over the transmission model. This resulted in a somewhat greater loading on the transmission system than the PSS/E data predicted. The model was built by first 
calibrating to the PSS/E transmission system solution and then replacing the loads lumped at the substation buses with the distributed feeder model.

2. As is typical, the transmission model contained thousands of buses and we were interested in approximately 30. However, one cannot simply extract these buses and expect to get the correct network flows. The rest of the system that is not explicitly modeled has a significant impact on the distribution of the power flowing through the lines. In this case, there was a 12 - 14 degree phase shift at peak load from the Sands Point end of the planning area to the Lewis end. This must be reasonable well modeled to obtain the proper flow to the Island. An equivalent impedance and loading was developed by trial-and-error to obtain this phase shift.

3. There are dozens of voltage and var control devices (tap changing transformers, 32step voltage regulators, and switched capacitors) in the system. One of the keys to the assessment methodology is to be able to model the system as it goes through its daily load cycle. Thus, it is very important to model the behaviors of regulators and capacitor controls. Modeling all of these controls simultaneously in a planning area can be a challenge and proved to be in this case. Again, by trial-and-error, we found model settings that would allow the simulation of daily load cycles without causing convergence failures. The modeling of these controls, particularly in a constrained area like the LBI planning area, taxes the computer algorithms and slows the solutions. However, good compromises were achieved. The general strategy was to expand the bandwidths on the controls and set the operating sequence so that not all controls attempt to change at once.

\section{Determining Capacity}

One of the keys to evaluating DG impacts on an electric power system is to evaluate the impact on "capacity." The capacity of a complex planning area consisting of numerous elements and constraints is often a nebulous and mercurial quantity. While planners often speak in terms of a single capacity, there are usually multiple capacities with different constraints being violated at different times. The following describes relevant issues for the LBI planning area.

When referring to the island by itself, there are often two capacity numbers discussed: approximately 65 MVA and approximately 80 MVA. When the lower number is used, capacity is based on the amount of load that can be served for the worst-case contingency. The present load can exceed 70 MVA. That is why the utility chose to lease $5 \mathrm{MW}$ of DG to cover the contingency. The larger number refers to the eventual maximum capacity of the present system to serve load without additional DG support. Modeling the conditions in question and increasing the load until either voltage or current-carrying limits are exceeded established these limits.

The basic approach of the Distco Suite software is to grow the load until a capacity constraint is encountered. This may be done either by a series of peak loading snapshot power flows or using peak day 24-hour simulations. When a capacity constraint is encountered, a judgment must be made about its relative importance. Will this constraint be solved by something relatively inexpensive such as adding a regulator or capacitor or reconductoring a small section of feeder? Or will it be necessary to make a major investment? This is often difficult to judge by just looking at the peak power flow. Most constraint violations appear about the same. 
A better picture is obtained by computing the energy exceeding certain limits set for the elements in the system. The daily load cycle is computed as the load is grown year by year (Figure A-6). The energy above the limit is accumulated, resulting in a curve like that shown in Figure A-7. This energy is generically termed "unserved energy" (UE), following the traditional term used in reliability analysis, because it is approximately the amount of energy that would have to be curtailed to keep the system out of constraint violations.

The example shown illustrates this for the LBI Planning area by assuming that we could continue to run peaking DG (7 MW) to support the system in its normal state. This analysis would suggest that from a purely technical viewpoint, this amount of DG could offer support for approximately 2 additional years. The UE increases slowly until years 5 or 6 , suggesting that operating constraints can probably be handled by relatively inexpensive options such as more regulators and capacitors. After this, the UE increases rapidly indicating something major must be done. This coincides with the projected time when the sub-transmission system limits will be exceeded. The DG can basically supply two year's growth. Whether this is economical, or not, depends on the cost of the DG and how much it costs to run compared to the cost of purchased power for the same time period.

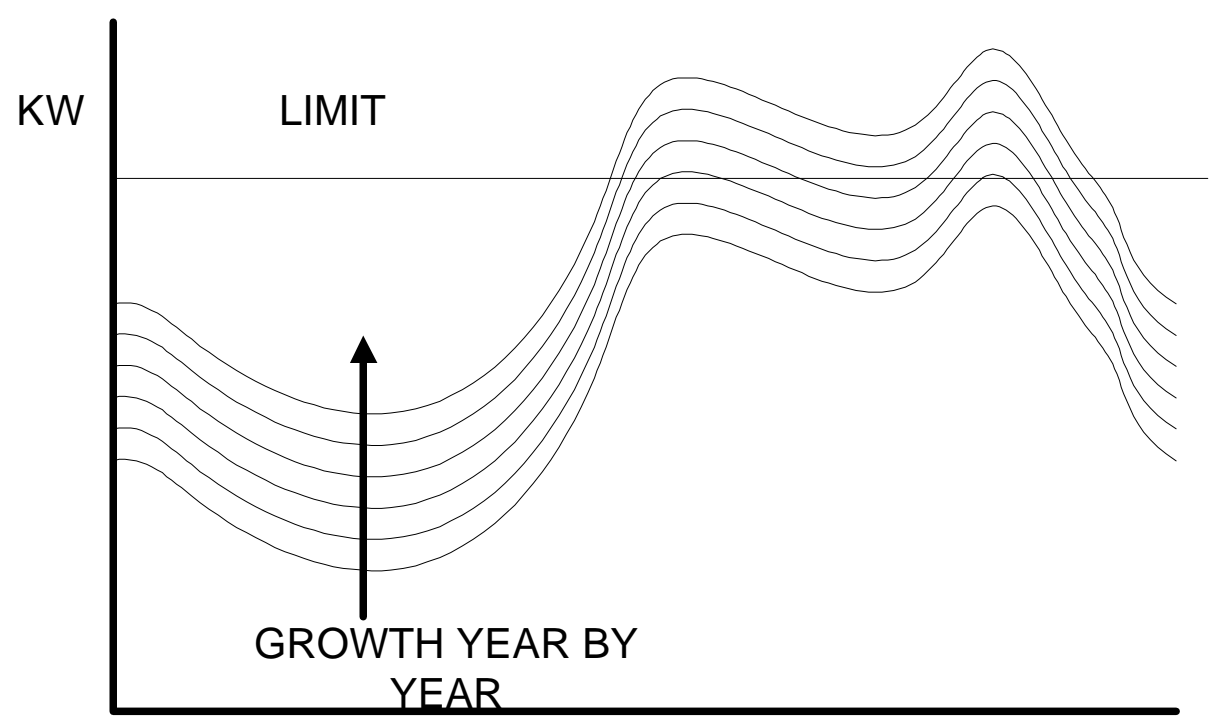

Figure A-6. The Energy (kWh) Served Above the Limit Is Computed As the Load Grows Year By Year. 


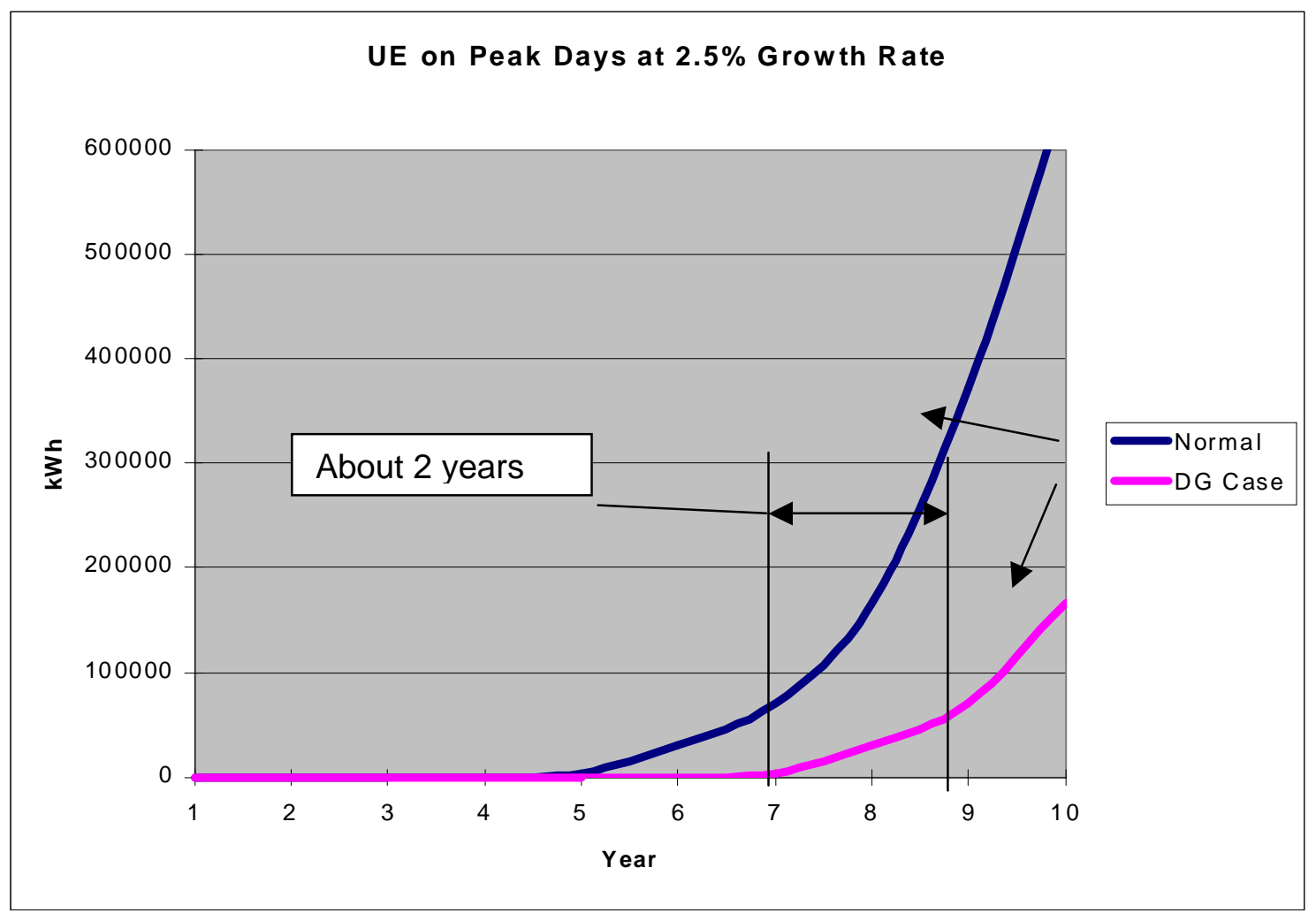

Figure A-7. Comparing Unserved Energy (UE) - Energy Above Maximum Limits - for Two Cases To Evaluate the Relative Impact of Peaking DG.

\section{Defining the Ratings}

One question that continually arises when evaluating constraints is which rating to use. There is not a single way to do this. The key is to use whatever technique is chosen consistently so that alternatives can be fairly compared.

We generally establish two ratings:

1. Emergency, or Maximum,

2. Normal

The Maximum rating is the current rating or voltage limit that absolutely cannot be exceeded. Of course, there is often some engineering margin in this rating, but not much. Some criteria for establishing this rating include national standards, continuous current rating, one-hour rating, and daily load cycle. It is assumed that power exceeding this rating will have to be curtailed for a certain period of time, resulting in unserved energy (UE).

The Normal rating is set at a lower value. It has been the practice among some utilities to use this value to trigger planning studies. Other utilities use only a maximum rating. There is still excess capacity left in the system, but plans must be made for upgrades. The setting of this value is subject to much engineering judgment and the history in a particular region. Current ratings are commonly set to $75 \%-80 \%$ of the maximum value. 
We prefer to use the Normal rating to compute to amount of energy that cannot be backed up with a single switching operation in case of a failure of a key failure. We refer to this energy as Energy Exceeding Normal (EEN). EEN is a measure of the amount of energy at risk of being unserved. The general idea is that when this energy is sufficiently large, the risk is no longer worth taking and it is time to make an investment in new facilities. Thus, EEN can be a very useful quantity for determining investment timing if properly defined. If there is only one backup switching option, the normal rating is frequently close to $50 \%$ of the Maximum rating. If there are multiple options, the rating is closer to $80 \%$.

EEN is also quite useful in DG evaluations on distribution feeders. DG becomes more valuable when the system becomes more heavily loaded. However, the loading may not exceed the Maximum rating and the UE value is zero. The EEN value is generally non-zero and provides a good measure of the relative impact of DG in a particular location on the overall capacity of the system. Thus, EEN is useful not only for investment timing but for differentiated between proposed sites for DG. This is one of the key quantities used in this study to determine the optimal locations for DG on the LBI system. (The other key quantity was losses.)

\section{Ratings for LBI Analysis}

Conectiv basically used only Maximum ratings and did not set a distinctively different Normal rating, particularly for distribution lines. The ratings we used came directly from the values in the PSS/E and TFEED data sets. Because we were basically looking at DG to cover contingencies in the $23 \mathrm{kV}$ system, the maximum ratings were the appropriate ones for most analyses.

The Normal rating was used primarily to help determine optimal sites for DG. A site that offered more relief relative to the ratings was judged to be better than sites offering less relief. The Normal rating for the lines was arbitrarily set to $80 \%$ of the Maximum ratings.

The Maximum ratings for the distribution substation were the lower of the transformer's rating or the amount of power that could be delivered by the lines. Both the Bay Avenue and Beach Haven substations were limited by line capacity. For example, while the Beach Haven transformer was rated at 18.6 MVA, Conectiv set the limit to 12 MVA because that is all the load that can be served when the $23 \mathrm{kV}$ line from Motts Farm to Beach Haven is out of service. Therefore, the excess energy into this transformer delivered when the demand measured at the primary exceeded 12 MVA was counted as unserved. It is this rating that largely dictates the need for the peaking DG at Beach Haven.

For voltages, the minimum allowable voltage was set to 0.95 per unit. When load on the distribution feeders was served at a voltage lower than this, an amount of load proportional to the degree of undervoltage was counted as being unserved. The Normal voltage rating was set to 0.975 per unit, which allows for some margin. This value was not used in this analysis; only current-carrying capacity was used for EEN computations.

\section{Load Growth Characteristics}

The Distco Suite software allows for each individual load to have its own growth characteristic. This capability is nominally provided to handle big block loads that have a significantly different growth characteristic than the rest of the feeder load. One example would be a new shopping center on an established feeder. 
This capability proved handy for this study. While we assumed that the growth was uniform geographically over the island, there were complications. In Figure A-5 it can be seen that the Barnegat and Island feeders both serve the North end of the island. In fact, one goes down one side of the main street and one down the other side. Load in the area may be served by either of them. However, very little load is to be added to the Island feeder. Its load growth is assumed to be zero. All new growth is to be served from the Barnegat feeder. Thus, the growth rate that must be assumed for the Barnegat feeder is double the general rate of the rest of the island where there is basically one feeder serving the area.

Figure A-8 shows the cumulative growth rate assumed for the study. This chart is the factor that would be multiplied by the base case load to achieve the actual load for a given year. This yields a nominal growth of 1.7 MVA per year.

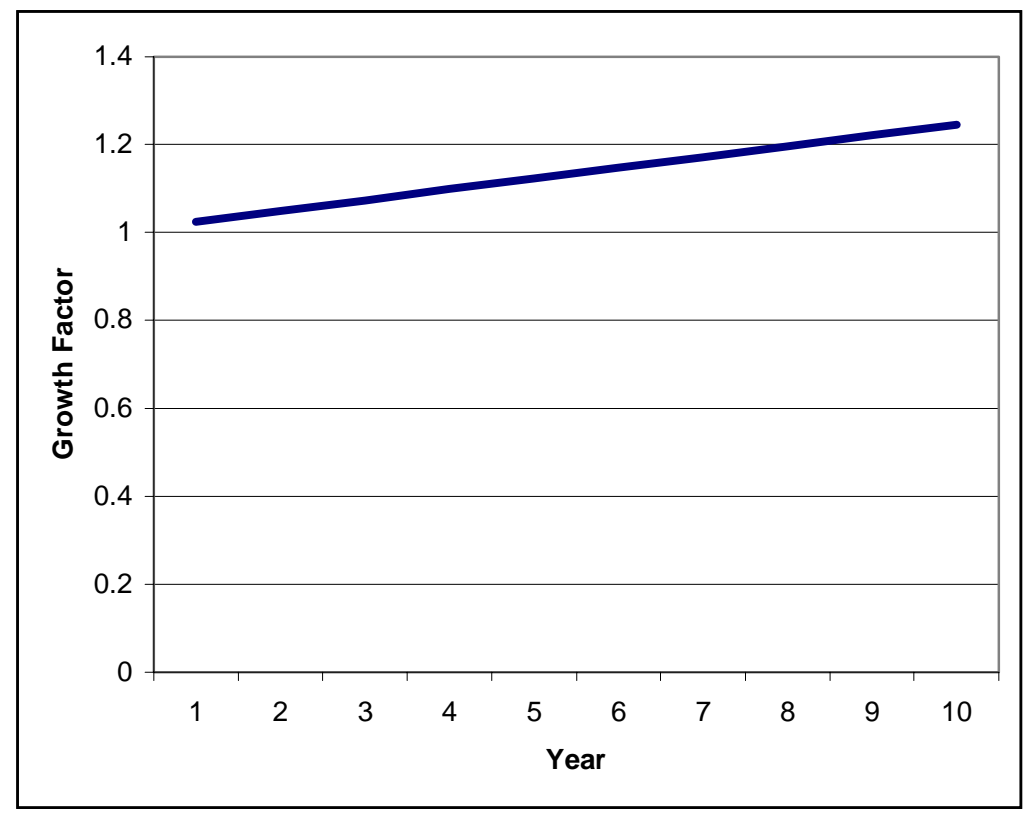

Figure A-8. Cumulative Average Growth Rate Assumed for LBI.

\section{Optimal DG Locations}

This section describes the general technique used to differentiate sites on the electric power system with respect to the engineering benefits to the system. This is the basis for the analyses that help establish possible plans for installing DG and for analyses that evaluate the relative merits of different locations.

A "cost function" is established using the following form :

$$
C=W_{L}{ }^{*} P_{L}+W_{U E}^{*} P_{U E}
$$

Where

$\mathrm{C}=$ "Cost" to be minimized

$W_{L}=$ Weighting factor for losses

$\mathrm{P}_{\mathrm{L}}=$ Power Losses in the area of interest 
$W_{U E}=$ Weighting factor for the power resulting in unserved energy

$\mathrm{P}_{\mathrm{UE}}=$ Power served above limits at this loading condition

This cost function is evaluation for each generator to be added for each location of interest on the feeders. The "optimal" location according to the chosen formulation of the cost function is the one that yields the lowest cost.

Charts like the one shown in Figure 13, which depicts the relative value of DG, were developed by plotting the magnitude of $\mathrm{C}$ for a specific generator size. This is also how the optimal locations for the two $2500 \mathrm{~kW}$ gensets to support the $69 \mathrm{kV}$ contingency were determined.

The weighting factors were varied over a wide range to observe the sensitivity of the optimization to different techniques. Because of the topology of the island feeders, there is not a lot of difference in the final result. Most combinations of this formula tend to favor locations at either end of the island. The key combinations of weighting factors investigated were:

\begin{tabular}{|c|c|l|}
\hline $\mathbf{W}_{\mathbf{L}}$ & $\mathbf{W}_{\mathrm{UE}}$ & \multicolumn{1}{|c|}{ Description } \\
\hline 1 & 0 & Losses only \\
\hline 1 & 1 & Equal weight to losses and capacity relief \\
\hline 1 & 10 & Capacity relief weighted 10 times more than loss reduction \\
\hline
\end{tabular}

$\mathrm{W}_{\mathrm{L}}$ should always be non-zero to always provide some differentiation between sites because the $P_{U E}$ can be zero in many cases. If $W_{L}$ is also zero, $C$ will be zero, which will not allow ranking the sites.

Simply optimizing on loss reduction alone can capture much of the essential behavior of this system. This tends to favor locations near the electrical center of the load, which should be good locations from a technical viewpoint. Adding capacity relief to the mix allows differentiation based on specific constraints. This was important in one analysis. For example, when optimizing the locations of the two $2500 \mathrm{~kW}$ gensets for the $69 \mathrm{kV}$ contingency support, both gensets were sited on the Barnegat feeder when optimizing by losses along. However, when capacity relief is also considered, there is also an optimal location on the Island feeder.

For computing $\mathrm{P}_{\mathrm{UE}}$, the Normal ratings were used. These ratings were nominally $80 \%$ of the Maximum ratings throughout the system. The main reason for using this rating is that it is exceeded more frequently, yielding a larger number. This provides more resolution to the evaluation of the impact of the proposed DG on the capacity of the system.

To evaluate locations for small generation such as distributed microturbines and fuel cells, the strategy is to site several smaller generators (small relative to the capacity of the power delivery system) and observe where they are clustered. This is illustrated in Figure A-9. We typically chose $100 \mathrm{~kW}$ as the test unit size and added these units one after the other at optimal locations defined by the cost function. As with most other similar analyses on this circuit, this yielded a clustering of generation toward the ends of the Holgate, Barnegat, and Island feeders. There was a scattering of generation at other locations depending on how one defined and weighted some constraints, but the main focus was the island extremities. The message of this 
analysis is that if there is to be any hope of achieving long-term capacity relief on the island, the greatest efforts should be concentrated of applying distributed resources at either end of the island.

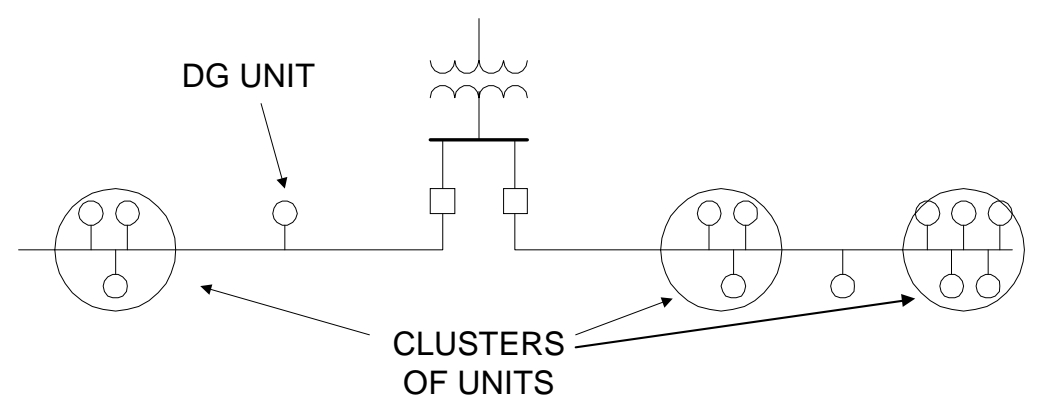

Figure A-9. Siting DG By Using Small Unit Sizes and Observing Cluster Locations

The impacts of the cost function weights on the results are, in general:

- Weighting for losses tends to site DG more toward the ends of feeders, generally to the point where the load is less than the DG size being considered.

- Weighting for UE will favor locations that yield maximum relief of capacity constraints in the power delivery system up to the point under consideration.

- UE weighting is also impacted by how circuit element ratings are defined. If the rating on one feeder or substation is set artificially low, more DG will be applied to that part of the circuit before it is sited elsewhere. Therefore, locations with the most risk of being unserved will receive the most attention.

\section{LOAD SHAPES}

Figure A-10 shows the peak daily load shapes for each month of the year. These were extracted from the 8760-hour yearly load shape and normalized to the annual peak. They clearly show the differences between the summer months and the rest of the year.

The daily curve in each of the summer months has approximately the same shape, but there is a substantial difference in magnitude. The two biggest peaks occurred in August and September in this particular year. On the peak days, the load reaches a high value by about 10 $\mathrm{AM}$ and stays near that value much of the day until a late afternoon peak occurs. It is this short peak that pushes the system over its limits.

For the non-summer months, the peak load seldom exceeds $40 \%$ of the annual peak, which illustrates one of the difficulties in serving this area. This is further emphasized by the monthly load-duration curves shown in Figure A-11 in which the quick drop off in load outside the summer months is apparent. Again, these values are normalized to the annual peak. This represent the number of days that the peak load is above a certain value.

The peak daily load shape for the year was used extensively in the analysis. The annual 3-D plots of losses and energy exceeding capacity limits were produced by combining the daily load 
shapes and the monthly load-duration curves (e.g., Figure 4). For each point on the loadduration curve, a daily simulation is performed. It requires approximately 1500 power flow solutions to simulate a year.

It is important to perform the daily simulation. This is considerably more work than the typical snapshot peak power flow, but is the only way to get a reasonable representation of the actions of the multitude of voltage and var control devices on the feeders. By following the daily load shape, the controls are more likely to be sequenced properly.

Unserved energy (UE) values can be determined for any analysis that simulates load over time and keeps track of the energy above limits. In this project, this was done for both peak day simulations and for annual simulations as described above. The values computed for the peak day only are generally denoted by the descriptor "peak day."

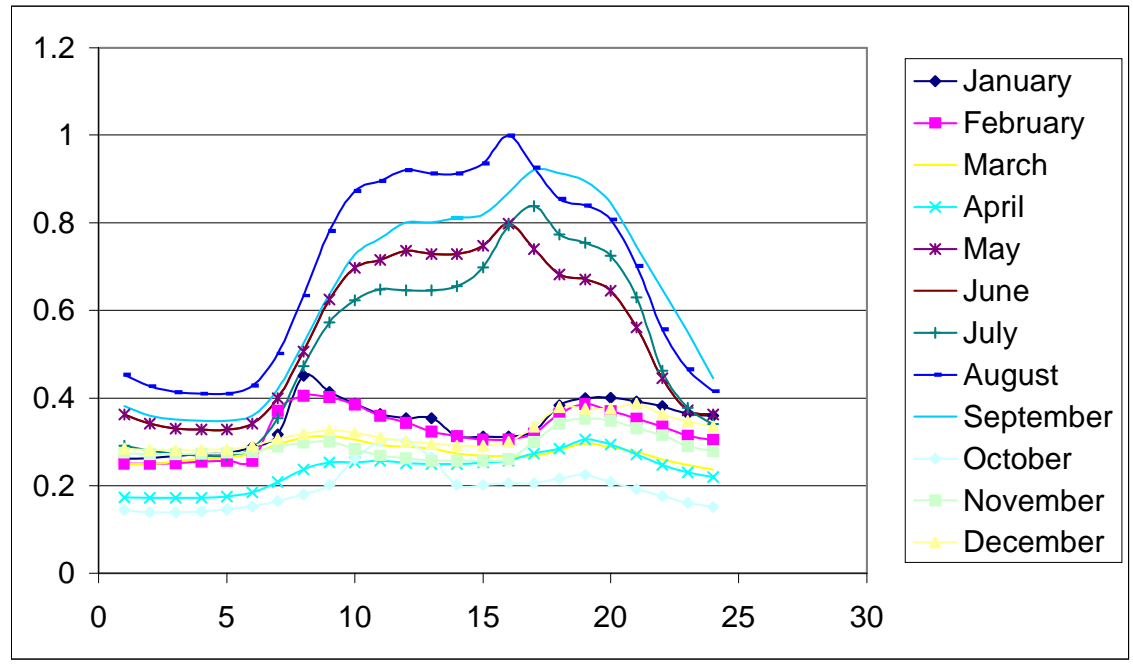

Figure A-10. 24-hour daily load shapes for the peak day of each month.

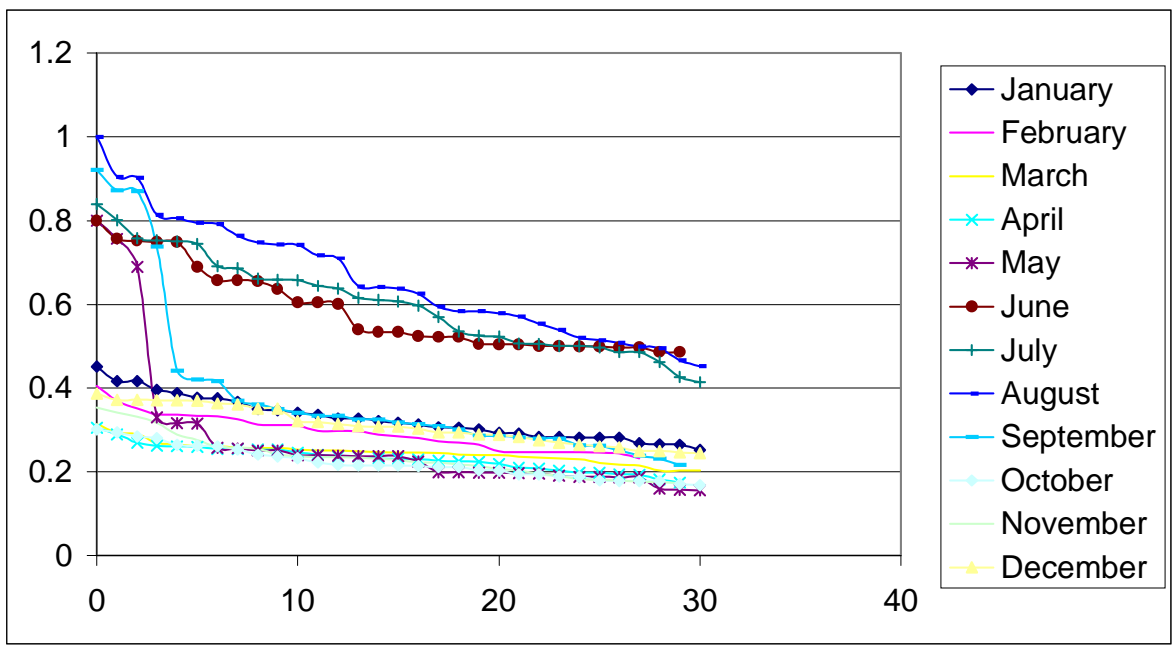

Figure A-11. Load-Duration Curve for Each Month - Peak Day Multiplier Normalized to Annual Peak vs. Number of Days this Peak Occurred 


\section{Appendix B. DG Siting Analysis Details}

\section{APPROACH}

The analysis of all three facilities is based on the following approach:

- Forecast the facility electrical load on daily basis.

- Select a generator (by type and size) to be able to cover the facility electric load according to options under evaluation.

- Determine amount of electricity from the grid.

- Determine generator's thermal output relevant to the generator electric load.

- Determine amount of thermal energy required for domestic hot water. If thermal output from on-site generators is not sufficient, calculate how much thermal energy is necessary to add to a domestic hot water system by using existing NG hot water heaters.

- In case amount of thermal energy available from the generators, is higher than is necessary for domestic hot water preparation, the excess is to be used to supplement thermal energy input into the existing facility heating system. Here the amount of NG for the existing heating system is determined with the account of thermal energy available from co-generation.

- Evaluate for each facility a scenario with electrical load curtailment during the three summer months. Load curtailment occurs every day for 6 hours. Price for curtailed electricity is the predicted market price for the peak time and relevant weather conditions minus the regular contract price for electricity.

- Total amounts of electricity and NG for each option is compared with base case scenario, to determine potential annual profit

- Annual profit from energy savings together with relevant capital expenses and O\&M costs determines project payback period and internal rate of return (IRR).

For all these scenarios the basic assumptions are as follows:

- Projected monthly electric demand based on correlation between monthly electricity demand and monthly heating degree-days/cooling degree-days (HDD/CDD).

- Daily electric demand is projected using the correlation between daily demand and HDD/CDD per day.

- Projections for the hourly facility electric load profile are similar to the years $2000 / 2001$.

- Hourly thermal energy requirement for domestic hot water is assumed to be constant along the entire year 
- Thermal energy daily demand for space heating is proportional to daily HDD over the heating period. .

- Thermal energy daily demand for roof-mounted heaters estimated as $10 \%$ of the central heating system thermal energy demand.

- Total annual electricity and fuel expenses for covering the facility electric and thermal energy demand consists of:

$>$ Total cost of the NG consumed by the fuel cell plant and existing equipment central heating system boiler, hot water heater, and roof-mounted space heaters,

$>$ Cost of electricity taken from the grid during periods when the facility demand is bigger than fuel cell plant maximum capacity,

$>$ Return for electricity developed during load curtailment, and

$>\mathrm{O} \& \mathrm{M}$ (non-fuel) for operation of the fuel cell and the entire energy supply system.

\section{FACILITY DESCRIPTIONS}

\section{St. Francis Community Center and Church}

\section{Burner data:}

Model \# GRU-G-25

Serial \# 109052114

Maximum NG input 6.3 Mbtu/hr

The central heating system also includes an accumulating tank and circulating pumps with average water flow of $85 \mathrm{gpm}$ and $190{ }^{\circ} \mathrm{F}$ in supply line.

The boiler and the auxiliary equipment are located in the boiler room, which also houses 100gallon domestic hot water heater (Mod\# BTC 250A, Ser\# LL95-0475698-920) with the heat input of $250,000 \mathrm{Btu} / \mathrm{hr}$ of NG.

Two roof-mounted space heaters are Lennox GCS16-651-125-BP model with max input of $125,000 \mathrm{Btu} / \mathrm{hr}$ of NG and max output of 100,000 Btu/hr

The third roof-mounted space heater is Lennox GCS24-1603-270-IY model with maximum NG input of $270,000 \mathrm{Btu} / \mathrm{hr}$ and heat output of $216,000 \mathrm{Btu} / \mathrm{hr}$.

The church is equipped with a separate central heating system and Weil McLain boiler with 3,025,000 Btu/hr NG input and 2,500,000 Btu/hr heat output. It also has a small domestic hot water heater.

The central heating system is in operation about 4 to 5 months, being started when the outside temperature drops below $65^{\circ} \mathrm{F}$. 
Information initially available from the St. Francis Community Center consists of monthly NG bills with total amount of gas used in the Center building. This NG is used in three systems: a) boiler for the central heating system, b) domestic hot water heater, and c) three roof-mounted space heaters. Separate profiles for daily gas consumptions used for central and local space heating and domestic hot water system based on the following:

- Roof-mounted space heaters will continue to operate during the heating season as they do now, independently of the central heating system.

- NG gas use for roof-mounted space heaters was calculated as being directly proportional to the facility space heated by these heaters versus total facility, which is about 10 to $12 \%$ of the total space. Thus, it was assumed that the central heating system consumes $90 \%$ of the NG used for space heating, and roof-mounted heaters use an additional $10 \%$ of NG.

\section{Harvey Cedars Bible Center}

Central heating system in the Conference Center is equipped with four NG Weil McLain boilers (Model \# PFG-6-PIN) with individual gross input of $247,000 \mathrm{Btu} / \mathrm{hr}$ and input to water of 215,000 $\mathrm{Btu} / \mathrm{hr}$.

The central heating system also includes an accumulating tank and circulating pumps.

The boiler and the auxiliary equipment are located in the boiler room, which also houses an 830 gal domestic hot water heater (A.O. Smith Corp, Mod\# BT 215A 830) with input of 251,000 $\mathrm{Btu} / \mathrm{hr}$ of NG. Other buildings are equipped with similar domestic hot water heaters or with water-jacketed boilers

The central heating system is in operation about 4 to 5 months, being started when the outside temperature goes below $65^{\circ} \mathrm{F}$.

Information on thermal energy demand available from the Harvey Cedars Bible Conference consists of monthly NG bills with total amount of gas used in each building. Separate profiles for daily gas consumptions used for space heating and domestic hot water systems were developed for each building. To develop these profiles, assumptions similar to St, Francis Center were used, i.e. NG consumption necessary for preparation of domestic hot water was determined during off heating season, and assumed to be constant for the entire year. NG consumption for the central heating system in the Conference Center was determined as a difference between the total NG consumption and thermal input to the domestic hot water system in this building.

\section{Long Beach Island Grade School}

The central heating system is equipped with five NG-fired steam boilers. Boilers are WeilMcLain; model EGH95 with input of 400,000 Btu/hr. Each boiler produces $320 \mathrm{lb} / \mathrm{hr}$ of steam at 15 psi. One additional identical boiler is for domestic hot water, which is supplied to an accumulating tank located in the boiler room. 


\section{FACILITY ELECTRIC AND THERMAL ENERGY DEMAND MODELING}

To evaluate performance of the fuel cell or microturbine power plant embedded into the existing power supply system, facility electric- and thermal demand profiles are predicted, as well as the cost of natural gas and market price of electricity.

Forecasting algorithms assume that both electrical and thermal energy demands correlate to weather conditions. Heating and cooling degree-days (HDD and CDD) are used as a characteristic for weather conditions. Historical data on HDD and CDD are used together with monthly billing and other information to develop algorithms for forecasting facility future electric and thermal demands. These demands are later modeled using 20 years average values of HDD and CDD.

Natural gas cost is a complicated function of several parameters, but mostly it depends on the total amount of NG used by a facility. To forecast it, an algorithm based on predicted demand of NG is developed for each facility.

Market electricity price for peak summer time is also assumed to correlate with CDD.

Development of forecast algorithms for all these parameters is described below.

\section{Facility Electric Demand}

For analysis of the future facility electricity demand, two parameters - average daily (24 hr) facility electric demand and peak daily demand are predicted.

Average daily $(24 \mathrm{hr})$ facility electric demand $(\mathrm{kWhr} / \mathrm{hr})$ is derived from two kinds of historical data: a) facility electric load profile (St Francis Community Center and Harvey Cedars Bible Conference), and b) monthly electricity bills (LBI Grade School). These data from years 2000 and 2001 are recalculated to $\mathrm{kWhr} / \mathrm{hr}$ and plotted against the HDD/CDD (cooling days were used as negative numbers) permitted to derive algorithms for prediction of average daily electrical demand as:

\section{$A D E L=f(D H D D / C D D)$}

\section{ADEL - AVERAGE DAILY ELECTRIC DEMAND KWHR/HR}

DHDD/CDD- daily heating (cooling) degree-days.

Historic average electric load for Harvey Cedars Bible Conference, presented in Figure B-1, shows two levels of load - summer months and the entire year, therefore two different algorithms were developed for these periods, as presented in Figures B-2 and B-3. 


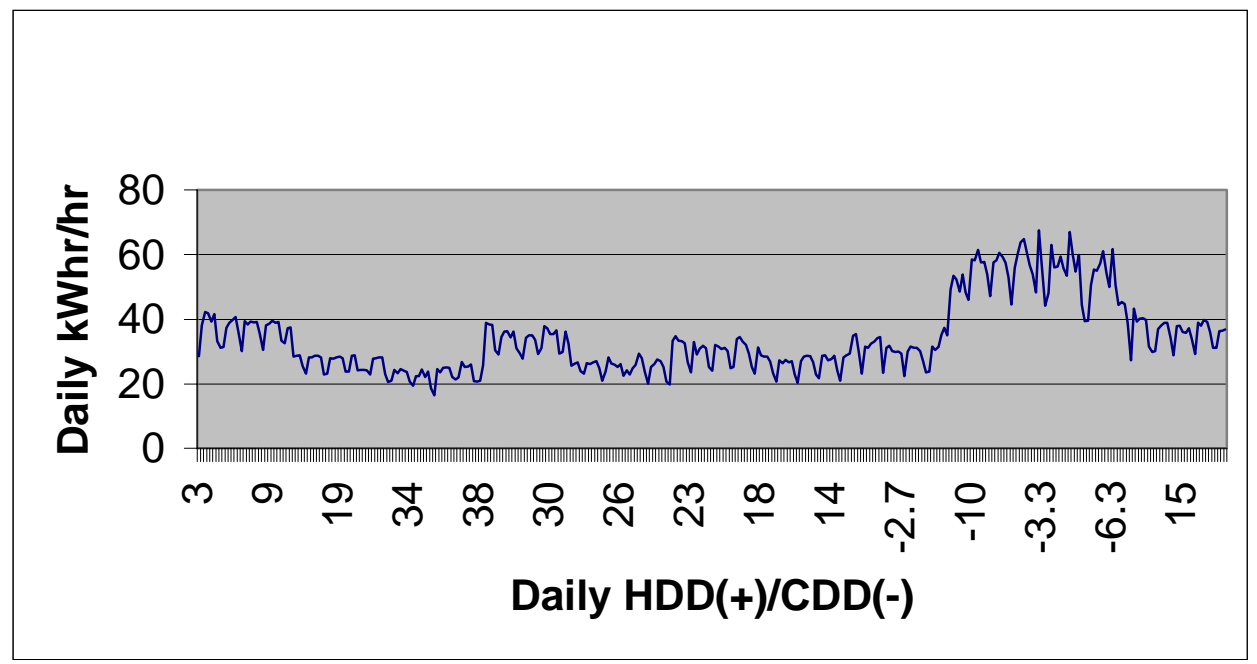

Figure B-1. Average Daily Load: Harvey Cedars Bible Conference

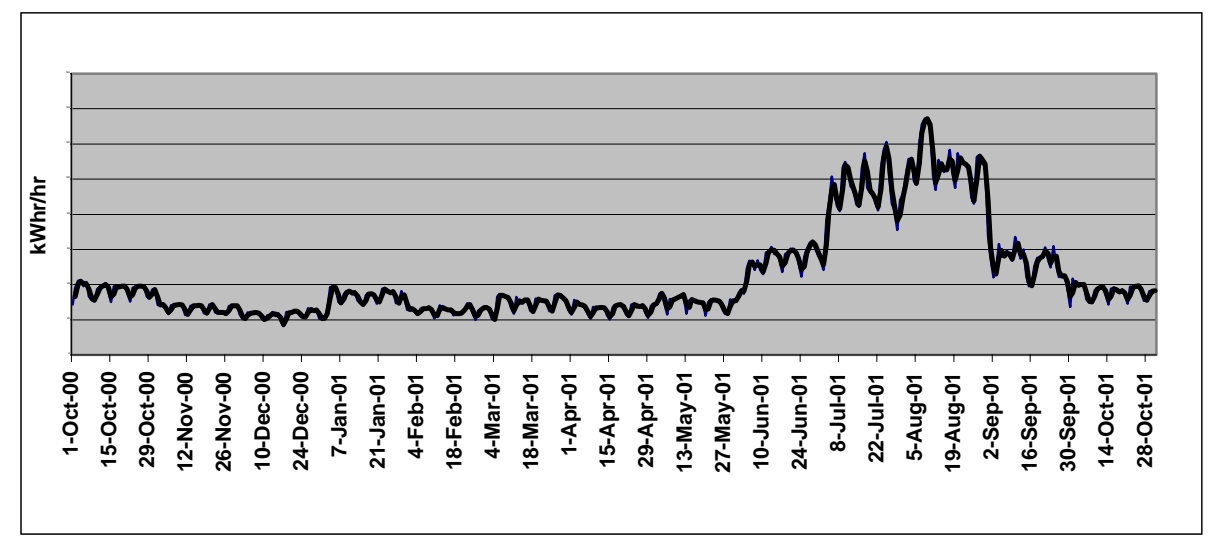

Figure B-2. Harvey Cedar Bible Center without July and August 


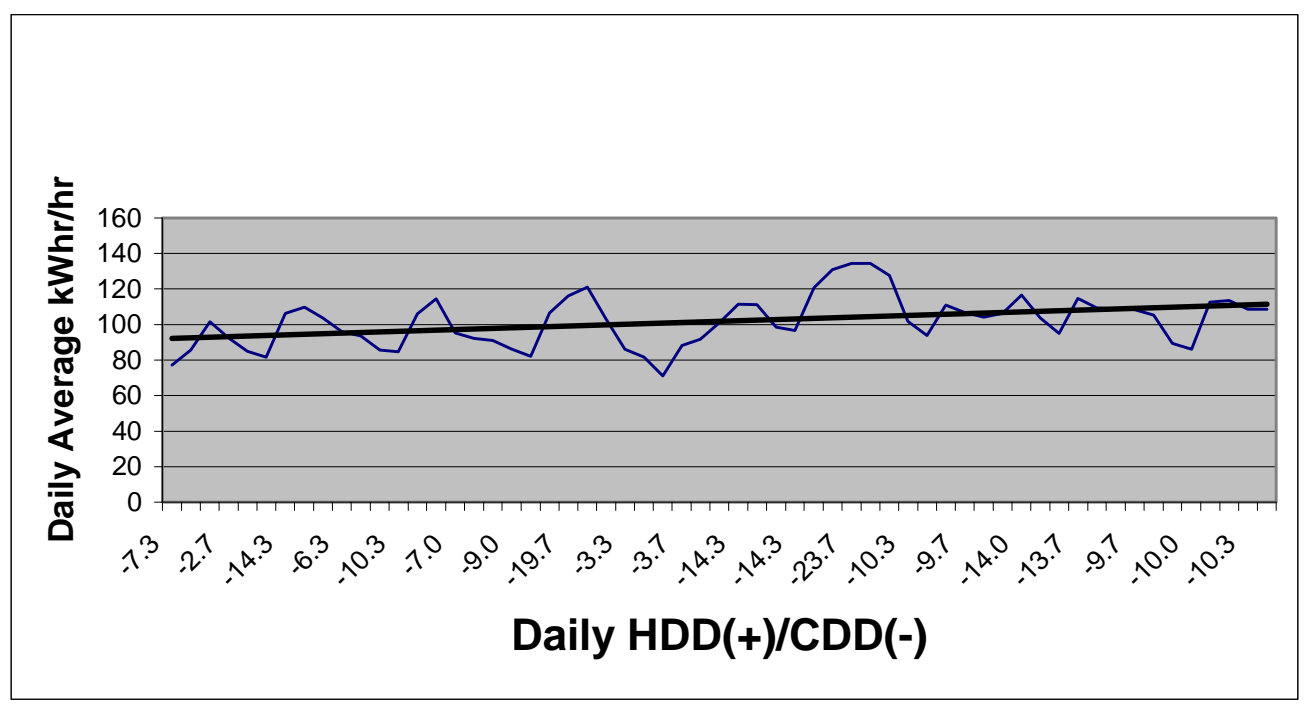

Figure B-3. Harvey Cedars Bible Center: Demand Projections for July and August

Historical average electric load for the St. Francis Community Center is shown in Figure B-4 containing three groups of data: summer period, winter period (December), and the entire year. Accordingly, three separate algorithms were developed to forecast the facility electric load. Electrical load for the LBI GS has a flat electricity load and a single algorithm is used for the entire year.

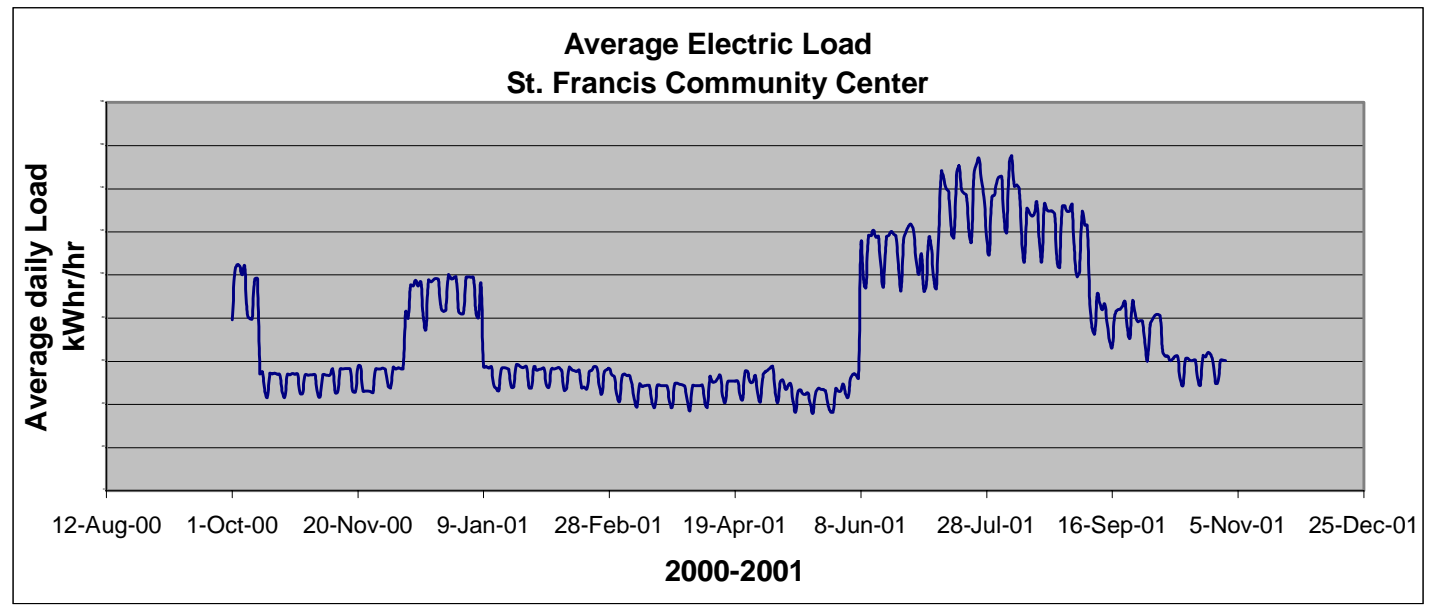

Figure B-4. Average Electric Load - St. Francis Community Center

Algorithms are used with twenty years average data on CDD and HDD to predict electric energy daily and annual consumptions for a hypothetical "average" year. An example of such a prediction for the Harvey Cedars Bible Conference is presented in Figure B-5. 


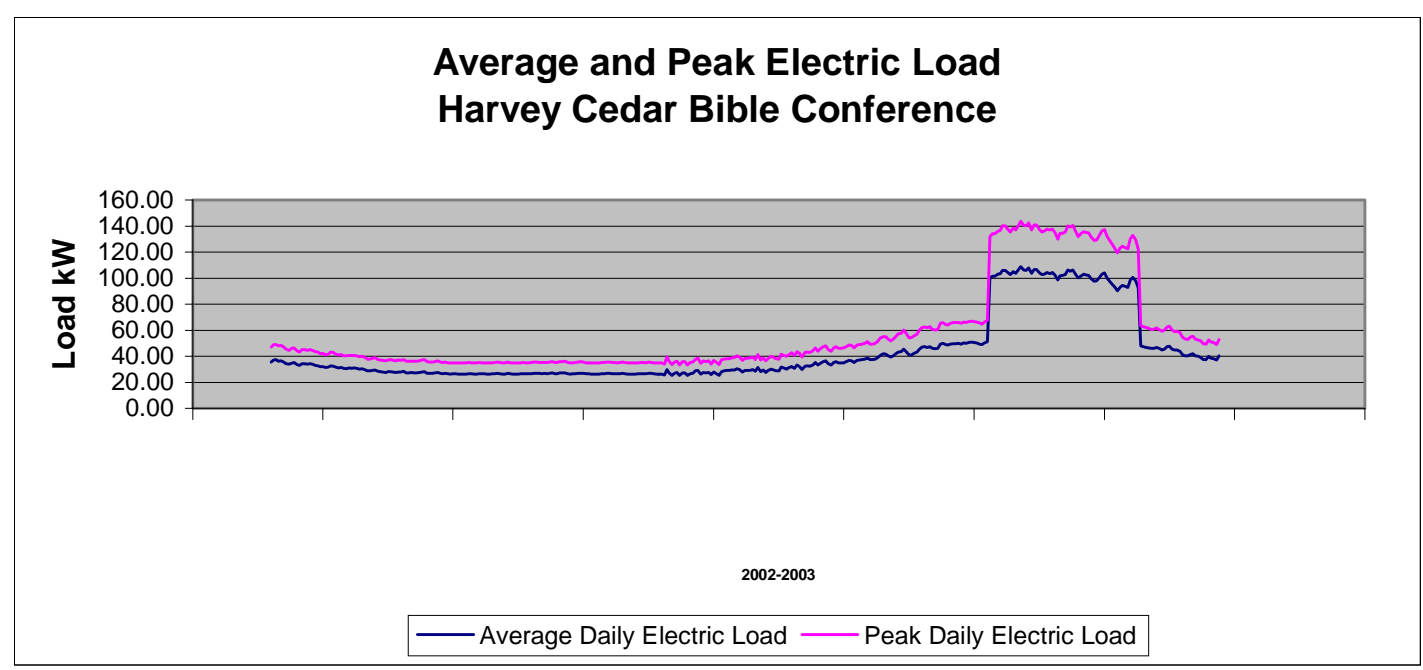

Figure B-5. Average and Peak Electric Load - Harvey Cedar Bible Conference

To be able to size the equipment, the average daily load and peak demand were determined. To calculate facility electric load during peak time, facility daily load profiles were obtained from the power supplier. A typical summer daily profile is shown in Figure 6. Assuming, that from 10:00 to 16:00 the peak load is constant, the ratio of peak load average for discussed 6 hours (PDEL) over the daily average (24 hr) load is calculated for all facilities. This ratio is usually higher for weekdays, than for weekends and is in the range:

\section{PDEL/ADEL = $1.18-1.30$}

ADEL is used to calculate electric energy daily and annual consumptions. To calculate facility electric load during peak time when usually the load curtailment occurs, facility daily load profiles obtained from the power supplier are used. A typical summer daily profile is shown in Figure B-8. Assuming that during curtailment period (from 10:00 to 16:00) the peak load is constant, the ratio of peak load average for 6 hours (PDEL) over the daily average (24 hr) load is calculated for all facilities. This ratio is usually higher for weekdays, than for weekends and is in the range:

PDEL/ADEL $=1.18-1.30$ 


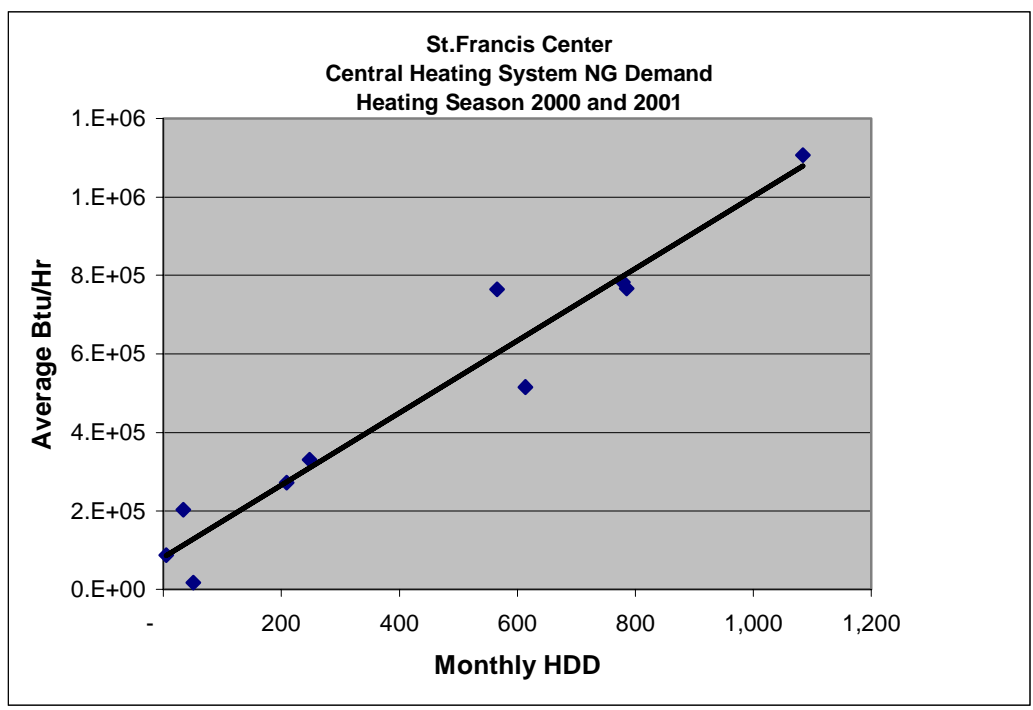

Figure B-6. LBI GS - Daily Electric Load Profile

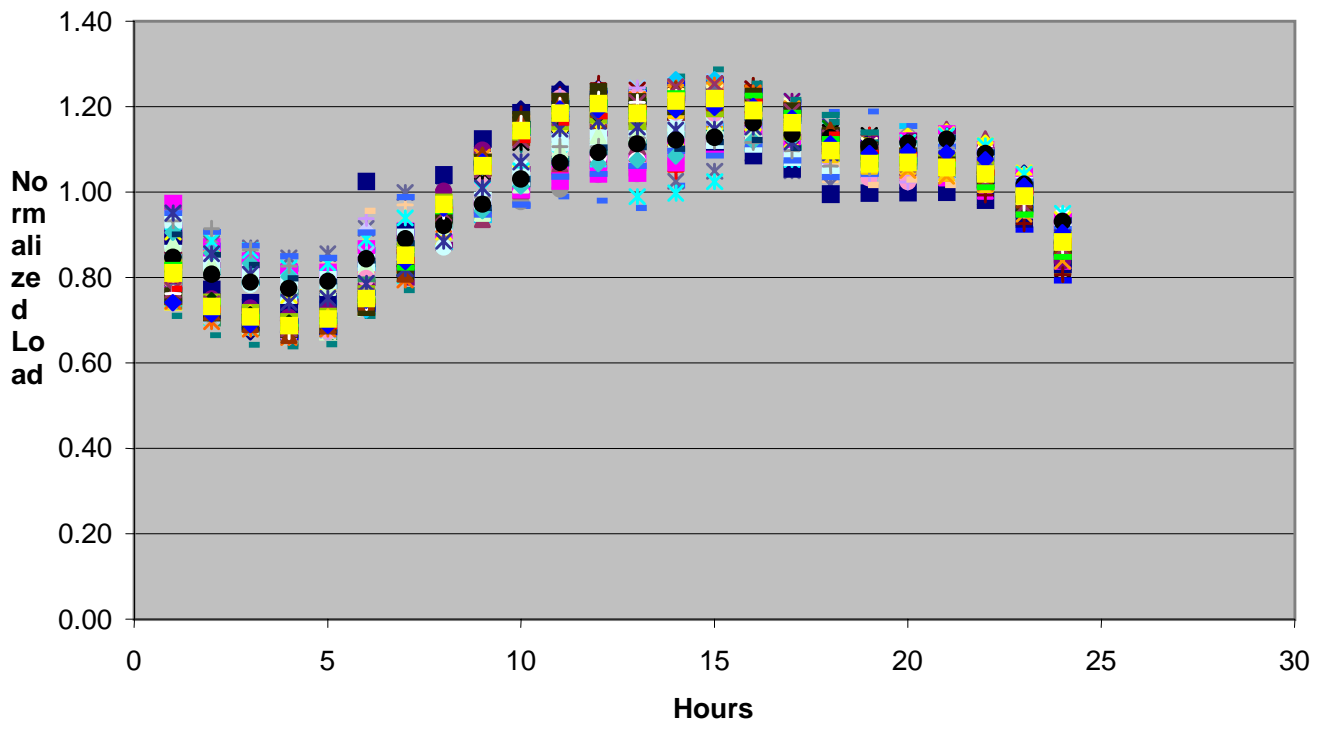

Figure B-7. St. Francis Center - Central Heating System NG Demand 


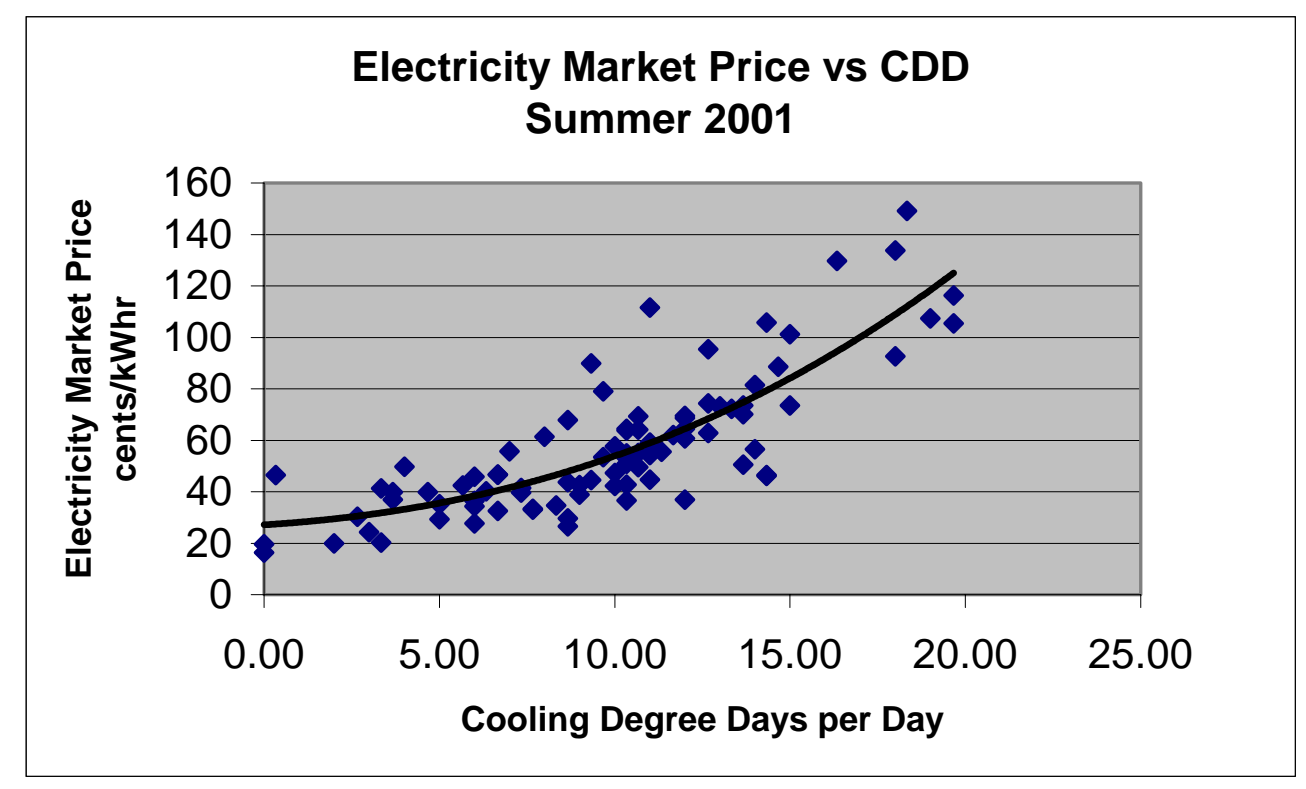

Figure B-8. Electricity Market Price vs. CDD - Summer 2001

\section{Facility Thermal Energy Demand}

Information available on thermal energy /natural gas demand, consists only of monthly NG bills. Algorithms were developed for separate forecasting of NG demand for heating system and domestic hot water system. Assumptions used are:

- Daily hot water demand is constant all year long.

- NG demand daily profile for central heating system is assumed to be constant during the day/night period. This assumption should be not far from reality because the Long Beach Island has a coastal climate with relatively small temperature difference between day and night.

- NG demand for the central heating system and for the local space heating (if present) is proportional to HDD.

Development of algorithms for thermal energy demand forecast, involves the following steps:

1. NG monthly consumptions are converted to Btu/hr (monthly average) using days of operation from NG bills.

2. Months off heating season are selected and the entire consumption of NG for these months is assumed to be used only for domestic hot water. Average annual NG Btu/hr for domestic hot water preparation is calculated.

3. Total amount of NG used for heating (both for central heating system and for roof-mounted units) is calculated as a difference between the total amount of NG and amount of NG used for domestic hot water. Plotted against the monthly total HDD they show very good correlation for all three facilities, which is described by the equation: 


\section{MAHNG $=f(M H D D)$}

MAHNG - Monthly average NG consumption used for heating system, (Btu/month)

MHDD - Total monthly heating degree-days

- MAHNG used by the central heating system determines the daily consumption of NG by the system. This calculation was made on the basis that the daily thermal energy demand for the heating system is proportional to daily HDD. (Daily Heating Degree Days data were obtained from the NG supplier.)

\section{DANG $=f(D H D D)$}

DANG - Daily average NG consumption, (Btu/hr);

DHDD - Daily total heating degree-days.

This equation allows forecasting of daily NG demand for the central heating system according to daily HDD during the heating season. In combination with NG demand for domestic hot water, the total daily HG demand for each of the three facilities is forecasted.

\section{Forecast of Market Price Of Electricity}

Participation of the facility in the load curtailment program is assumed for some of the scenarios. The market price of electricity should is forecasted to calculate potential profit from the curtailment, Market price of electricity depends on many factors and forecasting of this price is a subject for a separate and probably very elaborate project. It was decided to use a simplified approach trying to correlate this price with cooling degree days, assuming that the market price should correlate with electricity demand, which in turn, has a strong direct relationship to ambient conditions (temperature, humidity, and wind factor). Cooling degreedays appear to be the most convenient and simple parameter reflecting summer weather conditions. Market price of electricity for the summer of 2001 (June, July and August) is plotted against the daily CDD for the same period. Results are presented in Figure B-8. The correlation is described by the following equation:

$$
E M P=0.0028 D C D D^{3}+0.1552 D C D D^{2}+0.8435 D C D D+27.144
$$

EMP - Electricity market price (cents/kWhr)

DCDD - Cooling Degree Days per day

\section{Natural Gas Costs}

Natural gas cost is a complicated function of several parameters, but mostly it depends on the total amount of NG used by facility. To forecast it, historical data on NG costs for each facility are plotted against monthly NG gas consumption as shown in Figures B-9, B-10, and B-11.

$$
N G C=f(M N G C)
$$


NGC - Cost of natural gas $(\$ /$ Therm $)$

MNGC - Monthly NG consumption (Therm/month)

This algorithm is used with predicted demand for natural gas to calculate annual payment for NG.

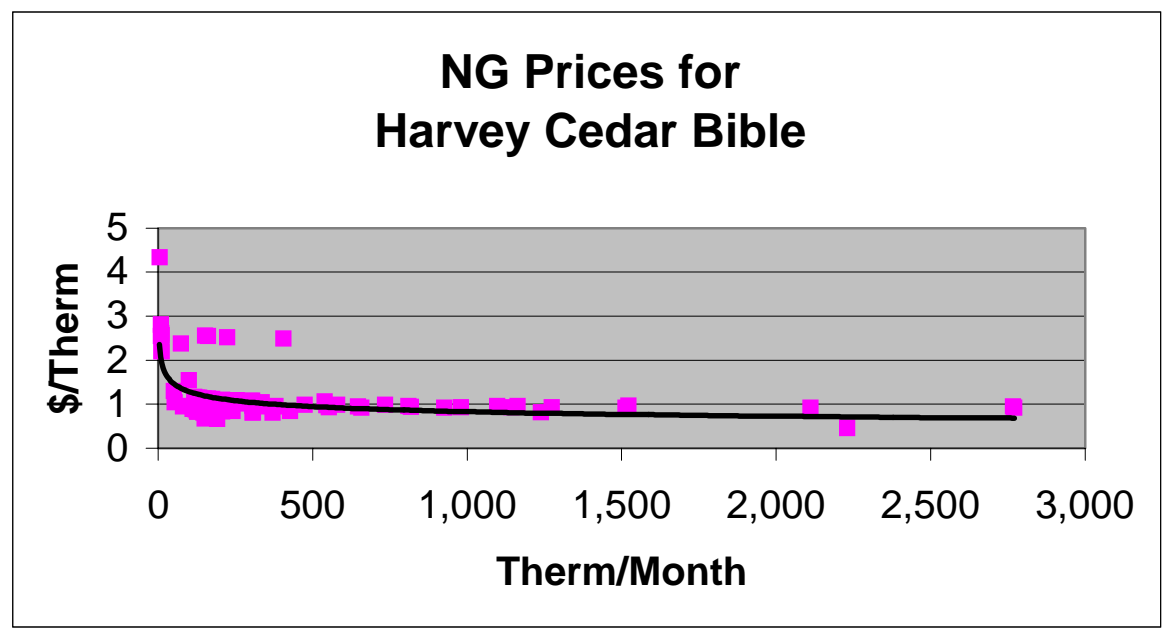

Figure 9. NG Prices - Harvey Cedar Bible 


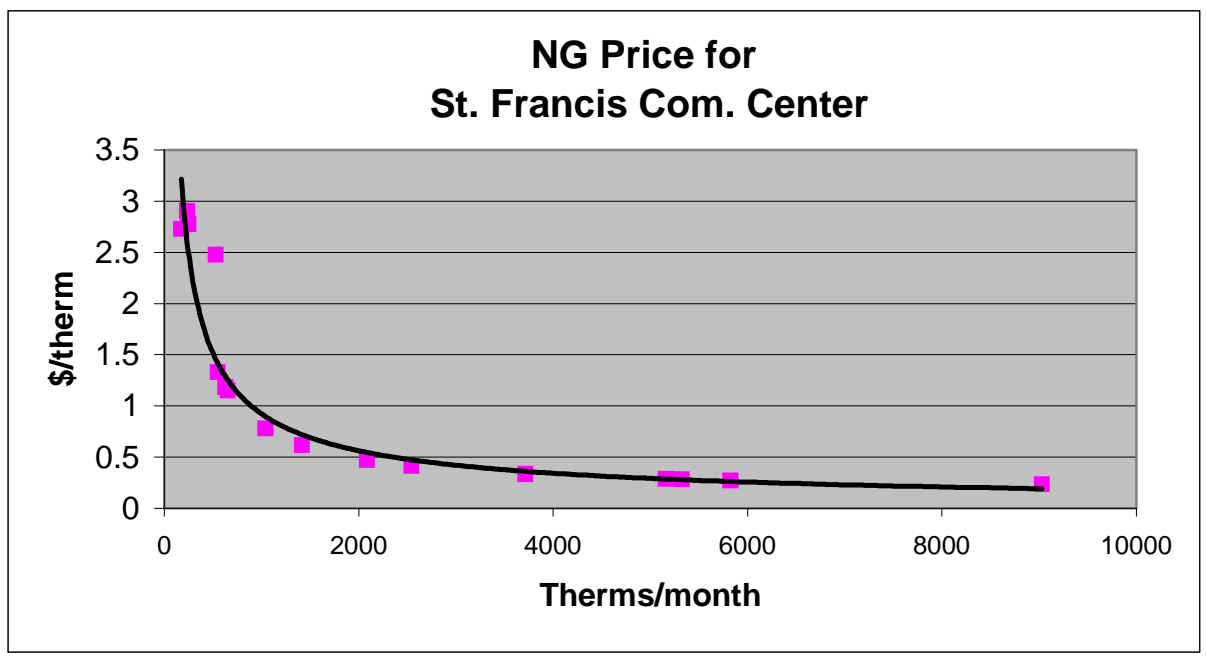

Figure B-10. NG Price - St. Francis Com. Center

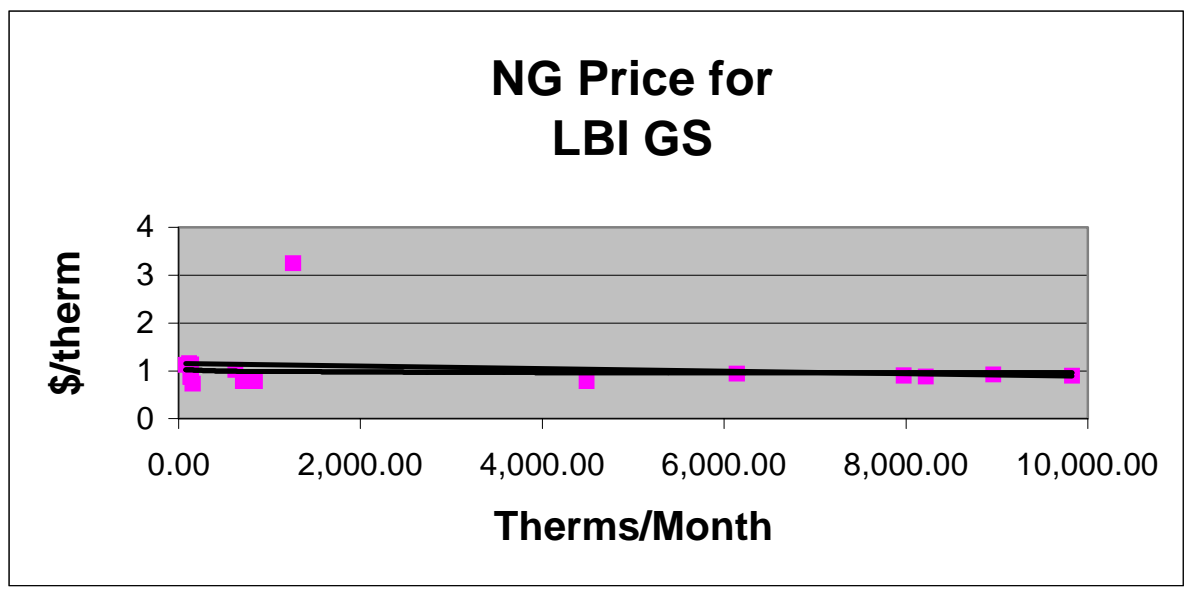

Figure B-11. NG Price - LBI GS 